Aus dem Institut für Neuro- und Sinnesphysiologie

(Prof. Dr. S. O. Rizzoli)

im Zentrum Physiologie und Pathophysiologie

der Medizinischen Fakultät der Universität Göttingen

\title{
Funktionelles ROS/Redox Imaging, basierend auf genetisch-kodierten optischen Sensoren, exzitationsratiometrischer Zwei-Photonen- Mikroskopie und Fluoreszenzlebenszeiten
}

\author{
INAUGURAL-DISSERTATION \\ zur Erlangung des Doktorgrades \\ der Medizinischen Fakultät der \\ Georg-August-Universität zu Göttingen
}

vorgelegt von

Kathrin Michaela Kizina

aus

Menden (Sauerland)

Göttingen 2019 
Dekan:

Referent/in

Ko-Referent/in:

Drittreferent/in:
Prof. Dr. rer. nat. H. K. Kroemer

Prof. Dr. rer. nat. M. Müller

Prof. Dr. rer. nat. S. Jakobs

Prof. Dr. mult. T. Meyer

Datum der mündlichen Prüfung: 27.06.2019 
Hiermit erkläre ich, die Dissertation mit dem Titel "Funktionelles ROS/Redox Imaging, basierend auf genetischkodierten optischen Sensoren, exzitationsratiometrischer Zwei-Photonen-Mikroskopie und Fluoreszenzlebenszeiten" eigenständig angefertigt und keine anderen als die von mir angegebenen Quellen und Hilfsmittel verwendet zu haben.

Göttingen, den 


\section{Inhaltsverzeichnis}

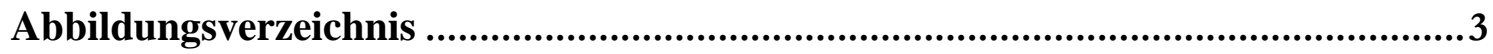

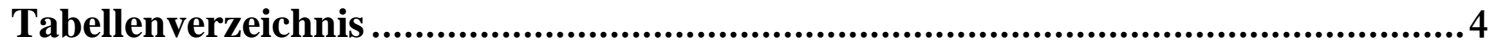

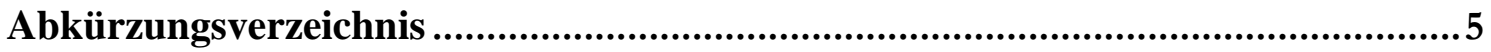

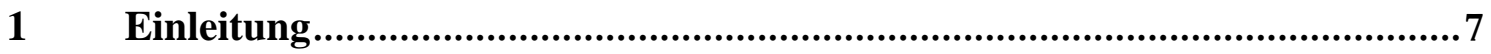

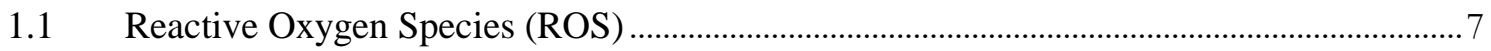

1.1.1 Zellulärer Redox-Status und seine Signalfunktion .........................................................

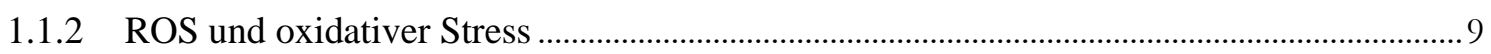

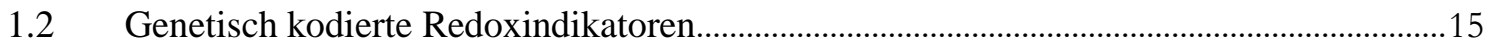

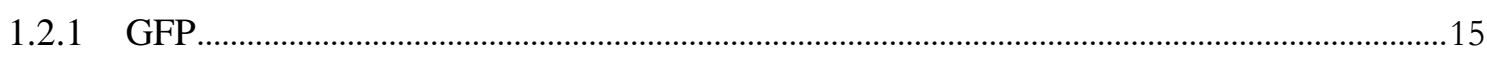

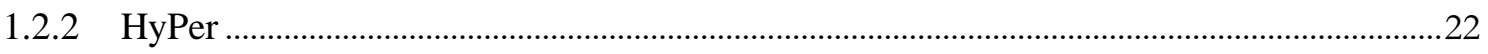

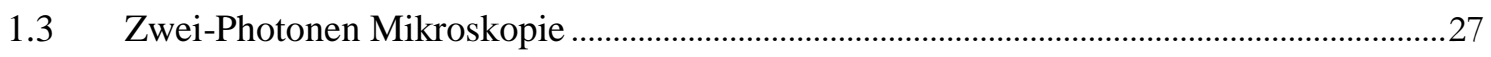

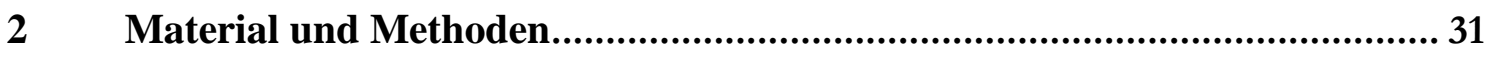

2.1 Überblick über die verwendeten Materialien.......................................................................... 31

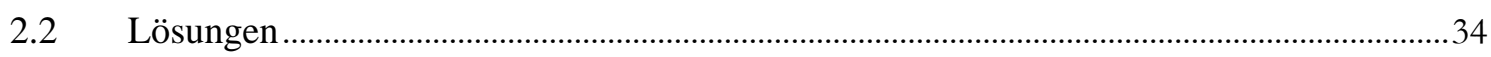

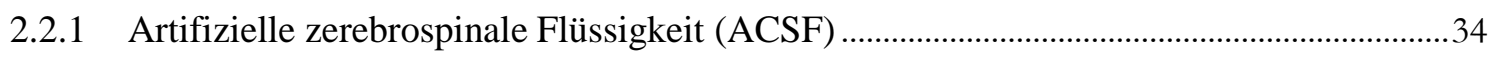

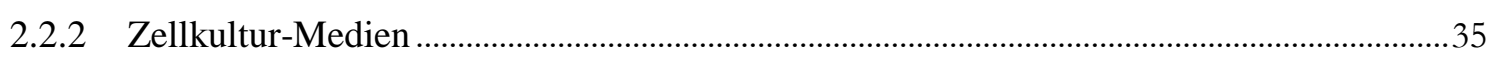

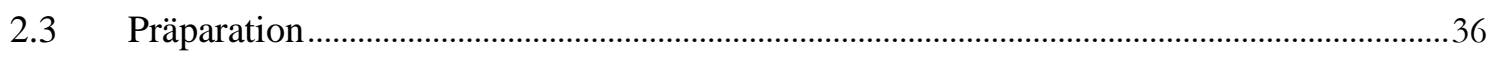

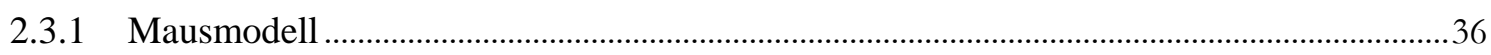

2.3.2 Herstellung der hippokampalen Zellkulturen .......................................................................

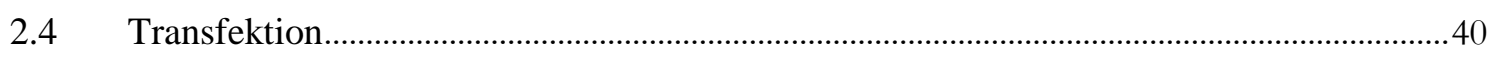

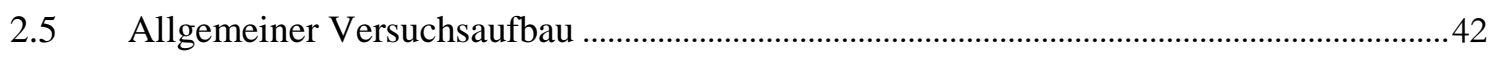

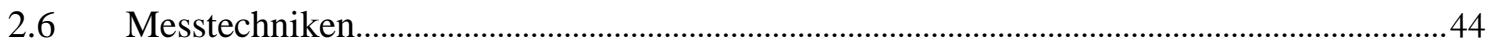

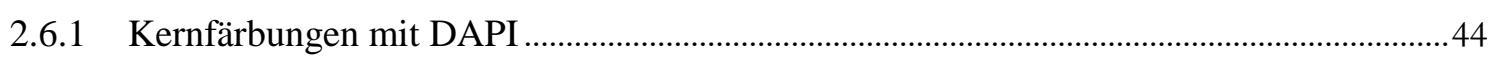

2.6.2 Zwei-Photonen-Anregungsspektrum der ROS-Indikatoren ....................................................45

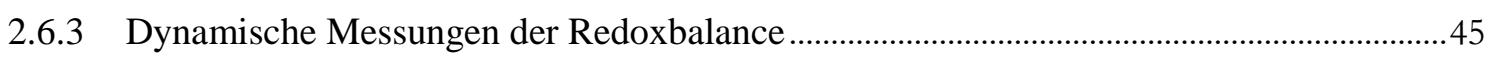

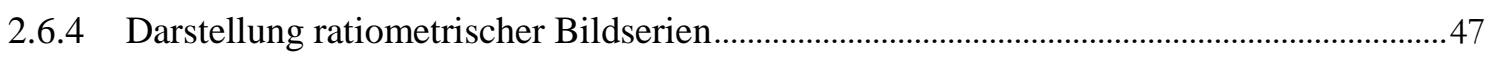

2.6.5 Messungen der Fluoreszenzlebenszeit............................................................................... 48

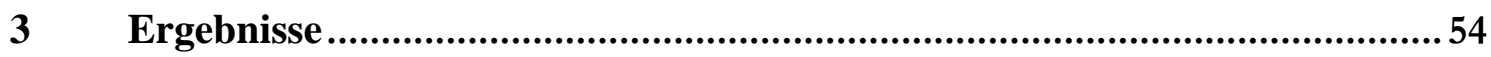

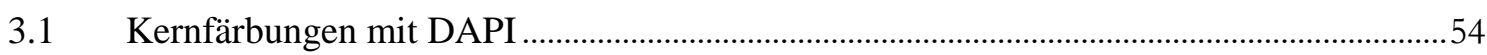

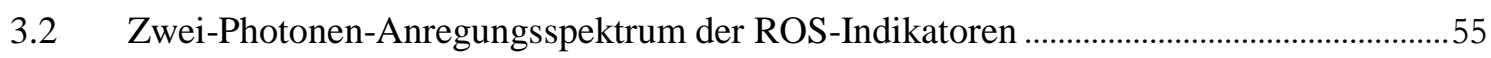

3.3 Dynamische Messungen der Redoxbalance .............................................................................59

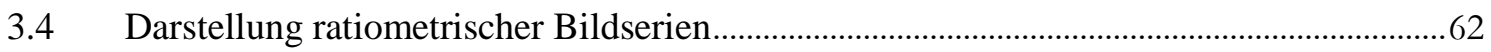

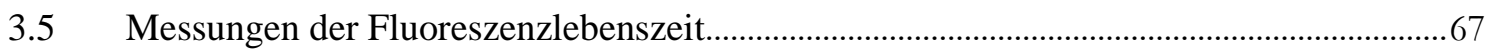




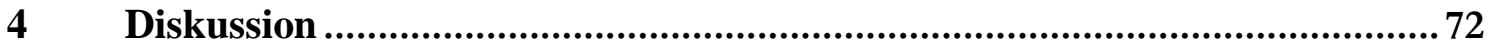

4.1 Limitationen und methodische Einschränkungen .................................................................

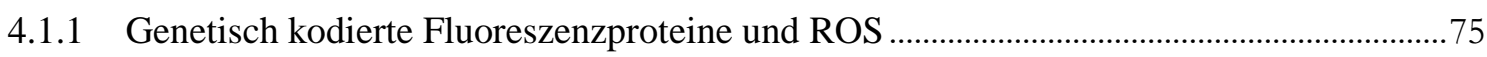

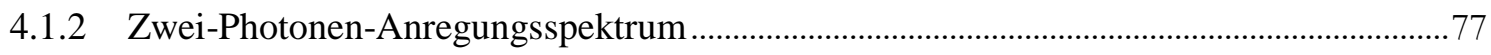

4.1.3 Dynamische Messungen und ratiometrische Bildserien....................................................... 78

4.1.4 Messungen der Fluoreszenzlebenszeit (FLIM) ......................................................................

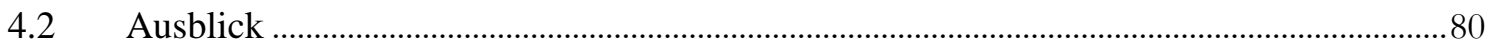

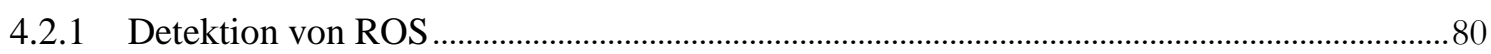

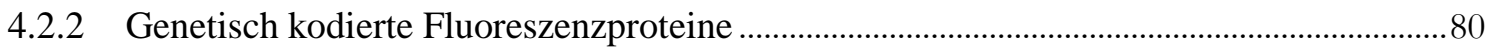

4.2.3 Messungen der Fluoreszenzlebenszeit (FLIM) ..................................................................... 83

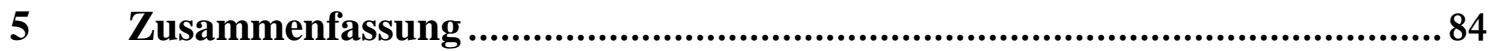

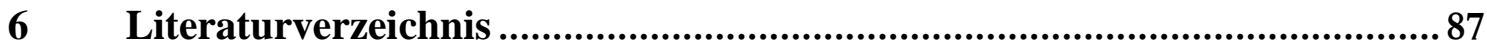




\section{Abbildungsverzeichnis}

Abbildung 1: Bildung von reaktiven Sauerstoffspezies. .....................................................

Abbildung 2: Signalwege als Antwort auf oxidativen Stress in vereinfachter Darstellung. ......10

Abbildung 3: Vereinfachte Darstellung des Mechanismus der Redox-Homöostase: ...................13

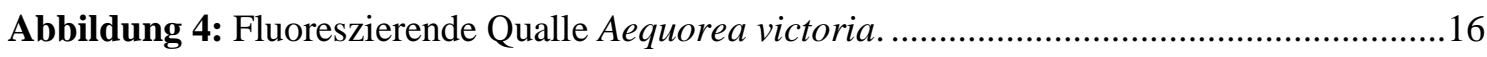

Abbildung 5: Darstellung der Architektur eines GFP-Moleküls. ..............................................

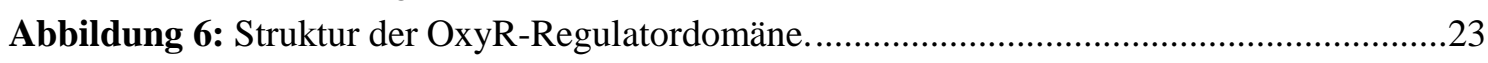

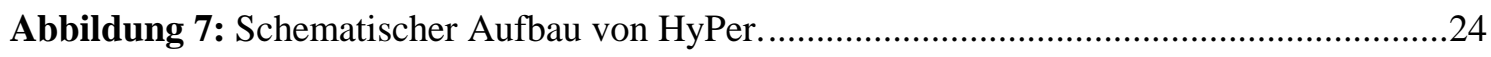

Abbildung 8: Vereinfachte Darstellung des Perrin-Jablonski-Diagramms..................................30

Abbildung 9: Schematische Darstellung der Hippocampus-Präparation...................................... 38

Abbildung 10: Herstellung der beiden Transfektionslösungen. ............................................

Abbildung 11: Das Zweiphotonen-Laser-Scanning-Mikroskop (TPLSM) . ................................43

Abbildung 12: Einteilung der verschiedenen Messreihen auf einen Blick.................................46

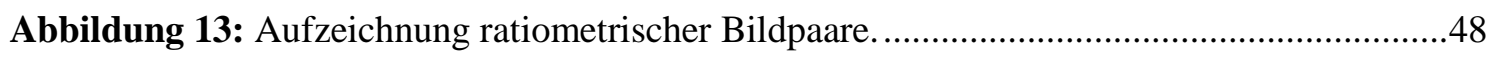

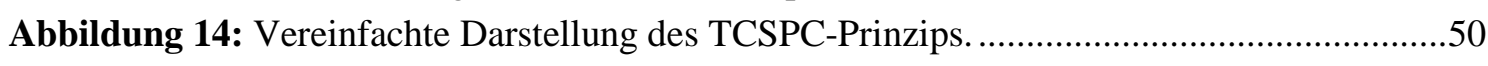

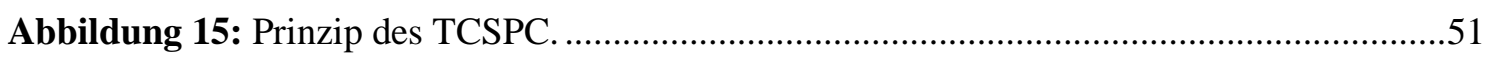

Abbildung 16: Darstellung einer Zelle mit roGFP1, HyPer und einer Kombination aus einer

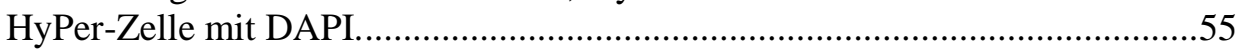

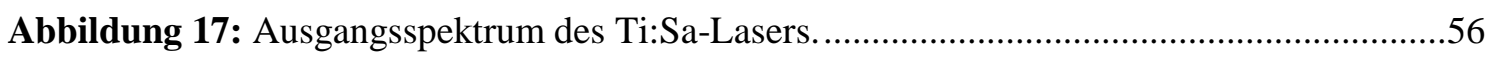

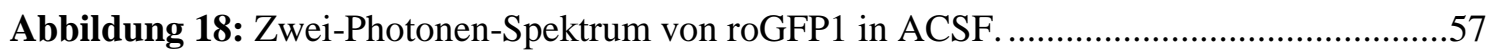

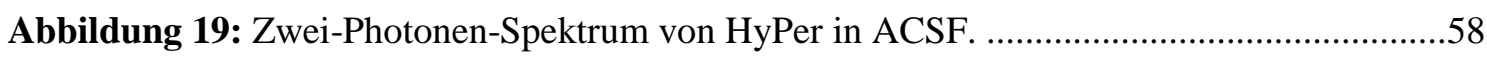

Abbildung 20: Zu erwartende Ergebnisse der Messreihe "Dynamische Messungen der

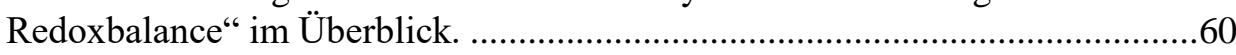

Abbildung 21: Dynamische Messungen der Redoxbalance von HyPer. .....................................62

Abbildung 22: Ratiometrische Bildserie (F740/F910) mit roGFP1 .........................................63

Abbildung 23: Ratiometrische Zwei-Photonen-Messungen mit roGFP1...................................64

Abbildung 24: Ratiometrische Bildpaare (F920/F760) mit HyPer............................................65

Abbildung 25: Ratiometrische Zwei-Photonen-Messungen mit HyPer. .....................................66

Abbildung 26: Redoxsensitivität der Fluoreszenzlebenszeit von roGFP1..................................68

Abbildung 27: Redoxmodulation der Fluoreszenzlebenszeit von HyPer. ...................................68

Abbildung 28: Messungen mit FLIM in der Zwei-Photonen-Mikroskopie...............................70 


\section{Tabellenverzeichnis}

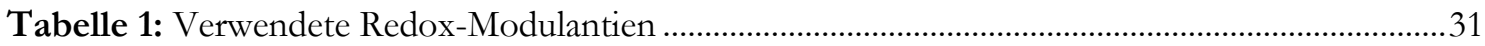




\section{Abkürzungsverzeichnis}

ACSF

ADP

Ara-c

ATP

cpYFP

DAPI

DCF

DNA

DNase

DTT

FCS

FLIM

GFP

GSH

GSSG

$\mathrm{H}_{2} \mathrm{O}_{2}$

HBSS

HeLa-Zellen

HEPES

HyPer

$\mathrm{KCl}$ artificial cerebrospinal fluid

Adenosindiphosphat

Cytosin-Arabinosid

Adenosintriphosphat

circulary permuted yellow fluorescent protein

(gelb fluoreszierendes zirkulär permutiertes Protein)

diamidino-2-phenylindol

Dichlorofluorescein

Desoxyribonukleinsäure

Desoxyribonuklease

Dithiothreitol, Reduktionsmittel

fetal calf serum, fötales Kälberserum

fluorescence lifetime imaging microscopy

green fluorescent protein (grün fluoreszierendes Protein)

Glutathion

oxidiertes Glutathion

Wasserstoffperoxid, Oxidationsmittel

Hank's balanced salt solution;

Hank`s Pulver, $350 \mathrm{mg} \mathrm{NaHCO} 3,238$ mg HEPES mit einem Liter dest. $\mathrm{H}_{2} \mathrm{O}$ auffüllen.

Permanente Zellline, benannt nach einer Patientin (Henrietta Lacks)

2-(4-(2-Hydroxyethyl)- 1-piperazinyl)-ethansulfonsäure (Puffer)

genetisch kodiertes Fluoreszenzprotein

Kaliumchlorid 
MEM minimal essential medium (Hersteller: Invitrogen)

$\mathrm{MgSO}_{4} \quad$ Magnesiumsulfat

$\mathrm{Na}_{2} \mathrm{HPO}_{4} \quad$ Dinatriumhydrogenphosphat

$\mathrm{NaCl} \quad$ Natriumchlorid (Kochsalz)

$\mathrm{NAD}(\mathrm{P}) \mathrm{H} \quad$ Nicotinsäureamid-Adenin-Dinukleotid-Phosphat

$\mathrm{NaHCO}_{3} \quad$ Natriumhydrogencarbonat

NIR near infrared

OxyR-RD Name der Regulatordomäne

P1 postnataler Tag 1

PG1 PeroxyGreen 1

$\mathrm{pH}-$ Wert potentia hydrogenii

PMT photomultiplier

roGFP1 reduction oxidation sensitive green fluorescent protein

ROI region of interest

ROS reactive oxygen species

TCSPC time correlated single photon counting

TPE two-photon excitation

TPLSM two-photon laser scanning microscopy

UV ultraviolett

YFP yellow fluorescent protein 


\section{Einleitung}

\subsection{Reactive Oxygen Species (ROS)}

Reaktive Sauerstoff $\left(\mathrm{O}_{2}\right)$ Spezies (ROS) sind Moleküle oder Molekülfragmente, die ein oder mehrere unpaare Elektronen in einem Orbital besitzen. Ihre Entstehung im biologischen Gewebe ist unumgänglich und so werden sie physiologisch zu jeder Zeit als Nebenprodukt des Stoffwechsels produziert (Dröge 2002; Valko et al. 2006a; Valko et al. 2006b). Unter den Begriff der reaktiven Sauerstoffspezies fallen verschiedene Formen und Verbindungen des Sauerstoffs, wie zum Beispiel das Hyperoxid-Anion $\mathrm{O}_{2} \cdot^{-}$, das Wasserstoffperoxid $\mathrm{H}_{2} \mathrm{O}_{2}$ oder das Hydroxyl-Radikal • $\mathrm{OH}$ (Gerich et al. 2009; Miller et al. 2007).

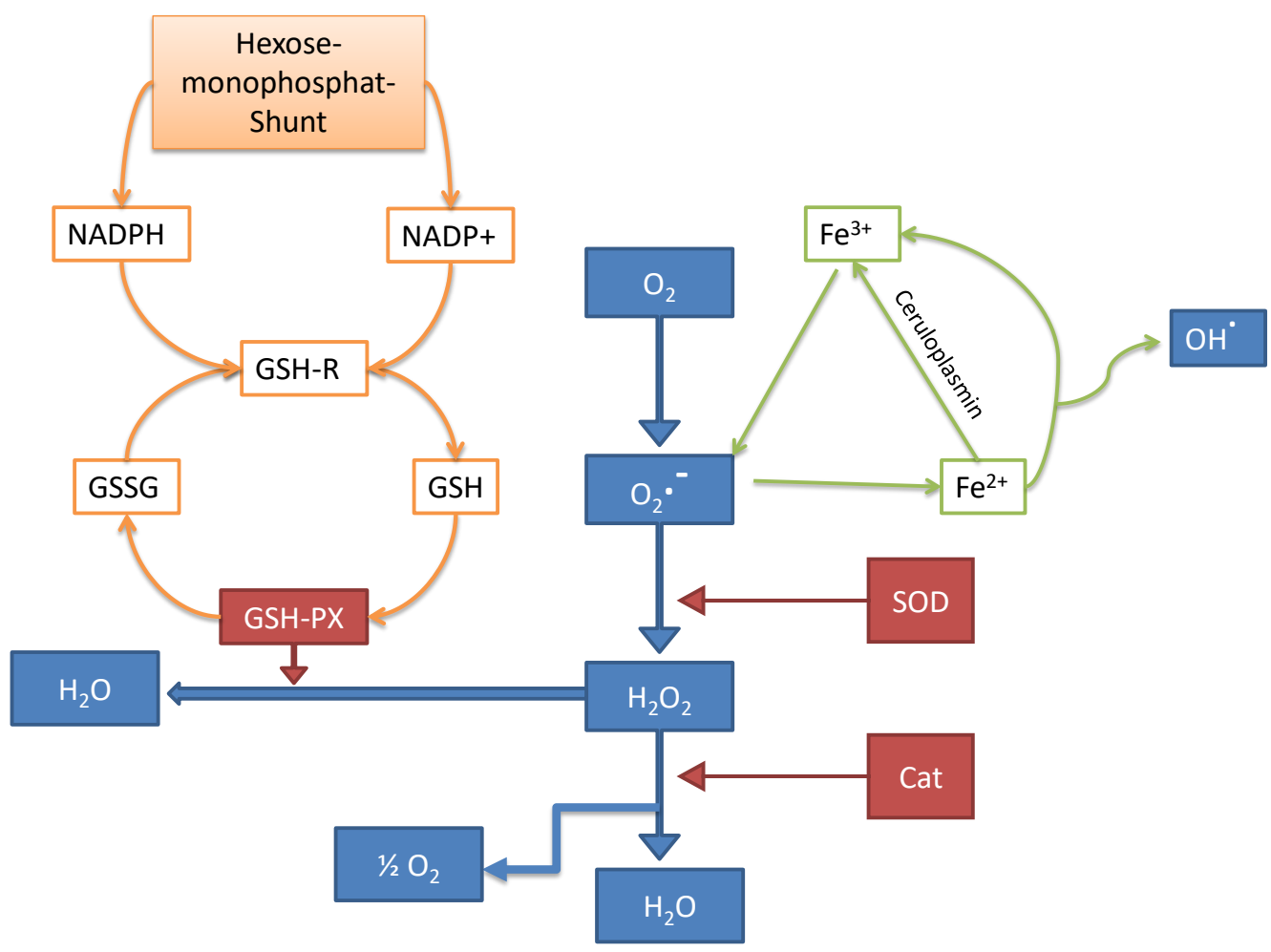

\footnotetext{
Abbildung 1: Bildung von reaktiven Sauerstoffspezies. Cat $=$ Katalase; GSH-Px $=$ GlutathionPeroxidase; GSH-R = Glutathion-Reduktase; $\mathrm{SOD}=$ Superoxiddismutase; $\mathrm{O}_{2}=$ molekularer Sauerstoff; $\mathrm{O}_{2}{ }^{-}=$Hyperoxid-Anion; $\mathrm{H}_{2} \mathrm{O}_{2}=$ Wasserstoffperoxid; $\mathrm{OH}^{-}=$Hydroxyl-Radikal; $\mathrm{Fe}^{2+/} \mathrm{Fe}^{3+}=$ Eisenion; GSH = reduziertes Glutathion; GSSG $=$ oxidiertes Glutathion; NADPH $/ \mathrm{NADP}^{+}=$reduziertes/oxidiertes Nicotinamid-Adenindinucleotid-Phosphat.
} 


\subsubsection{Zellulärer Redox-Status und seine Signalfunktion}

Der Redox-Status beschreibt das gesamte Redox-Milieu, welches sich in einer Zelle befindet. Die beiden einfließenden Komponenten sind das Reduktionspotential und die reduzierende Kapazität von miteinander verknüpften Redox-Paaren. Da es jedoch nicht möglich ist, an allen Redox-Paaren separat Messungen durchzuführen, um die Ergebnisse schließlich zum Redox-Status zusammenzufassen, wird ein repräsentatives Paar, der RedoxPuffer GSSG/2GSH (oxidiertes Glutathion/Glutathion), herangezogen. Anhand dieses Verhältnisses kann nahezu definiert der Redox-Status einer Zelle bestimmt werden.

Der Charakter des Redox-Status einer Zelle beeinflusst maßgeblich die Richtung zellulärer Prozesse. Energie, die bei oxidativen Prozessen entsteht, wird für den Aufbau von Zellstrukturen sowie für den Aufrechterhalt dieser Konstrukte und für die Bereitstellung von Energie zur Durchführung unterstützender Zellprozesse benötigt. Die erzeugte Energie entstammt der Elektronenwanderung von oxidierbaren Molekülen zum Sauerstoff (Schafer und Buettner 2001).

Der Einfluss von ROS auf das Gewebe lässt sich nicht einheitlich als positiv oder negativ einstufen, da es sowohl nützlich und vorteilhaft als auch toxisch und destruktiv auf die Zellen des menschlichen Körpers wirken kann (Valko et al. 2006a). In physiologisch geringen, aber messbaren Konzentrationen übernehmen ROS wichtige Aufgaben, zu denen die Signalübertragung oder deren Modulation während physiologischer Prozesse zählt. Hierbei wird durch ROS eine Modifikation von spezifischen Cystein-Resten beobachtet, welche wiederum veränderte Proteinaktivitäten und davon beeinflusste Signalwege mit sich bringt (Finkel 2011). Diese Modifikationen beeinflussen den Vasotonus der Gefäßzellen, die Kontrolle über die Ventilation während des Atmungsvorgangs sowie die generelle Weiterleitung von Zellinformationen (Dröge 2002). Auch das Bekämpfen von Bakterienund Pilzbefall im menschlichen Körper (Halliwell und Cross 1994) oder die Einleitung der Apoptose als Schutz vor der Tumorentstehung unterliegen dem Einfluss von ROS (Valko et al. 2006a). Die Konzentration der reaktiven Sauerstoffspezies steigt hier durch Signale an, die von Wachstumsfaktoren, Hormonen oder Zytokinen ausgesandt werden (Finkel 2003). Zudem haben beispielsweise Experimente an Kaulquappen bewiesen, dass ROS Signalwege, wie die Zellproliferation, induzieren kann. Forscher amputierten diesbezüglich den Schwanz einer Kaulquappe und beobachteten durch eine Zugabe von wasserstoffperoxid-sensiblen Markern eine erhöhte $\mathrm{H}_{2} \mathrm{O}_{2}$-Produktion genau an dieser verwundeten Zielstelle. Wurde diese lokale $\mathrm{H}_{2} \mathrm{O}_{2}$-Produktion unterdrückt oder reduziert, fand keine 
Zellproliferation und somit kein Nachwachsen dieses abgetrennten Körperteils statt (Love et al. 2013). Ähnliche Ergebnisse wurden mit Experimenten an Zebrafischen erzielt (Niethammer et al. 2009). Eine übermäßig angeregte Zellproliferation hingegen kann jedoch unter bestimmten Bedingungen auch zum Tumorwachstum führen.

\subsubsection{ROS und oxidativer Stress}

Tritt jedoch der Fall ein, dass die zelluläre ROS-Konzentration bis in einen pathologischen Bereich ansteigt, kann oxidativer Stress entstehen. ROS oxidiert dann verschiedene Angriffsziele, wie die DNA (Desoxyribonukleinsäure), Lipide und Proteine (Valko et al. 2006a). Dies kann einerseits Funktionsverluste der Proteine oder gegenteilig eine Hyperaktivität selbiger bewirken und sogar das betroffene Protein zu völlig neuen Funktionen befähigen (Dröge 2002). Auch die Permeabilität der Zellmembranen kann verändert werden, was erhebliche Auswirkungen auf die Vorgänge innerhalb der Zelle haben kann (Halliwell 1991). Aufgrund dessen werden ROS und oxidative Schäden für vielerlei bedeutende und lebensbedrohliche Erkrankungen des menschlichen Organismus verantwortlich gemacht, wie beispielsweise Diabetes mellitus, koronare Herzkrankheiten und andere Kardiopathien (Giacco und Brownlee 2010; Becker 2004; Dhalla et al. 1996), Atherosklerose (Brennan und Hazen 2003), neurodegenerative Erkrankungen, wie die amyotrophe Lateralsklerose, Morbus Parkinson, Morbus Alzheimer, Chorea Huntigton (Halliwell 1992; Cooper und Schapira 1997), Erkrankungen mit genetischen Mutationen, wie das Rett-Syndrom (Grosser et al. 2012), rheumatoide Arthritis, obstruktive Schlafapnoe, ARDS (acute respiratory distress syndrome) (Baldwin et al. 1986) und verschiedene Tumorerkrankungen (Beal 1998; Agar und Durham 2003; Dröge 2002; Hugon et al. 1996; Kishida und Klann 2007). Besonders die Zellen des Gehirns reagieren sehr sensibel auf einen Anstieg der ROSKonzentration, was sich häufig in Krampfanfällen (Epilepsie) zeigen kann (Turrens 2003). Ein wichtiger und viel diskutierter Punkt, für den ROS ebenfalls verantwortlich sein soll, ist zudem das Altern (Harman 1956; Balaban et al. 2005). Das Eingrenzen des oxidativen Stresses mithilfe von Antioxidantien soll als protektive und lebensverlängernde Maßnahme gesehen werden (Dröge 2002; Finkel und Holbrook 2000; Harman 1992). 


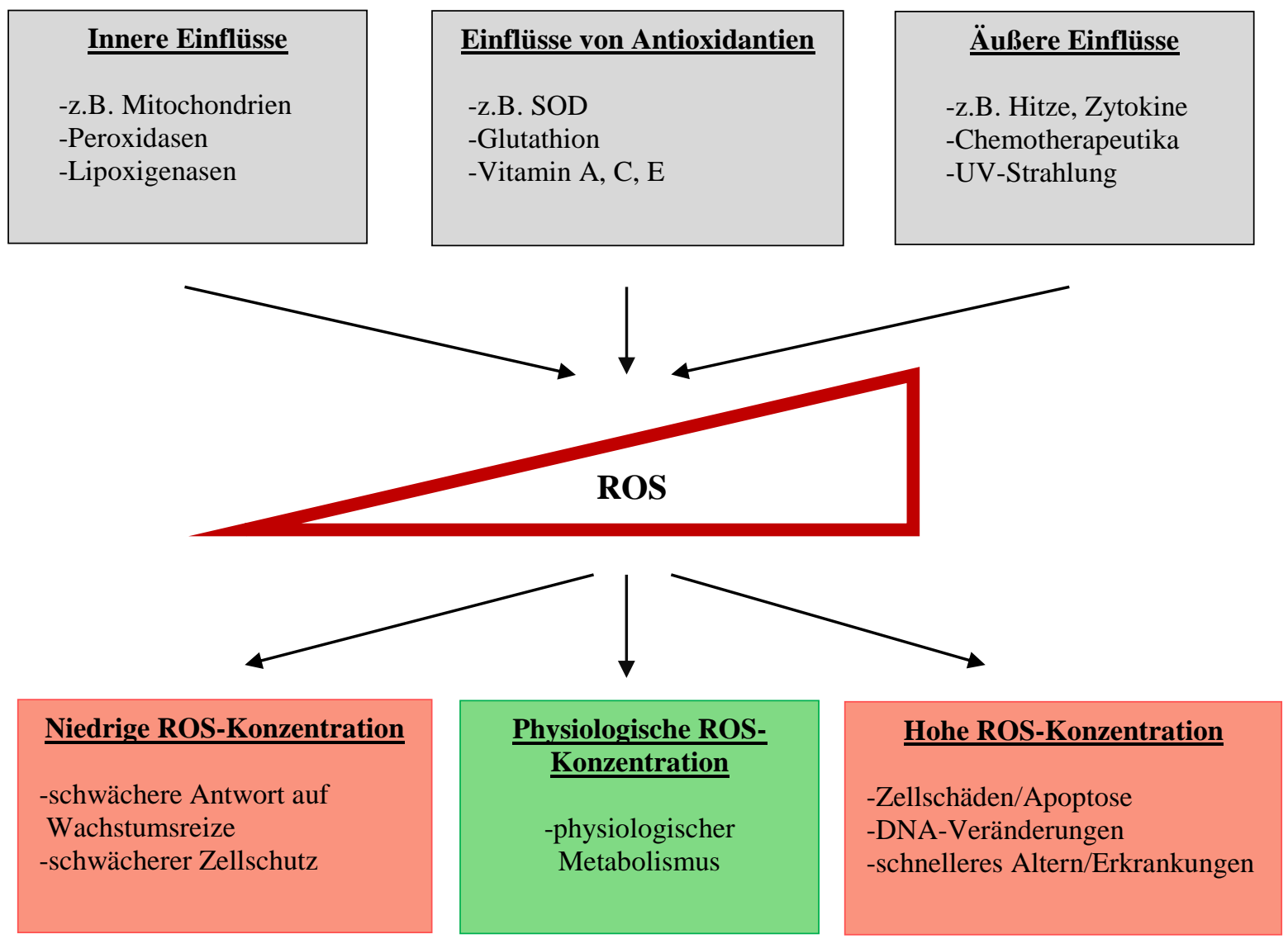

Abbildung 2: Signalwege als Antwort auf oxidativen Stress in vereinfachter Darstellung. Die Entscheidung dafür, welcher Weg im oben gezeigten Schema verfolgt wird, hängt ab von der Charakterisierung, der Dauer des oxidativen Stresses und dem Zelltyp. Die Konsequenzen variieren sehr weitläufig und sind abhängig von der Balance zwischen den aktivierten Signalwegen (modifiziert nach Finkel und Holbrook 2000, Abb. 1, mit freundlicher Genehminung von Nature Publishing Group).

ROS wird vor allem von den Mitochondrien der Zellen (Nemoto et al. 2000; Valko et al. 2006a; Foster et al. 2006; Liu et al. 2002) und zusätzlich von der NADPH-Oxidase, die unter anderem auf der Zellmembran von Makrophagen und Endothelzellen lokalisiert ist (Turrens 2003), als Nebenprodukt produziert. Besonders ältere Mitochondrien produzieren sogar mehr ROS als ATP (Adenosintriphosphat) (Shigenaga et al. 1994). Die Makrophagen tragen mit der Produktion von ROS zudem zur Immunabwehr bei. Wird der körpereigene Metabolismus intensiviert, steigt gleichzeitig die ROS-Bildung an (Finkel und Holbrook 2000). Ein ROS-Anstieg kann auch als Zellantwort auf verschiedene Xenobiotika, vor allem Pharmaka, hervorgerufen werden (Ray et al. 2012) sowie durch exogene Faktoren, wie Zigarettenrauch (Halliwell und Cross 1994), UV-Licht (Ultraviolettstrahlung), Ozon $\left(\mathrm{O}_{3}\right)$, Chemotherapien, Entzündungsmodulatoren (Finkel und Holbrook 2000) oder nach traumatischen oder ischämisch bedingten Verletzungen des Gehirns. Der ischämische 
Zustand nach einem Schlaganfall führt zu einer vermehrten ROS-Produktion. Das vulnerable Gewebe (Penumbra) wird daraufhin durch ROS zusätzlich angegriffen, was in einer Zunahme des Zelluntergangs der Neurone resultiert (Chan 2001; Rodrigo et al. 2013).

In den Mitochondrien spielen innerhalb der Atmungskette die Komplexe I (NADHOxidase) und III (Cytochrom-c-Reduktase) eine besondere Rolle, welche auf der inneren Mitochondrienmembran lokalisiert sind (Muller et al. 2004; Guzy et al. 2005; Finkel und Holbrook 2000; Valko et al. 2006a). Die Mitochondrien werden auch als das Kraftwerk der Zelle bezeichnet, da sie die Aufgabe haben, mithilfe der Atmungskette das energiereiche ATP aus dem energieärmeren ADP (Adenosindiphosphat) herzustellen (Beal 1998).

Vereinfacht besteht die Atmungskette aus vier Proteinkomplexen und der ATP-Synthase, die letztendlich ATP synthetisiert. NADH-Moleküle entstehen während des katabolen Stoffwechselweges und geben jeweils zwei Elektronen zu Beginn der Atmungskette an Komplex I (NADPH-Oxidase) ab, welche dann auf Eisen-Schwefel-Komplexe übertragen werden und über das Ubichinon zu Komplex II (Succinatdehydrogenase) gelangen. Von hier aus werden die Elektronen wiederum über Ubichinon auf Komplex III (Cytochrom-cReduktase) übertragen. Von dort aus gelangen die Elektronen über Cytochrom c zu Komplex IV (Cytochrom-c-Oxidase), welches die Endstation des Elektronentransports darstellt. Die beiden Elektronen reagieren hier mit einem $\mathrm{O}_{2}$-Molekül und zwei Protonen aus der Umgebung zu zwei Wassermolekülen $\left(2 \mathrm{H}_{2} \mathrm{O}\right)$.

Dieser stark exergone Vorgang wird als Knallgasreaktion bezeichnet, und die dadurch freiwerdende Energie wird dafür genutzt, vier Protonen in den Intermembranraum zu transportieren. Während die Elektronen die einzelnen Komplexe der Atmungskette durchlaufen, ist es das Ziel, kontinuierlich einen Protonengradienten aufzubauen. Protonen werden von der Matrix, dem zentralen Innenraum des Mitochondriums, in den Intermembranraum gegen den eigentlichen Gradienten transportiert. Der fünfte Komplex, die ATPSynthase, ist ein Multiproteinkomplex und wird durch den Rückstrom der Protonen vom Intermembranraum in die Matrix angetrieben, wobei aus ADP dann das End- und Zielprodukt ATP entsteht. Von großer Bedeutung ist also hier der Protonengradient, den es im Verlauf der Atmungskette aufzubauen gilt. Schon ein einziges NADH-Molekül, bewirkt einen Transport von insgesamt zehn Protonen entlang der Atmungskette gegen den Gradienten.

Gelingt dieser Transport beispielsweise durch eine Störung im Verlauf der Elektronen nicht, kann kein ATP produziert werden und demnach steht den Zellen final weniger Ener- 
gie zur Verfügung (Cadenas und Davies 2000). Wasser entsteht in der Atmungskette als Nebenprodukt, ebenso wie die reaktiven Sauerstoffspezies, die täglich physiologisch zu 1 bis $3 \%$ bei der Bildung von $\mathrm{H}_{2} \mathrm{O}$ mithilfe eines $\mathrm{O}_{2}$-Molekül produziert werden (Valko et al. 2006a). Verlassen also die zu transportierenden Elektronen ihren regulär vorbestimmten Weg von Komplex I bis hin zu Komplex IV über ein sogenanntes Leck (leaking (Valko et al. 2006a), leakage (Coyle und Puttfarcken 1993)), entsteht ROS, indem ein negativ geladenes Elektron auf ein $\mathrm{O}_{2}$-Molekül aus der Umgebung trifft. Physiologisch verlassen ca. 2 bis $5 \%$ aller Elektronen ihren regulären Weg und verbinden sich mit verschiedenen Molekülen in der Umgebung (Boveris und Chance 1973; Dröge 2002).

Ein Atom besteht aus einem Kern und einer Hülle, die aus Orbitalen zusammengesetzt ist. Jedes Orbital innerhalb eines Atoms kann zwei Elektronen halten und strebt nach diesem Zustand. Trägt ein Atom nur ein Elektron in einem seiner Orbitale, wird es als freies Radikal bezeichnet. Es wird als instabiler und somit als reaktionsfreudiger charakterisiert. Der Großteil aller biologischen Moleküle sind keine Radikale. In ihren Orbitalen befinden sich demnach stets Elektronenpaare. $\mathrm{H}_{2} \mathrm{O}_{2}$ wird nicht unter den Begriff der Radikale gefasst, da es ausschließlich paarige Elektronen besitzt. Es ist ein sogenanntes Nicht-Radikal, welches trotzdem zusammen mit den Radikalen zu der Gruppe der ROS gehört (Halliwell 1991); (Winterbourn 2008). Wasserstoffperoxid $\left(\mathrm{H}_{2} \mathrm{O}_{2}\right)$ kann aus einem Superoxid-Anion $\left(\mathrm{O}_{2}{ }^{-}\right.$) gebildet werden, indem durch Zuführen eines weiteren Elektrons, sowie zwei Protonen und mithilfe der Superoxiddismutase (SOD) diese Reaktion katalysiert wird. Das $\mathrm{H}_{2} \mathrm{O}_{2}$ modifiziert reversibel Thiol-Reste von Proteinen innerhalb der Zellen, wodurch ihre katalytische Aktivität sowie andere Funktionen des Proteins beeinträchtigt werden können (Veal et al. 2007; Markvicheva et al. 2011). $\mathrm{H}_{2} \mathrm{O}_{2}$ kann schließlich zu einem sehr reaktionsfreudigen Radikal reagieren, wenn es sich jeweils mit einem weiteren Proton und Elektron verbindet. Es entsteht Wasser $\left(\mathrm{H}_{2} \mathrm{O}\right)$ und ein Hydroxylradikal $(\cdot \mathrm{OH})$. Dieses, für den Körper schädliche Radikal, kann durch ein abermaliges Reagieren mit einem Proton und einem Elektron wiederum zu Wasser umgebaut werden, wodurch es seine Toxizität verliert (Valko et al. 2004; Boveris und Chance 1973). Treffen zwei Radikale aufeinander, können die beiden jeweils unpaaren Elektronen unter Bildung einer kovalenten Bindung reagieren. Radikale reagieren auch mit Nicht-Radikalen, da sie danach streben, paarige Elektronen zu besitzen. Dabei wird das Nicht-Radikal zum Radikal: Eine Kettenreaktion entsteht (Halliwell 1991). Um den Körper vor dem oxidativen Stress und der zu hohen Konzentration der radikalen Sauerstoffspezies zu bewahren, existieren Substanzen, deren Aufgabe es ist, eine übermä- 
Bige ROS-Akkumulation zu unterbinden, zu mindern oder rechtzeitig zu limitieren. Diese Antioxidantien sind ebenfalls in der Lage, Schäden, die bereits durch ROS verursacht wurden, zu reparieren. Für eine physiologische Stimmigkeit muss also eine stetige Balance zwischen dem produzierten ROS und den schützenden Antioxidantien vorliegen (Halliwell 1991; Dröge 2002; Valko et al. 2006a). Ein Mangel an Antioxidantien, beziehungsweise deren Verlust kann somit oxidativen Stress, sowie Zellschäden induzieren (Finkel und Holbrook 2000; Turrens 2003). Unter die Bezeichnung der Radikalfänger fallen neben Antioxidatien, wie Vitamin C (Ascorbinsäure) und Vitamin E (Tocopherol) unter anderem auch die Superoxiddismutase (SOD), die Katalase oder die Glutathionperoxidase, welche physiologisch in den Zellen als weitere schützende Faktoren vorhanden sind (Fridovich 1974; Dröge 2002).

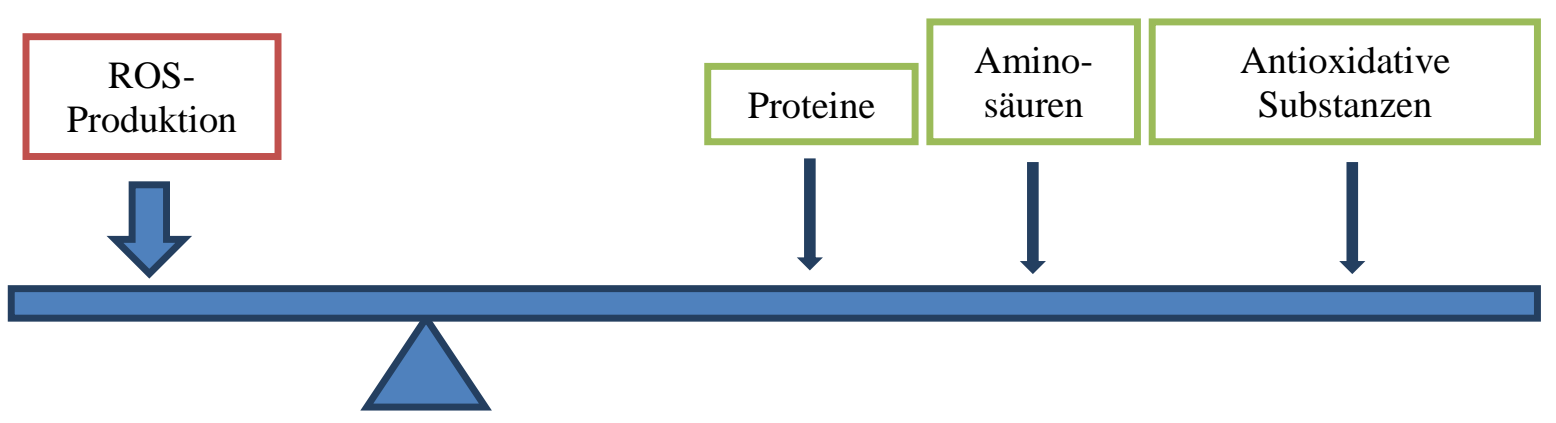

Abbildung 3: Vereinfachte Darstellung des Mechanismus der Redox-Homöostase: Hier ist die Balance zwischen ROS-Produktion und verschiedenen Typen von Radikalfängern dargestellt. Bei einer deutlichen ROS-Überproduktion kann das Gleichgewicht nicht aufrecht gehalten werden und Zellschäden können entstehen (modifiziert nach Dröge 2002, Abb. 2, mit freundlicher Genehmigung von The American Physiological Society).

Den zum Erhalt der Balance notwendigen Gegenpart zu ROS stellen also die Antioxidantien dar. In die Kategorie der enzymatischen Antioxidantien fallen die Superoxiddismutase (SOD), die Glutathionperoxidase (GPx) und die Katalase (CAT). Zu den nichtenzymatischen Antioxidantien zählen unter anderem die beiden Vitamine A und E (Ascorbinsäure und $\alpha$-Tocopherol), Glutathion (GSH), Carotinoide oder auch Flavonoide (Valko et al. 2006a; Halliwell und Cross 1994). Tritt nun aus verschiedenen Gründen der Fall ein, dass weniger Antioxidantien als notwendig vorliegen, wird in den Zellen bei konstanter physiologisch niedriger Konzentration der Antioxidantien überdurchschnittlich viel ROS produziert. Möglicherweise durch einen fehlerhaften Elektronentransport in der Atmungskette oder durch eine exzessive Aktivierung des Coenzyms NADPH-Oxidase, kann die notwendige Balance nicht mehr aufrecht gehalten werden und die reaktiven Sauerstoffspe- 
zies beginnen aufgrund ihrer Überproduktion die Zellen oxidativ zu schädigen. Die Aufgabe einer Zelle ist es also, diese Balance kontinuierlich aufrecht zu erhalten (Winterbourn 2008; Valko et al. 2006a; Halliwell und Cross 1994).

ROS greift vorrangig Proteine, Lipide und die DNA an und kann diese wichtigen Zellbestandteile irreversibel schädigen (Halliwell und Cross 1994; Turrens 2003; Circu und Aw 2010). Zahlreiche Proteine besitzen redox-reaktive Cysteine, welche durch die reaktiven Sauerstoffspezies reversibel oder irreversibel oxidiert werden können. Durch die veränderte Proteinstruktur werden demzufolge auch deren Funktionen und Eigenschaften modifiziert (Ray et al. 2012). Besonders gefährdet ist hierbei die mitochondriale DNA (mtDNA), da sie, im Gegensatz zu der nukleären DNA, keine Histone besitzt (Turrens 2003). Dadurch reagiert sie sensitiver auf vielerlei Angriffe und besitzt zudem weniger ausgeprägte Reparaturmechanismen.

Durch neu entstehende Mutationen wird also ein Circulus vitiosus (Teufelskreis) erzeugt (Finkel und Holbrook 2000; Turrens 2003): Eine pathologisch veränderte mtDNA kann für die Produktion fehlerhafter Komponenten der Komplexe der Atmungskette in Mitochondrien verantwortlich sein, was wiederum zu einem gestörten Elektronenfluss durch die Komplexe I bis IV führen kann. Elektronen entfliehen demnach vermehrt ihrem physiologischen Weg, zusätzliches ROS entsteht und schädigt unter anderem wiederholt die mtDNA. Für eine physiologische Zellentwicklung ist also eine Balance zwischen ROS und den Antioxidantien von ausschlaggebender Bedeutung. Es ist wichtig festzuhalten, dass ROS in geringen Konzentrationen und bei Anwesenheit von Antioxidantien nicht schädlich, sondern im Gegenteil dazu sogar nützlich für die Zellen sein können. Die Eliminierung von Fremdkörpern durch Phagozyten wird dadurch ermöglicht, und bestimmte Erkrankungen können verhindert werden (Winterbourn 2008; Halliwell 1991). Pathologische Zellschäden entstehen meist erst, wenn das Gleichgewicht zwischen den beiden Substanzen nicht mehr aufrechterhalten werden kann (Circu und Aw 2010) und entweder der physiologische Schutz, den die Antioxidantien aufbauen, einer erhöhten ROS-Konzentration nicht standhalten kann und/oder bei einer sich im Normbereich befindlichen ROS-Konzentration ein Abfall der Antioxidans-Kapazität vorliegt (Ray et al. 2012). Der zeitliche Faktor und somit die Dauer, wie lange eine zu hohe ROS-Konzentration auf die Zellen einwirkt, trägt ebenfalls erheblich zum Ausmaß einer möglichen Destruktion von Zellen und Zellbestandteilen bei. Temporär begrenzte, akute Konzentrationsspitzen können gut von den vorliegenden Antioxidantien gepuffert und kontrolliert werden, wobei jedoch eine stetig erhöhte Kon- 
zentration auf Dauer nicht zu bewältigen ist und oxidativer Stress verursacht werden kann (Dröge 2002; Halliwell 1991).

\subsection{Genetisch kodierte Redoxindikatoren}

Um das Vorkommen und die Verteilung der reaktiven Sauerstoffspezies innerhalb einer Zelle zu erkennen, existieren verschiedene Redoxindikatoren mit unterschiedlichen Eigenschaften, die die Visualisierung von ROS im Rahmen mikroskopischer Untersuchungen ermöglichen. Gleichzeitig veranschaulichen die auftretenden Fluoreszenzen dieser Indikatoren neben der Verteilung auch die Konzentration von bestimmten Proteinen in Zellkompartimenten und stellen sich damit als Biosensor ihrer Umgebung dar (Miesenböck et al. 1998).

Es gibt zwei verschiedene Typen von Redox-Indikatoren: Organische/synthetische Farbstoffe und genetisch kodierte Redox-Konstrukte. Die organischen/synthetischen Farbstoffe haben den Nachteil, dass sie wenig spezifisch für bestimmte Arten von ROS sind und kaum oder gar keine Eigenschaft besitzen, die Zelle zu durchdringen (Markvicheva et al. 2011). Zudem können sie nicht spezifisch in Subkompartimente einer Zelle eingebracht werden. Vor der Generierung des green fluorescence protein (GFP) existierten beispielsweise die synthetischen oxidations-empfindlichen Farbstoffe DCF (Dichlorofluorescein), Hydroethidium oder Rhodamin 123, welche als irreversibel veränderbar gelten und nicht gezielt in definierte Zellkompartimente eingebracht werden können. Zudem reagieren sie sehr sensibel auf Autooxidation oder Schädigung durch das Exzitationslicht (Malinouski et al. 2011; Gerich et al. 2009). Auf Reduktion antworten diese Farbstoffe gar nicht. Vertreter der Gruppe der genetisch kodierten Redoxindikatoren sind beispielsweise das grünfluoreszierende Protein roGFPl (reduction oxidation sensitive green fluorescent protein) und das gelbfluoreszierende Protein HyPer. Genetisch entschlüsselte Redox-Proben haben den Vorteil, für Echtzeitaufnahmen von ROS in lebenden Zellen und Geweben eingesetzt werden zu können (Lukyanov und Belousov 2013; Meyer und Dick 2010).

\subsubsection{GFP}

Im Jahr 1962 entdeckte der Wissenschaftler Osamu Shimomura das grün fluoreszierende Protein, GFP, nachdem er jahrelang mit fluoreszierenden Quallen der Gattung Aequorea victoria arbeitete. Die Chromophore der genetisch entschlüsselten fluoreszierenden Protei- 
ne (GEFIs) sind in ihrer Wildtyp-Form des GFP pH- und die YFP-Variante (yellow fluorescent protein) sogar Chlorid-sensitiv (Elsliger et al. 1999).
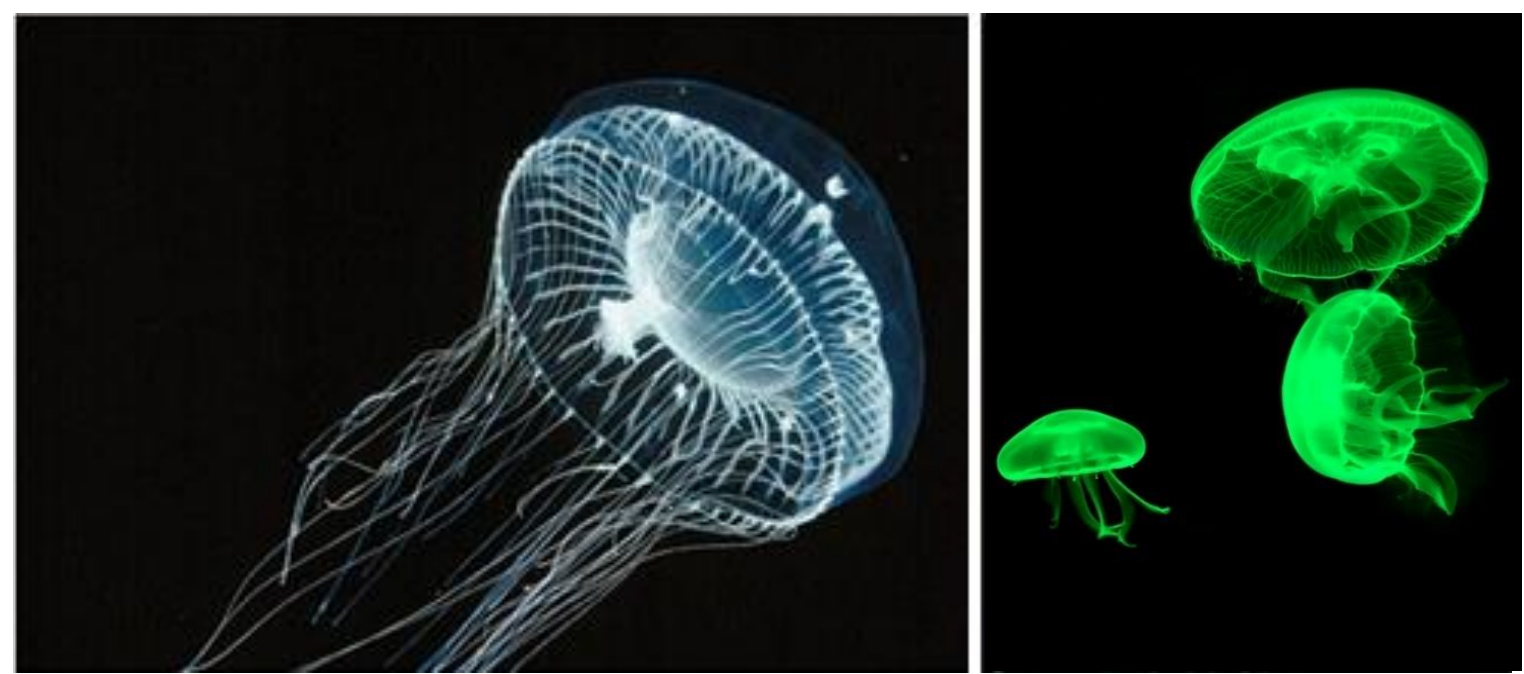

Abbildung 4: Fluoreszierende Qualle Aequorea victoria: Zwei eindrucksvolle Darstellungen der Qualle: Links, blau leuchtend durch das Protein Aequorin. Rechts, grün leuchtend durch das Green Fluorescent Protein (GFP). Internetquellen: http://il-news.softpediastatic.com/images/news2/Nobel-For-Chemical-Jellyfish-Lights-2.jpg,

http://blog.microbiologics.com/green-fluorescent-proteins-shining-new-light-on-food-qc/ (Zugriff am 01.10.2017)

Zuvor jedoch fiel das Augenmerk auf das blau fluoreszierende Protein Aequorin, welches Jahre vor dem GFP entdeckt wurde. Eher beiläufig erkannte Shimomura, dass die Qualle Aequorea victoria noch ein weiteres Protein, das GFP, exprimiert (Shimomura et al. 1962). Shimomura stellte fest, dass das grün fluoreszierende Protein (GFP) erst dann Fluoreszenz emittiert, wenn es bereits emittiertes blaues Licht des Aequorins absorbiert. Die beiden Moleküle liegen im Schirm der Qualle nah beieinander, sodass die blaue Fluoreszenz das GFP anregen kann (Shimomura et al. 1962; Shimomura 2008; Morise et al. 1974). Zusätzlich erkannte er, dass das blau leuchtende Aequorin durch eine bestimmte Konzentration von $\mathrm{Ca}^{2+}$-Ionen, welche im Salzwasser vorhanden ist, aktiviert werden konnte. Nach seiner Entdeckung und der Identifizierung seiner Chromophor (Shimomura 1979), blieb das GFP zuerst beinahe dreißig Jahre ohne weitere signifikante Forschung (Shimomura 2008). Im Jahr 1992 entschlüsselte der amerikanische Molekularbiologe Douglas Carl Prasher den genetischen Code des GFP, was ein Klonen des Proteins und somit die eigene Reproduktion ermöglichte. Zwei Jahre später wurde das GFP erstmalig in lebenden Organismen exprimiert (Chalfie et al. 1994) und schließlich modifiziert und weiterentwickelt (Tsien 1998). Im Jahr 2008 gewannen Osamu Shimomura, Roger Tsien und Martin Chalfie den 
Nobelpreis für die Entdeckung und die vollständige Entschlüsselung, Modifizierung und Charakterisierung des Proteins (Zimmer 2009).

Das GFP besteht aus einer Kette von 238 aneinandergereihten Aminosäuren und bildet mit $11 \beta$-Faltblattstrukturen einen Zylinder, in dessen Zentrum sich nach außen hin vor Hitze und Denaturierung gut geschützt eine $\alpha$-Helix-Struktur mit dem Chromophor befindet (Østergaard et al. 2001; Ormö et al. 1996; Lim 2010; Yang et al. 1996; Cody et al. 1993). Bei den bisher angewandten Fluorophoren war der Chromophor ein zusätzliches Fragment, welches dem Protein anhing. Das GFP jedoch beinhaltet seinen Chromophor, welche aus drei Aminosäureresten besteht, inmitten des Proteins, was das Klonen somit überhaupt erst ermöglicht (Shimomura 2008; Prasher et al. 1992). Die Aminosäurereste des Chromophors sind definiert als Serin, Tyrosin und Glycin $\left(\operatorname{Ser}^{65}-\mathrm{Tyr}^{66}-\mathrm{Gly}^{77}\right)$ in den Positionen 65 bis 67. Der Chromophor wird posttranslational durch einen internen Ringschluss (Zyklisierung) und durch Oxidation modifiziert und erlangt somit seine Zielfunktionen und -eigenschaften (Heim et al. 1994; Shimomura 2008; Tsien 1998). 

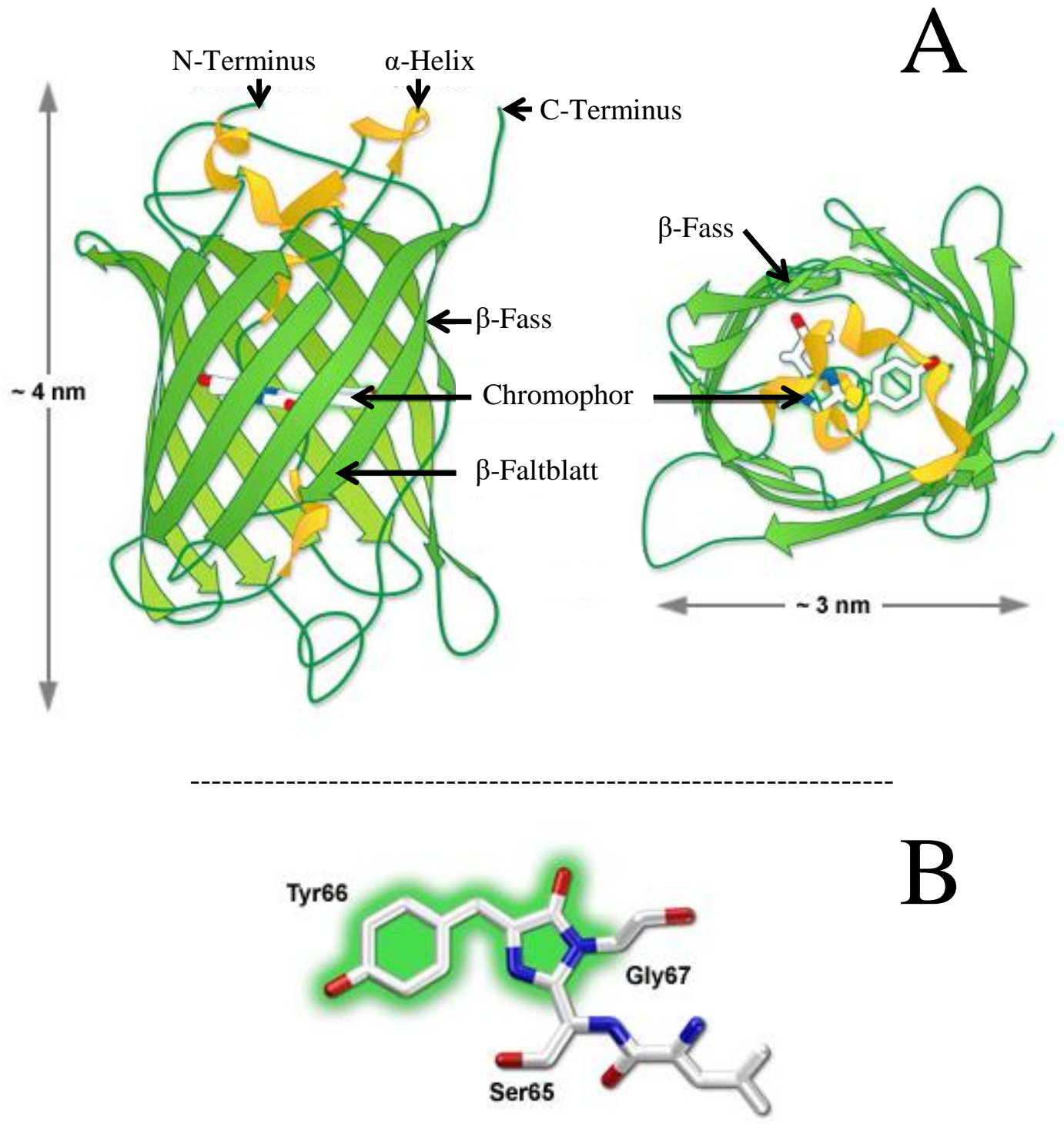

B

Chromophor

Abbildung 5: Darstellung der Architektur eines GFP-Moleküls: Der fassförmige Aufbau des grün fluoreszierenden Proteins wird hier schematisch verdeutlicht (Teil A). In seiner Mitte befindet sich die wichtigste Komponente, der Chromophor, bestehend aus den drei Aminosäuren Serin, Tyrosin und Glycin (Teil B). Internetquellen (modifiziert):

http://zeiss-campus.magnet.fsu.edu/articles/probes/jellyfishfps.html,

http://zeiss-campus.magnet.fsu.edu/articles/probes/fpintroduction.html (Zugriff am 01.10.17).

Mit freundlicher Genehmigung von Carl Zeiss Microscopy GmbH.

Im Jahr 1987 hatte Prasher die Vorstellung, an die DNA eines zu untersuchenden Proteins die DNA des grün fluoreszierenden Proteins anzuknüpfen und GFP so erst als Reporterprotein einzusetzen. Da das GFP ein verhältnismäßig kleines Protein ist (27 kDA), wird die physiologische Funktion und die Struktur des zu untersuchenden Proteins durch diesen Verbindungsvorgang beinahe nicht verändert oder gestört. Die Produktion und Verteilung des Zielproteins in der Zelle kann demnach indirekt optisch dargestellt werden, indem es zusammen mit der angeknüpften DNA des GFP transkribiert und translatiert wird. Verein- 
facht beschrieben wird die Gensequenz des GFP hinter der Sequenz des Zielproteins, jedoch noch vor der Stoppsequenz, eingebaut. Beide Sequenzen werden demnach nacheinander abgelesen und das Zielprotein, verbunden mit GFP, wird exprimiert. Die Konzentration des GFP steigt also proportional zur Konzentration des zu untersuchenden Zielproteins an, sodass sichere Aussagen über die Konzentration und Verteilung des Zielproteins gemacht werden können und GFP aus diesem Grund als Reporterprotein bezeichnet wird $(\operatorname{Lim} 2010)$.

Martin Chalfie gelang es 1994 erstmalig, GFP in Lebewesen zu integrieren. Er nutzte dafür das Bakterium Escherichia coli und den Nematoden Caenorhabditis elegans (Chalfie et al. 1994) und entdeckte zudem, dass das GFP völlig selbstständig, ohne weitere Enzyme oder Substanzen der Qualle Aequorea victoria, exprimiert werden kann. Dies brachte die Erkenntnis, dass alle notwendigen Informationen für die Expression des GFP demnach in seinem Genmaterial selbst vorhanden sein müssen (Chalfie et al. 1994; Tsien 1998). Das Protein kann mit dieser Eigenschaft zielgerecht in ein spezifisches Subkompartiment einer Zelle, unter anderem in Mitochondrien, eingebracht werden (Tsien 1998; Hanson et al. 2004; Dooley et al. 2004).

Roger Tsien begann 1998 einen Teil seiner Forschung dem GFP zu widmen. Durch die von Prasher 1992 entschlüsselte DNA-Sequenz des GFP war es ihm möglich, durch Austausch von Aminosäuren weitere farbige Fluorophore zu entwickeln. Insgesamt deklariert er nach den verschiedenen Änderungen der Aminosäuren und den individuell neu entstandenen Charaktereigenschaften, vor allem in Bezug auf die unterschiedlichen Exzitationswellenlängen, sieben verschiedene Klassen innerhalb der Gruppe der GFP. So gehört beispielsweise das gelb fluoreszierende YFP (yellow fluorescent protein) zur Klasse vier oder das blau fluoreszierende CFP (cyan fluorescent protein) zur Klasse fünf (Tsien 1998).

Zwei weitere positive Eigenschaften des GFP sind einerseits die nur äußerst selten vorkommende Phototoxizität, andererseits die große variable Einsetzbarkeit in den verschiedenen Geweben, was zu einem weitläufigen Spektrum an unterschiedlichen Verwendungsmöglichkeiten des Proteins führt (Zhang et al. 2002). Es kann gezielt in Zellsubkompartimente eingebaut werden und kann somit besonders Vergleiche im Redox-Verhalten gut darstellen. Außerdem reagiert es reversibel auf Oxidation und Reduktion.

Zudem zeigen weitere Forschungen, dass GFP in der Lage ist, dynamische Prozesse in lebenden Zellen in Echtzeitaufnahme darzustellen (Hanson und Ziegler 2004). 
Bei den meisten Fluorophoren spielt das Photobleaching während mikroskopischer Analysen eine wichtige Rolle. Es wird definiert als eine irreversible Zerstörung eines Fluorophors unter einem bestimmten Lichteinfluss, vor allem unter UV-Licht $(1-380 \mathrm{~nm})$ und weiteren kurzen Wellenlängen (Zhang et al. 2002). Generell reagiert das GFP nicht sehr sensitiv auf Photobleaching, wobei jedoch bei relativ hoher Laserkraft, auch in Abhängigkeit von der bereits erwähnten Klassenzugehörigkeit des GFP (z. B. yellow fluorescent protein (YFP): Klasse vier; cyan fluorescent protein (CFP): Klasse fünf (Tsien 1998) Photobleaching in einem gewissen Umfang auftreten kann (Tsien 1998). Die Exzitationsmaxima für wtGFP (wild type) liegen bei $395 \mathrm{~nm}$ und, mit einer deutlich geringeren Antwort, bei $475 \mathrm{~nm}$. Die emittierte grüne Fluoreszenz hat eine Wellenlänge von $508 \mathrm{~nm}$ (Elsliger et al. 1999; Heim et al. 1994).

Der Redox-Indikator roGFP ist eine Oxidations- und Reduktions-sensitive, aber $\mathrm{pH}$ insensitive Variante des GFP, wobei die Buchstabenkombination „ro“ für „reduction/oxidation“" steht (Funke et al. 2011; Lukyanov und Belousov 2013). Die diesbezüglichen Mutationen für roGFP1 sind an den Stellen C48S, S147C und Q204C lokalisiert (Dooley et al. 2004). Dies sagt aus, dass das GFP zusätzlich zwei Cystein-Reste an seiner Oberfläche trägt, nämlich an den Positionen 147 und 204, welche in der Lage sind, bei Oxidation Disulfidbrücken zu bilden. An Position 48 wurde ein Cystein-Rest zu Serin geändert, um dort eine unwillkürliche Bildung von Disulfidbrücken zu verhindern. Die neuen, gezielt entstandenen Disulfidbrücken verändern das Protein in seiner Konformität, wodurch der Chromophor, der sich im Zentrum des Moleküls befindet, neue Eigenschaften erhält. Durch eine Oxidation der Thiolgruppen (-SH) der Cysteine wird Cystin gebildet. Dies bewirkt eine Blauverschiebung der Fluoreszenz des roGFP (Dooley et al. 2004). Gleichzeitig verändern sich die optischen Eigenschaften. Dies bedeutet, dass die Lichtabsorption durch den Fluorophor moduliert wird, ohne die Zelle zu schädigen (Hanson und Ziegler 2004; Lohman und Remington 2008; Hanson et al. 2004).

Das roGFP besitzt die Eigenschaften, die auch die Ausgangsform GFP aufweist, ist jedoch besonders spezifisch und sensitiv für die Visualisierung und Quantifizierung von Echtzeitaufnahmen des Redoxstatus einer Zelle und ihrer spezifischen Zellkompartimente. Es können zudem räumliche und zeitliche Muster von Genaktivitäten sowie die intrazelluläre Verteilung der fokussierten Proteine und ihrer Interaktionen mit anderen Proteinen dargestellt werden (Lukyanov und Belousov 2013). Im Gegensatz zu üblichen ROS-Farbstoffen, welche eine deutliche irreversible Autooxidation und Fotosensibilität aufweisen, kann 
roGFP reversibel oxidiert werden. Das roGFP1, eine Unterform des roGFP, reagiert nur in geringem Ausmaß sensibel auf Änderungen im pH- oder Chlorid-Bereich (Funke et al. 2011). Es besitzt in der konfokalen Ein-Photonen-Mikroskopie seine Absorptionsmaxima bei Wellenlängen von $400 \mathrm{~nm}$ und $475 \mathrm{~nm}$ (Lukyanov und Belousov 2013).

Das im Vergleich zu roGFP minimal veränderte roGFP1 veranschaulicht demnach zuverlässig den Einfluss von $\mathrm{H}_{2} \mathrm{O}_{2}$ als Oxidationsmittel und von DTT (Dithiothreitol) als Reduktionsmittel auf die Zelle. Es wird angeregt durch die Exzitationswellenlängen 400 und 488 nm, die Emission des Fluorophor liegt bei einer Wellenlänge von $515 \mathrm{~nm}$ (Dooley et al. 2004). Der isosbestische Punkt von roGFP1 liegt in der Ein-Photonen-Mikroskopie bei $\sim 425 \mathrm{~nm}$ (Hanson et al. 2004).

$\mathrm{H}_{2} \mathrm{O}_{2}$ gehört, wie bereits beschrieben, zu den reaktiven Sauerstoffspezies (ROS) und kommt in relativ geringer Konzentration physiologisch in jeder Zelle vor. Diese besteht aus verschiedenen Zellsubkompartimenten, welche täglich eine individuelle Menge an ROS produzieren. In den Zellbestandteilen, in denen ein intensiver und ausgeprägter Metabolismus vorliegt, besteht ein reduzierendes Milieu, beispielsweise im Cytoplasma und in den Mitochondrien, um die beteiligten Enzyme, welche mit einem oxidierbaren Cystein im sensiblen aktiven Zentrum ausgestattet sind, vor den Veränderungen durch ROS und somit vor Oxidation und Funktionsverlust zu schützen (Hanson et al. 2004; Dooley et al. 2004). Wird dort eine bestimmte Konzentration an ROS überschritten, können Zell- und Enzymschäden verursacht und das reduzierende Milieu nicht mehr aufrechterhalten werden. Das roGFP1 befindet sich also im Cytoplasma und Mitochondrium in einem reduzierten Zustand. Eine erhöhte Konzentration an ROS kann also durch roGFP1 dargestellt und nachgewiesen werden (Cannon und Remington 2006; Meyer und Dick 2010).

Eine alternative Methode, um die ROS-Konzentration innerhalb einer Zelle zu bestimmen, ist die Berechnung des Verhältnisses des Redox-Paares GSH und GSSG. Das Glutathion (GSH) kann ROS zu einem unschädlichen Molekül modifizieren, indem es als wichtiger Redox-Puffer ein Elektron seiner Thiol-Gruppe (-SH) auf das ROS-Molekül überträgt. Die reaktiven Sauerstoffspezies werden dadurch reduziert und sind somit weniger schädlich für die Zellen und den gesamten Organismus, wobei das Glutathion bei dieser Reaktion selbst zu Glutathion-Disulfid (GSSG) oxidiert wird. Befindet sich also eine hohe Konzentration des oxidierten Glutathions (GSSG) in der Zelle, kann gleichzeitig darauf geschlossen werden, dass eine hohe ROS-Konzentration vorliegt (Dringen 2000; Dooley et al. 2004). Das Verhältnis von GSH und GSSG wird meist invasiv gemessen, das heißt, die Lyse der Zel- 
len oder des Gewebes ist erforderlich, was demzufolge Artefakte erzeugen kann. Zudem ist es anhand dieses Verfahrens nicht möglich, kompartimentspezifische Messungen durchzuführen (Dardalhon et al. 2012). Aus diesem Grund stellt die Entdeckung des GFP eine erhebliche methodische Bereicherung für die Wissenschaft dar, da es nun möglich ist, aufgrund der genetisch vollständigen Entschlüsselung, eine kontinuierliche spezifische Messung der zellulären Redox-Balance durchzuführen, ohne die Zellen zu schädigen oder anzugreifen (Dooley et al. 2004). Das grün fluoreszierende Protein (GFP) wurde bisher erfolgreich in Experimenten unter anderem mit Hefen, Bakterien, Pflanzen, Zebrafischen, Drosophila-Fruchtfliegen sowie Zellen von Säugetieren eingesetzt (Yang et al. 1996).

Diesbezüglich ist roGFP1 seiner Aufgabe gut angepasst worden, es zeigt jedoch auch einige Nachteile, beispielsweise die relativ langsame Antwort auf Änderungen des RedoxStatus. Ein möglicher schneller Anstieg einer ROS-Konzentration kann somit nur weniger deutlich dargestellt werden (Cannon und Remington 2006). Auch die Wissenschaftler Gutscher und Pauleau kritisierten 2008 die nur langsame Reaktion des roGFP auf schnelle Redox-Veränderungen innerhalb der Zelle (Gutscher et al. 2008). Sie kombinierten daraufhin Glutaredoxin-1 (Grx1) mit roGFP2, um diesbezüglich ein besseres Antwortverhalten erzielen zu können.

\subsubsection{HyPer}

Das Protein HyPer ist ein Redox-Sensor, der auf der gelb fluoreszierenden Variante (YFP) beruht. Es erhielt seine Bezeichnung durch die Abkürzung des Molekülnamens „Hydrogen Peroxide“ - HyPer. Roger Tsien forschte 1998 an dem grün fluoreszierenden Protein GFP und entdeckte, dass sich durch verschiedene Mutationen auf Ebene der Aminosäuren des Proteins verschiedenfarbig leuchtende Proteine erschaffen ließen (Tsien 1998). Diese teilte er für eine bessere Übersicht in sieben Untergruppen ein. Jede dieser Gruppen ist charakterisiert durch ihre jeweiligen individuellen Exzitations- und Emissionsmaxima.

Das YFP (yellow fluorescent protein) gehört zur vierten Gruppe nach der Einteilung durch Roger Tsien und besitzt unter Berücksichtigung aller sieben Untergruppen die längste Wellenlänge mit einer Emissionsspitze von 529 nm. Die anderen Gruppen erreichen in ihrer Emission etwa einen durchschnittlichen Wert zwischen $350 \mathrm{~nm}$ und $450 \mathrm{~nm}$. Die Exzitationsmaxima für HyPer liegen bei $392 \mathrm{~nm}$ und $514 \mathrm{~nm}$ mit einem isosbestischen Punkt bei $432 \mathrm{~nm}$. Der isosbestische Punkt ist definiert als eine spezifische Wellenlänge, bei der sich während einer Reaktion die Lichtabsorption im Verlauf der Reaktion nicht ändert 
(McNaught und Wilkinson 1997; Wachter et al. 2000). Die Proteine dieser Klasse sind zudem vergleichsweise groß $(74 \mathrm{kDa})$ und gelangen somit nicht ohne weitere Hilfsmaßnahmen vom Zytosol in den Zellkern. Auf einer mikroskopischen Aufnahme bleibt der Zellkern inmitten der Zelle demnach charakteristisch dunkel gefärbt, also von HyPer weitestgehend unbeeinflusst (Tsien 1998; Miyawaki et al. 1997).

HyPer besteht aus zwei zusammengesetzten Komponenten: Zum einen aus der Regulatordomäne OxyR-RD des gramnegativen Bakteriums Escherichia Coli und zum anderen aus dem zirkulären Protein aus der Gruppe der Fluoreszenzproteine (cpYFP - circulary permuted yellow fluorescent protein). Das zirkuläre Protein entsteht, indem sich die ursprünglichen N- und C- Enden des Moleküls verbinden und dadurch neue N- und C- Enden entstehen (Lukyanov und Belousov 2013; Belousov et al. 2006). OxyR-RD reagiert äußerst sensitiv auf $\mathrm{H}_{2} \mathrm{O}_{2}$ und dessen Konzentrationsänderungen in der Umgebung.
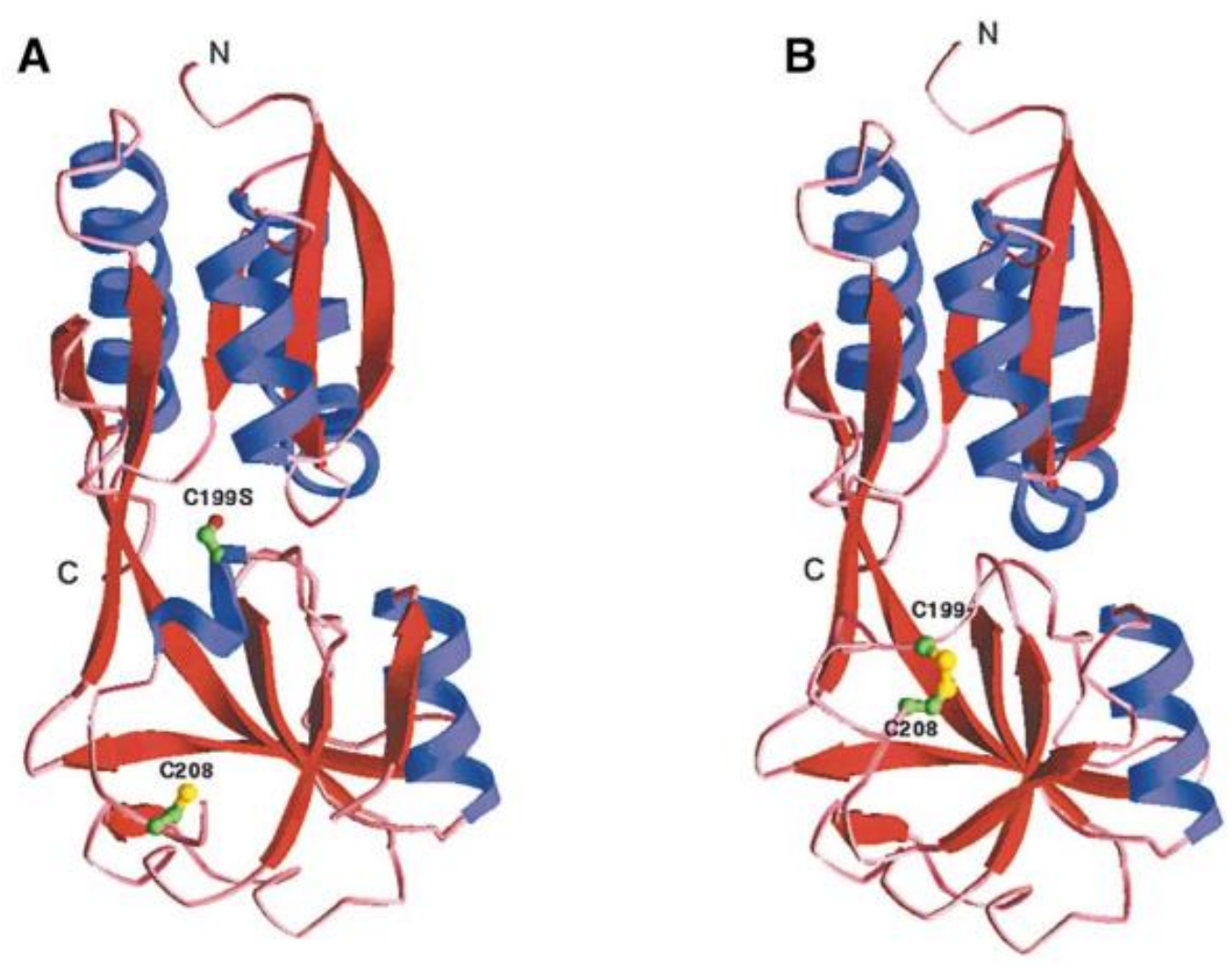

Abbildung 6: Struktur der OxyR-Regulatordomäne. (A) Reduzierte Form mit den redoxaktiven Cystein-Resten C208 und C199S. (B) Oxidierte Form. Die Cystein-Anteile sind durch Disulfidbrücken verbunden (grün und gelb) und bewirken eine reversible Konformationsänderung der Regulatordomäne. Der Buchstabe $\mathrm{C}$ steht für den Carboxy-Terminus, $\mathrm{N}$ steht für den AminoTerminus des Proteins. Der Buchstabe S bedeutet, dass das Cystein an Position 199 durch Serin ersetzt wurde (Choi et al. 2001, Abb. 1, mit freundlicher Genehmigung von Elsevier). 
Die Wildtyp-OxyR-Regulatordomäne besteht aus zwei Domänen: Eine $\mathrm{H}_{2} \mathrm{O}_{2}$-sensitive Domäne und eine DNA-bindende Domäne. In Anwesenheit von $\mathrm{H}_{2} \mathrm{O}_{2}$ verändert sich die im Ausgangszustand befindliche reduzierte Form zur oxidierten Form, was mit einer Konformationsänderung des gesamten Moleküls einhergeht. Die Schlüsselkomponenten für diesen Prozess sind hier die beiden Cystein-Anteile Cys199 und Cys208, wobei sich Cys199 in einer wasserabweisenden Umgebung befindet (siehe Abbildung 6). Der Kontakt mit $\mathrm{H}_{2} \mathrm{O}_{2}$ wandelt das Cys199 zu einem Sulfensäurederivat um, welches sich nun außerhalb des wasserabweisenden Bereichs befindet. Das Sulfensäurederivat formt eine Disulfidbrücke mit Cys208, welche ausschlaggebend für die Konformationsänderung der gesamten Regulatordomäne ist (Choi et al. 2001; Belousov et al. 2006).

Diese sensible und selektive Reaktion auf $\mathrm{H}_{2} \mathrm{O}_{2}$ ist in der intrazellulären Umgebung reversibel und stellt deshalb einen großen Vorteil für HyPer dar. Das Escherichia coli Bakterium nutzt diese Sensibilität für $\mathrm{H}_{2} \mathrm{O}_{2}$ durch seine Regulatordomäne OxyR-RD und die darauffolgende Veränderung als überlebenswichtigen Vorteil, um die Transkription von notwendigen Genen zu initiieren. Diese Gene stellen einen Selbstschutz vor dem oxidativen Stress dar (Aslund et al. 1999; Lukyanov und Belousov 2013; Malinouski et al. 2011; Markvicheva et al. 2011).

HyPer ist vollständig genetisch entschlüsselt, hochspezifisch und kann demnach ebenfalls, wie GFP, in jedem Subkompartiment einer Zelle exprimiert werden, beispielsweise in Mitochondrien, durch Anheftung einer spezifischen Lokalisationssequenz an das Protein, (Markvicheva et al. 2011; Weller et al. 2014), um dort den aktuellen Redox-Status und auch die dazugehörigen schnellen, dynamischen Veränderungen zu visualisieren (BanachLatapy et al. 2013; Belousov et al. 2006; Lukyanov und Belousov 2013).

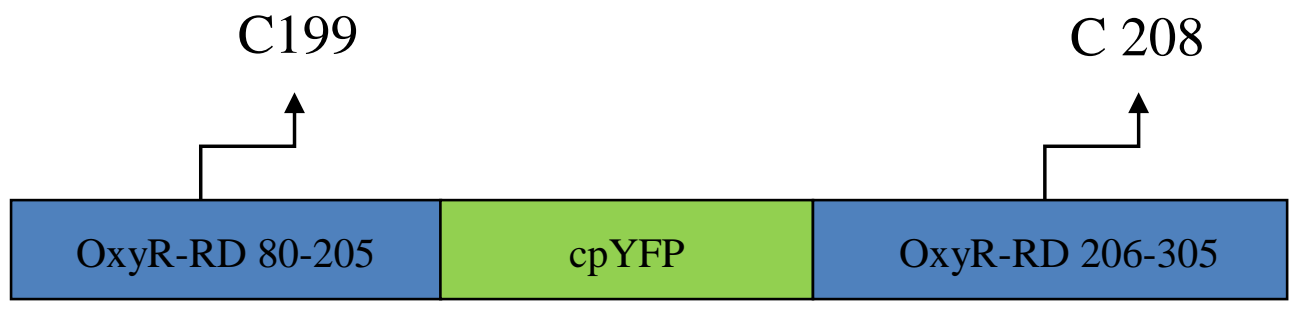

\footnotetext{
Abbildung 7: Schematischer Aufbau von HyPer. HyPer besteht aus dem cpYFP (grün), was sich zwischen dem Rest 205 und 206 der Regulatordomäne von OxyR (blau) befindet. An den Stellen C199 und C208 (im Wildtyp) befinden sich jeweils die beiden für Funktion und Eigenschaft wichtigsten Cystein-Reste (modifiziert nach Markvicheva et al. 2011, Abb. 1a, mit freundlicher Genehmigung von Elsevier).
} 
Um HyPer zu bilden, wird cpYFP an eine bestimmte Stelle in der Regulatordomäne OxyRRD zwischen die beiden Reste 205 und 206 eingebaut (Abbildung 7). Es zeigt zwei Exzitationsmaxima bei den Wellenlängen $420 \mathrm{~nm}$ und $490 \mathrm{~nm}$, wobei unter oxidierenden Umständen durch Einwirken von $\mathrm{H}_{2} \mathrm{O}_{2}$, bei $420 \mathrm{~nm}$ ein Exzitationsabfall und bei $490 \mathrm{~nm}$ ein Anstieg zu beobachten ist. Das Emissionsmaximum liegt unbeeinflusst durch $\mathrm{H}_{2} \mathrm{O}_{2}$ bei einer Wellenlänge von 516 nm (Lukyanov und Belousov 2013; Belousov et al. 2006).

Besonders bedeutsam erscheint die Erkenntnis, dass das $\mathrm{pH}$-sensitive HyPer ausschließlich, also sehr selektiv, auf das Vorhandensein von Hydrogenperoxid $\left(\mathrm{H}_{2} \mathrm{O}_{2}\right)$ zu reagieren scheint, wobei auch schon geringste Konzentrationen davon zur Veränderung und Beeinflussung des Proteins führen können. HyPer-Proben können mehrfach hintereinander kurzzeitig oxidiert werden und gelangen zwischen den Oxidationen zu ihrem Ausgangszustand zurück. Interessant ist hierbei jedoch, dass die zweite und dritte Oxidation jeweils abgeschwächte ratiometrische Antworten zeigen (Weller et al. 2014; Malinouski et al. 2011). Die zu messende Reaktion auf $\mathrm{H}_{2} \mathrm{O}_{2}$ kann, zumindest theoretisch, nicht durch andere in der Zelle vorhandenen reaktiven Sauerstoffspezies verfälscht werden (Belousov et al. 2006). Aktuellere Forschungsergebnisse zeigen, dass HyPer auf höhere Konzentrationen von $\mathrm{H}_{2} \mathrm{O}_{2}(2 \mathrm{mM})$ nach einem steilen Anstieg der Verhältniskurve anschließend mit einem Absinken der Kurve sogar unter die Basislinie reagiert. Dies bestätigt, dass HyPer also nicht ausschließlich von $\mathrm{H}_{2} \mathrm{O}_{2}$ beeinflusst wird, sondern durch das entstandene oxidative Milieu sekundäre Reaktionen ausgelöst wurden, die das Absinken unter die Basislinie bedingen. Bei geringeren $\mathrm{H}_{2} \mathrm{O}_{2}$-Konzentrationen wurde dies nicht beobachtet. Auch andere Oxidationsmittel, wie TBHP (tert-Butylhydroperoxid) beeinflussen die ratiometrische Antwort von HyPer reversibel. Weitere Forschungen zeigen Reaktionen von HyPer auf das Reduktionsmittel DTT dargestellt mithilfe von CCD-Kameras: DTT ist nicht in der Lage, HyPer vollständig zu reduzieren, vielmehr entstehen multiphasische, inkonsistente Antworten (Weller et al. 2014).

Charakteristisch für HyPer ist außerdem, dass es aufgrund seines Redoxpotentials bei Oxidation vor allem in Zellsubkompartimenten mit überwiegend reduzierendem Milieu, wie beispielsweise dem Zytosol, den Peroxisomen, dem Nukleus oder dem Mitochondrium deutliche Ergebnisse zeigt. In diesen Zellkompartimenten liegt nur ein Anteil von 10 bis $16 \%$ des gesamten HyPer oxidiert vor, der übrige größere Teil ist reduziert und somit sensitiv für eine Oxidation durch $\mathrm{H}_{2} \mathrm{O}_{2}$. Vor allem im endoplasmatischen Retikulum (ER), in Endosomen und Lysosomen, liegt jedoch eine überwiegend oxidierende Umgebung vor: 
Hier ist HyPer bereits zu 70 \% oxidiert (Austin et al. 2005; Dooley et al. 2004; Hwang et al. 1992). Aus diesem Grund steigt wiederum die Affinität des oxidierten HyPer zur Reaktion mit dem Reduktionsmittel DTT erheblich an. HyPer würde demnach im ER keine weitere Oxidation anzeigen können, da es sich bereits im vollständig oxidierten, also gesättigten Zustand befindet (Malinouski et al. 2011; Enyedi et al. 2010). Die Oxidation des Proteins erfolgt in der Regel innerhalb von wenigen Sekunden, wohingegen die Reduktion zurück in den Ausgangszustand mehrere Minuten in Anspruch nehmen kann und das erzeugte Signal eventuell sogar unter den Ausgangswert sinken kann (Weller et al. 2014). Dies erklärt sich dadurch, dass möglicherweise ein Bleaching (Ausbleichen) stattfindet oder sogar die Konzentration von vor $\mathrm{H}_{2} \mathrm{O}_{2}$ schützenden Radikalfängern, wie Antioxidantien, als Autoreaktion in der Zelle im Rahmen eines Selbstschutzes angestiegen ist (Malinouski et al. 2011).

Zudem ist zu berücksichtigen, dass HyPer sehr schnell, aber im Vergleich deutlich langsamer als ROS, von seinem vorbestimmten Zielort fortdiffundiert, da HyPer ein volumenmäßig größeres Molekül als ROS darstellt. Somit wird allein ein Durchschnittssignal der vorbestimmten Region ermittelt (Lukyanov und Belousov 2013; Malinouski et al. 2011).

Weitere Sensoren für Oxidation stellen Substanzen, wie PG1 (PeroxyGreen 1) und DCF $\left(2^{\prime}, 7^{\prime}\right.$-dichlorofluorescein) dar, die jedoch synthetische Farbstoffe, aber keine fluoreszierenden Proteine sind (Karlsson et al. 2010). Sie haben den Vorteil, bei einem Konzentrationsanstieg von $\mathrm{H}_{2} \mathrm{O}_{2}$ stärker und deutlicher zu reagieren als HyPer. Als Nachteil ist jedoch festzuhalten, dass vor allem DCF erst auf $\mathrm{H}_{2} \mathrm{O}_{2}$-Konzentrationen ab $50 \mu$ mol und größer anspricht. Unterhalb dieser Konzentrationsschwelle sind keine Veränderungen sichtbar. DCF und PG1 zeigen zudem eine irreversible Veränderung nach Oxidation und reagieren im Gegensatz zur Theorie von HyPer auch auf andere Oxidationsmittel. Sie sind zudem nicht gezielt in ein bestimmtes Zellkompartiment einzubringen und können durch Lichtexposition zusätzlich ROS produzieren, was das Ergebnis verfälschen würde. HyPer hingegen reagiert reversibel, ist theoretisch selektiv für $\mathrm{H}_{2} \mathrm{O}_{2}$ und gut geeignet für Messungen während metabolischer Prozesse und Signalübertragungen. Es ist abhängig vom pH-Wert (potentia hydrogenii) der Umgebung und zeigt schon kleinste Veränderungen bei sehr niedrigen $\mathrm{H}_{2} \mathrm{O}_{2}$-Konzentrationen $(<50 \mu \mathrm{mol})$ sehr sensitiv an. Zudem scheint bei einer Konzentration über $200 \mu \mathrm{mol}$ für HyPer eine Sättigung erreicht zu werden, sodass die Ergebnisse der Reaktion bei weiterem Konzentrationsanstieg unverändert bleiben (Weller et al. 2014; Belousov et al. 2006; Malinouski et al. 2011). 


\subsection{Zwei-Photonen Mikroskopie}

Die Ursprünge der Zwei-Photonen-Mikroskopie liegen im Jahr 1931 und beruhen auf den Forschungen der Göttinger Physikerin Maria Göppert-Mayer (Piston 1999; Masters und So 2004; Göppert-Mayer 1931; Denk et al. 1990). Von diesem Zeitpunkt an wurden weiterhin stetig Forschungen in Bezug auf die Zwei-Photonen-Exzitation (TPE: Two-PhotonExcitation) betrieben.

Die Zwei-Photonen-Mikroskopie (TPLSM: two-photon laser scanning microscopy) besitzt im Vergleich zur konfokalen Laser-Scanning-Mikroskopie (Ein-Photonen-Mikroskopie) gewisse Vorteile, sowohl in Bezug auf die Auflösung, als auch auf das Einwirken auf die Gewebsprobe. Es ist vorerst festzuhalten, dass sich die Ergebnisse der konfokalen LaserScanning-Mikroskopie in Bezug auf dünnere Gewebsproben $(<1 \mu \mathrm{m})$ kaum von denen der TPLSM bei selbiger Probe unterscheiden. Interessant wird es bei Gewebsschichten mit größerem Durchmesser, bei denen die TPLSM bei Messungen in tieferen Schichten ihre Vorteile zeigt. Wichtig ist die Tatsache, dass TPLSM nicht durchführbar ist, wenn eine konfokale Laser-Scanning-Mikroskopie bereits keine Ergebnisse erzielen konnte, da beide Verfahren doch ein ähnliches Prinzip verfolgen und ähnliche Bedingungen als Voraussetzung gegeben sein müssen (Benninger und Piston 2013; Denk et al. 1990). Das konfokale Laser-Scanning-Mikroskop besitzt eine sogenannte Lochblende (Pinhole). Sie verhindert, dass Emission von ober- oder unterhalb der Zielregion sowie Streulicht aus benachbarten Regionen detektiert werden (out-of-focus fluorescence) (Theer et al. 2003). Durch die Exzitationsstrahlung werden jedoch Bereiche ober- und unterhalb des ausgewählten Zielbereichs angeregt, wodurch diese durch Photobleaching und Phototoxizität geschädigt werden. TPLSM hat den großen Vorteil, dass das ausgesandte Exzitationslicht ausschließlich in einem ausgewählten, eng umgrenzten fokalen Bereich die gewünschte Emission erzeugt und nur dort Photobleaching und Phototoxizität stattfinden kann, sodass umliegende Bereiche in der Gewebsprobe keinen Schaden nehmen und auch kein ergebnisverfälschendes Hintergrundsignal entsteht. Dies ist eine gute Voraussetzung für Langzeitmessungen von fotosensiblen Proben (Piston 1999; Patterson und Piston 2000; Moneron und Hell 2009). Üblicherweise wird mit einem non-descanned-Detektor in der TPLSM das gesamte emittierte Licht der Probe von dem Photomultiplier aufgenommen. Eine Lochblende ist in dieser Konfiguration demnach nicht notwendig.

Für die konfokale Laser-Scanning-Mikroskopie gilt: Je tiefer die Zielregion im Gewebe liegt, desto mehr Streulicht wird erzeugt und desto mehr Hintergrundsignal entsteht, sodass 
generell im Ergebnis der Kontrast, also das Signal der Fluoreszenz, sinkt. Die Penetrationstiefe ist demnach aufgrund des erzeugten Streulichts limitiert. In der TPLSM spielt diese Penetrationstiefe keine Rolle, da das Exzitationslicht ausschließlich den definierten Zielbereich mit konzentrierter Intensität anregt und dieser Bereich der voll ausgesandten Exzitationsenergie ausgesetzt ist und keine Energie durch Anregung außerhalb des fokussierten Bereichs verloren geht (Piston 1999; Rubart 2004). Das Erzeugen von Streulicht lässt sich auch hier nicht ganz vermeiden, jedoch streut das verwendete langwelligere infrarote Licht weniger als das kurzwellige UV-Licht, das für die konfokale Laser-Scanning-Mikroskopie notwendig ist. Wenn also das Exzitationslicht streut, entsteht kein verfälschendes Signal, da es äußerst unwahrscheinlich ist, dass simultan zur selben Zeit und im gleichen Winkel ebenfalls ein anderes gestreutes Photon vorhanden ist und beide Photonen gleichzeitig auf den Fluorophor treffen. Ist jedoch das emittierte Photon der Fluoreszenzemission gestreut, geht es nicht verloren, sondern wird detektiert und trägt zum Gesamtergebnis bei (Rubart 2004).

Als Zielgewebe für die TPLSM gelten alle Gewebe, die der konfokalen Laser-ScanningMikroskopie zur Verfügung stehen, jedoch besteht noch zusätzlich die Möglichkeit, vollständige Organe, Embryos, lebende Tiere (intra-vital imaging) und Hirnschnitte untersuchen zu können. Es können neuronale Strukturen, Gliazellen und Blutgefäße, sowie der Blutfluss und die Abgabe von Neurotransmittern, dargestellt werden (Piston 1999; Stetter et al. 2013; Diaspro et al. 2006; Denk et al. 1990). Zudem ist heute eine zuverlässige Darstellung der Dynamik einer Zelle, ihrer Entwicklung und ihrer Reaktion auf Reize sowie die Morphologie und die strukturelle Plastizität von Molekülen in Unterbereichen der Zelle mit einer hohen räumlichen und zeitlichen Auflösung durch nur minimale Gewebsinvasion gegeben (Kondo und Okabe 2013; Patterson und Piston 2000; Rubart 2004; Helmchen und Denk 2002).

Das Grundprinzip der konfokalen Laser-Scanning-Mikroskopie beruht darauf, dass ein Anregungsphoton mit einer bestimmten Wellenlänge auf den Fluorophor trifft, dieser absorbiert sowie angeregt wird und auf ein angestrebtes höheres Energielevel gelangt. Sobald der Fluorophor wieder in seinen Ausgangszustand zurückkehrt, wird durch die entstandene Energie ein neues Photon emittiert, das als Licht detektiert wird. In der TPLSM absorbiert der Fluorophor simultan zwei Photonen zur selben Zeit. Die beiden Photonen tragen jeweils nur die Hälfte der Energie aber dafür die doppelte Wellenlänge (Infrarotlicht bei z.B. $800 \mathrm{~nm}$ ), die das Anregungsphoton der konfokalen Laser-Scanning-Mikroskopie besitzt 
(UV-Licht bei z.B. 400 nm) (Centonze und White 1998; Rubart 2004; Bush et al. 2007). Die erzeugte Emission ist jedoch bei beiden Vorgehensweisen gleich (Denk et al. 1994). Wichtig ist die Tatsache, dass die Emissionsintensität der Fluoreszenz in der TPLSM in Bezug auf die Exzitationsintensität quadratisch ansteigt (Denk et al. 1990; Rubart 2004). Zusätzlich ist hier festzuhalten, dass das in der konfokalen Laser-Scanning-Mikroskopie angewandte UV-Licht die Probe in einem noch größeren Umfang schädigen kann, als das Infrarotlicht der TPLSM, was sich wiederum als Vorteil für Letzteres herausstellt. Die Eindringtiefe des Anregungslichts ist hier im Vergleich zur konfokalen Laser-ScanningMikroskopie aufgrund der größeren Wellenlänge um einen Faktor zwei und mehr größer und kann sich somit auf bis zu $1 \mathrm{~mm}$ durch das Gewebe erstrecken. Von Vorteil ist hier, dass sich dadurch auch das Zeitfenster verlängert, innerhalb dessen die Messung vollzogen werden kann, bevor die Zelle durch Fototoxizität beeinträchtigt wird (Centonze und White 1998; Stetter et al. 2013).

Als Voraussetzung für die TPLSM gilt, dass zwei Photonen zu exakt derselben Zeit am selben Ort simultan absorbiert werden müssen (Piston 1999). Um diese Chance der gleichzeitig eintreffenden Photonen zu erhöhen, sind eine größere Photonenflussdichte, sowie eine höhere Laserleistung notwendig. Die Dichte der Photonen kann durch sehr kurze Laserpulse mit jeweils einer Dauer von $\sim 100$ fs und einer Frequenz von $\sim 80$ MHz gesteigert werden: Je kürzer die Pulse, desto größer die Anzahl der Photonen und desto höher ist die maximale Exzitationskraft (peak power) im Vergleich zur durchschnittlichen Power. Für die Gewebeprobe erwies es sich als schonend, wenn nur kurze Pulse des Lasers die Energiemaxima aufweisen, jedoch die durchschnittliche Leistung verhältnismäßig niedrig liegt (Piston 1999; Centonze und White 1998; Diaspro et al. 2006). Die Photonenflussdichte muss millionenfach größer sein, um dasselbe Ausmaß an Absorption des Fluorophors zu erzielen, die die konfokale Laser-Scanning-Mikroskopie aufweisen würde (Denk et al. 1990; Denk et al. 1994).

Die Fluoreszenzintensität steigt für die TPLSM quadratisch an, für die konfokale LaserScanning-Mikroskopie zeigt sich ein linearer Anstieg. Zu beachten ist, dass der Fluorophor in Bezug auf die Exzitationsleistung ein Sättigungslimit zeigt. Für die TPLSM liegt dies bei $\sim 50 \mathrm{~mW}$, für die konfokale Laser-Scanning-Mikroskopie bei $\sim 1 \mathrm{~mW}$. Wird dieses überschritten, steigt die Wahrscheinlichkeit für das Auftreten von Fototoxizität oder Photobleaching (Denk et al. 1990). Einen Nachteil gibt es bei der Anwendung der TPLSM in hochpigmentierten Gewebsproben: Diese können das infrarote Licht (near-infrared light), 
welches mit Wellenlängen zwischen etwa $700 \mathrm{~nm}$ und $1000 \mathrm{~nm}$ erzeugt wird, absorbieren und dadurch die Probe im größeren Maße schädigen (Masters und So, Peter T. 2004). Limitierende Faktoren für den Gebrauch des TPLSM stellen heute die hohen Erwerbskosten und die anfänglich komplizierte und umfangreiche Bedienung des Geräts dar (Piston 1999).

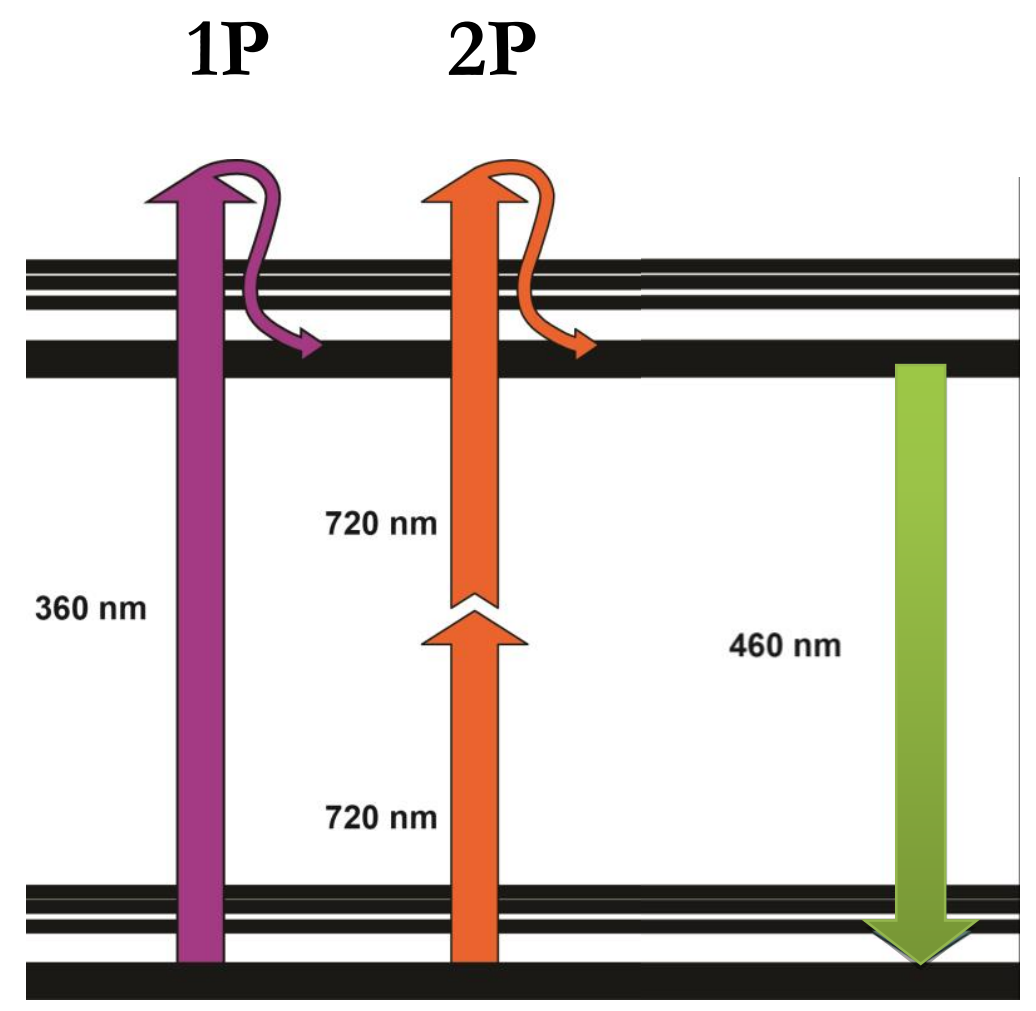

Abbildung 8: Vereinfachte Darstellung des Perrin-Jablonski-Diagramms. Dargestellt wird die ausgesandte Fluoreszenz in Bezug auf die Ein- und Zwei-Photonen-Mikroskopie. In beiden Systemen wird das gleiche Energieniveau erreicht und aus diesem Grund auch immer die gleiche Emission erzeugt (grün). In der konfokalen Laser-Scanning-Mikroskopie ist die anregende Wellenlänge verhältnismäßig kurz. Sie liegt zum Teil im Bereich des ultravioletten Lichts (lila). In der TPLSM wird die Wellenlänge, welche in der konfokalen Laser-Scanning-Mikroskopie genutzt wurde, etwa verdoppelt (orange). Diese liegt nun im nah infraroten (NIR) Bereich. Zwei Photonen mit der doppelten Wellenlänge werden nun gleichzeitig absorbiert und erzeugen in dem Fluorophor das gleiche Energielevel, wie ein einziges Photon der halben Wellenlänge (modifiziert nach Diaspro et al. 2006, Abb. 1, mit freundlicher Genehmigung von BioMed Central). 


\section{Material und Methoden}

\section{1 Überblick über die verwendeten Materialien}

Dieser Abschnitt stellt einen Überblick über die verschiedenen Arbeitstechniken und die dafür verwendeten Materialien und Lösungen dar, die für meine Versuche gebraucht wurden. Für die Durchführung benötigte ich Zellen aus dem Hippocampus von Mäusen, welche sich in einem Alter von ein bis fünf Tagen befanden. Es fand eine Tiertötung mit anschließender Organentnahme statt. Die Dekapitation wurde durch entsprechend autorisierte Mitglieder der Arbeitsgruppe durchgeführt. Direkt im Anschluss wurden die lebenden Zellen selbstständig von mir präpariert. Meine Versuche fanden ausschließlich an isoliertem Gewebe statt.

Mitteilung zur Tötung von Wirbeltieren. T-13/08; Tierschutzbeauftragter der Universitätsmedizin Göttingen.

Tabelle 1: Verwendete Redox-Modulantien

\begin{tabular}{|c|c|c|c|c|}
\hline Substanz & Lieferant & Wirkung & Lösungsart & Einsatz des Stoffes \\
\hline $\begin{array}{c}\mathrm{H}_{2} \mathrm{O}_{2} \\
\text { Wasserstoffperoxid }\end{array}$ & SIGMA & Oxidationsmittel & $\begin{array}{l}\text { Klare Flüssigkeit } \\
8,8 \mathrm{M}(30 \%) \\
\text { wässrige Stammlö- } \\
\text { sung }\left(4^{\circ} \mathrm{C}\right) \text {. }\end{array}$ & $\begin{array}{l}\text { 1. Erstellen einer einmolaren } \\
\text { Stammlösung: } \\
886 \mu \mathrm{H}_{2} \mathrm{O}_{2} \text {-Lösung und } 114 \\
\mu 1 \text { dest. } \mathrm{H}_{2} \mathrm{O} \text {. } \\
\mathbf{1 . 1} \mathbf{5 0 0} \boldsymbol{\mu M} \text { Lösung: } \\
50 \mu 1 \text { der Stammlösung mit } \\
100 \mathrm{ml} \text { ACSF (artifizielle } \\
\text { Cerebrospinalflüssigkeit) } \\
\text { mischen. } \\
\mathbf{1 . 2} \mathbf{5} \mathbf{~ m M ~ L o ̈ s u n g : ~} \\
0,5 \mathrm{ml} \text { der Stammlösung mit } \\
100 \mathrm{ml} \text { ACSF mischen. }\end{array}$ \\
\hline $\begin{array}{c}\text { DTT } \\
\text { DL-Dithiothreitol }\end{array}$ & SIGMA & Reduktionsmittel & $\begin{array}{l}\text { Pulver; bei } 4{ }^{\circ} \mathrm{C} \\
\text { gekühlt. }\end{array}$ & $\begin{array}{l}\text { 1. } 2 \text { mM Lösung: } \\
0,0617 \text { g DTT in } 200 \mathrm{ml} \\
\text { ACSF lösen. } \\
\text { 2. } 10 \text { mM Lösung: } \\
0,3085 \text { g DTT in } 200 \mathrm{ml} \\
\text { ACSF lösen. }\end{array}$ \\
\hline
\end{tabular}




\begin{tabular}{|c|c|c|c|c|}
\hline Substanz & Lieferant & Wirkung & Lösungsart & Einsatz des Stoffes \\
\hline \multicolumn{5}{|c|}{ Hanks - Balanced Salt Solution } \\
\hline Hanks & SIGMA & $\begin{array}{l}\text { Puffersubstanz; Kon- } \\
\text { trolle des pH-Wertes }\end{array}$ & Pulver & $\begin{array}{l}\text { Notwendig für Lösungen } \\
\text { bezüglich der Zellkultur- } \\
\text { Präparation. }\end{array}$ \\
\hline $\begin{array}{c}\mathrm{NaHCO}_{3} \\
\begin{array}{c}\text { Natriumhydrogen- } \\
\text { carbonat }\end{array}\end{array}$ & Roth & $\begin{array}{l}\text { Regulation des Säure- } \\
\text { Basen-Haushalts. }\end{array}$ & Pulver & $\begin{array}{l}\text { Notwendig zur Herstellung } \\
\text { der Hanks Salz Lsg. (HBSS). }\end{array}$ \\
\hline $\begin{array}{c}\text { HEPES } \\
\text { 4-(2-hydroxyethyl)- } \\
1- \\
\text { piperazineethanesul- } \\
\text { fonic acid }\end{array}$ & SIGMA & $\begin{array}{l}\text { pH-Puffersubstanz; } \\
\text { Kontrolle des pH- } \\
\text { Wertes }\end{array}$ & Pulver & $\begin{array}{l}\text { Notwendig zur Herstellung } \\
\text { der Hanks Salz Lsg. (HBSS). }\end{array}$ \\
\hline $\begin{array}{c}\text { FCS } \\
\text { Fötales } \\
\text { Kälberserum }\end{array}$ & Biochrom & $\begin{array}{l}\text { Mischung aus } \\
\text { Wachstumsfaktoren, } \\
\text { Spurenelementen, } \\
\text { Proteinen }\end{array}$ & $\begin{array}{l}\text { Braun-rötliche } \\
\text { Flüssigkeit; } \\
\text { Lagerung bei }-18^{\circ} \mathrm{C}\end{array}$ & $\begin{array}{l}\text { Notwendig zur Herstellung } \\
\text { bestimmter Lösungen bezüg- } \\
\text { lich der Präparation. }\end{array}$ \\
\hline $\begin{array}{c}\mathrm{MgSO}_{4} \\
\text { Magnesiumsulfat }\end{array}$ & Merck & $\begin{array}{l}\text { Stabilisiert die Zell- } \\
\text { membran bei mecha- } \\
\text { nischer Belastung. }\end{array}$ & Pulver & $\begin{array}{l}\text { Notwendig zur Herstellung } \\
\text { der Hanks Salz Lsg. (HBSS) }\end{array}$ \\
\hline \multicolumn{5}{|c|}{ Digestions-Lösung zur Zellvereinzelung } \\
\hline $\begin{array}{c}\mathrm{NaCl} \\
\text { Natriumchlorid }\end{array}$ & Roth & Kochsalz & Salzkristalle & $\begin{array}{l}\text { Bestandteil der Digestionslö- } \\
\text { sung }\end{array}$ \\
\hline $\mathrm{KCl}$ & Roth & Salz; Kaliumchlorid & Salzkristalle & $\begin{array}{l}\text { Bestandteil der Digestionslö- } \\
\text { sung }\end{array}$ \\
\hline $\mathrm{NaOH}$ & Roth & $\begin{array}{l}\text { Natriumhydroxid, } \\
\text { beeinflusst pH-Wert } \\
\text { (Lauge). }\end{array}$ & $\begin{array}{l}1 \text { molar } \\
\text { in wässriger Lösung }\end{array}$ & $\begin{array}{l}\text { Bestandteil der Digestionslö- } \\
\text { sung }\end{array}$ \\
\hline $\begin{array}{c}\mathrm{Na}_{2} \mathrm{HPO}_{4} \\
\text { Dinatriumhydro- } \\
\text { genphosphat }\end{array}$ & Roth & $\begin{array}{l}\text { Geeignet zur Her- } \\
\text { Stellung von pH- } \\
\text { Pufferlösungen. }\end{array}$ & Salzkristalle & $\begin{array}{l}\text { Bestandteil der Digestionslö- } \\
\text { sung }\end{array}$ \\
\hline Trypsin & SIGMA & $\begin{array}{l}\text { Verdauungsenzym; } \\
\text { Endopeptidase }\end{array}$ & $\begin{array}{l}\text { Klare Flüssigkeit; } \\
\text { Gekühlt bei }-18^{\circ} \mathrm{C}\end{array}$ & $\begin{array}{l}\text { Bestandteil der Digestionslö- } \\
\text { sung; Ermöglicht das Andauen } \\
\text { des Gewebes. }\end{array}$ \\
\hline
\end{tabular}




\begin{tabular}{|c|c|c|c|c|}
\hline Substanz & Lieferant & Wirkung & Lösungsart & Einsatz des Stoffes \\
\hline $\begin{array}{c}\text { DNase } \\
\text { Desoxyribonuklease }\end{array}$ & SIGMA & $\begin{array}{l}\text { Hydrolyse von DNA- } \\
\text { Molekülketten zu } \\
\text { kürzeren Molekülket- } \\
\text { ten oder Einzelbau- } \\
\text { steinen. }\end{array}$ & $\begin{array}{l}\text { Wässrige, klare } \\
\text { Flüssigkeit; Gefro- } \\
\text { ren bei }-18{ }^{\circ} \mathrm{C}\end{array}$ & $\begin{array}{l}\text { Bestandteil der Digestionslö- } \\
\text { sung; Ermöglicht das Andauen } \\
\text { des Gewebes. }\end{array}$ \\
\hline \multicolumn{5}{|c|}{ Zellkultur - Medium } \\
\hline $\begin{array}{l}\text { MEM } \\
\text { Minimal essential } \\
\text { medium }\end{array}$ & Invitrogen & $\begin{array}{l}\text { Nährstoffgrundlage. } \\
\text { Beinhaltet z.B. Ami- } \\
\text { nosäuren, Salze, } \\
\text { Vitamine. }\end{array}$ & $\begin{array}{l}\text { Wässrige, klare } \\
\text { Flüssigkeit; Bei } \\
4{ }^{\circ} \mathrm{C} \text { gekühlt. }\end{array}$ & $\begin{array}{l}\text { Ausgangssubstanz zur Herstel- } \\
\text { lung von Medium, Plating- } \\
\text { Medium und Growth- } \\
\text { Medium. }\end{array}$ \\
\hline Glucose & SIGMA & Nährstoff für Zellen. & $\begin{array}{l}\text { Weißliches Pulver; } \\
\text { bei Zimmertempe- } \\
\text { ratur gelagert. }\end{array}$ & $\begin{array}{l}\text { Wichtiger Inhaltsstoff für das } \\
\text { Medium, Plating-Medium und } \\
\text { Growth-Medium. }\end{array}$ \\
\hline Transferrin & Calbiochem & $\begin{array}{l}\text { Glykoprotein, das } \\
\text { Eisen binden und } \\
\text { transportieren kann. }\end{array}$ & $\begin{array}{l}\text { Bräunliches Pulver; } \\
\text { Lagerung in getön- } \\
\text { tem Glasgefäß bei } \\
-18^{\circ} \mathrm{C} \text {. }\end{array}$ & $\begin{array}{l}\text { Wichtiger Inhaltsstoff für das } \\
\text { Medium, Plating-Medium und } \\
\text { Growth-Medium. Ermöglicht } \\
\text { Eisenaufnahme in die Zellen. }\end{array}$ \\
\hline L-Glutamin & Invitrogen & $\begin{array}{l}\text { Proteinogene, nicht } \\
\text { essentielle Amino- } \\
\text { säure. } \\
\text { Für Wassereinlage- } \\
\text { rungen in die Zellen } \\
\text { verantwortlich. } \\
\text { Proteinbildung wird } \\
\text { gefördert. }\end{array}$ & $\begin{array}{l}\text { Klare Flüssigkeit; } \\
\text { bei }-18{ }^{\circ} \mathrm{C} \text { gelagert. }\end{array}$ & $\begin{array}{l}\text { Wichtiger Inhaltsstoff für das } \\
\text { Plating-Medium und das } \\
\text { Growth-Medium. }\end{array}$ \\
\hline Insulin & SIGMA & $\begin{array}{l}\text { Fördert die } \mathrm{Zu}- \\
\text { ckeraufnahme in die } \\
\text { Zellen. }\end{array}$ & $\begin{array}{l}\text { Klare Flüssigkeit; } \\
\text { Bei }-18^{\circ} \mathrm{C} \text { gelagert. }\end{array}$ & $\begin{array}{l}\text { Im Plating-Medium vorhande- } \\
\text { ner Wirkstoff. }\end{array}$ \\
\hline B-27 Supplement & Invitrogen & $\begin{array}{l}\text { Fördert das langsa- } \\
\text { me/schnelle Dichte- } \\
\text { wachstum der Zellen } \\
\text { in Kulturen und ver- } \\
\text { kürzt/verlängert Le- } \\
\text { benszeiten von hip- } \\
\text { pocampalen oder } \\
\text { anderen Neuronen } \\
\text { aus dem ZNS. }\end{array}$ & $\begin{array}{l}\text { Klare Flüssigkeit; } \\
\text { Lagerung bei } \\
-18^{\circ} \mathrm{C} \text {. }\end{array}$ & $\begin{array}{l}\text { Wichtiger Inhaltsstoff für das } \\
\text { Growth-Medium. }\end{array}$ \\
\hline
\end{tabular}




\begin{tabular}{|c|c|c|c|c|}
\hline $\begin{array}{l}\text { Cytosin- } \\
\text { arabinosid } \\
\text { Ara-C }\end{array}$ & SIGMA & $\begin{array}{l}\text { Isomer des Nukleo- } \\
\text { sids Cytidin } \\
\text { Verhindert Verdrän- } \\
\text { gung der Neuronen } \\
\text { durch andere (Glia-) } \\
\text { Zellen. }\end{array}$ & $\begin{array}{l}\text { Klare Flüssigkeit; } \\
\text { Bei }-18^{\circ} \mathrm{C} \text { gelagert. }\end{array}$ & $\begin{array}{l}\text { Wichtiger Inhaltsstoff für das } \\
\text { Growth-Medium. } \\
\text { Zyto- und Virostatikum }\end{array}$ \\
\hline $\begin{array}{c}\text { Penicillin/ } \\
\text { Streptomycin }\end{array}$ & Biochrom & $\begin{array}{l}\text { Antibiotische Wir- } \\
\text { kung. }\end{array}$ & $\begin{array}{l}\text { Klare Flüssigkeit; } \\
\text { Bei }-18^{\circ} \mathrm{C} \text { gelagert. }\end{array}$ & $\begin{array}{l}\text { Verhindert das Wachstum und } \\
\text { die Ansiedlung von Bakterien } \\
\text { in der Zellkultur. }\end{array}$ \\
\hline Opti-MEM & Invitrogen & $\begin{array}{l}\text { Eine Modifikation } \\
\text { von MEM, gepuffert } \\
\text { u.a. mit HEPES, } \\
\text { Natriumbikarbonat, } \\
\text { Wachstumsfaktoren. }\end{array}$ & $\begin{array}{l}\text { Klare Flüssigkeit; } \\
\text { Lagerung bei } 4^{\circ} \mathrm{C} \text {. }\end{array}$ & $\begin{array}{l}\text { Besonders geeignet für Zell- } \\
\text { kulturen, mit denen eine Lip- } \\
\text { id-Transfektion durchführt } \\
\text { wird. }\end{array}$ \\
\hline \multicolumn{5}{|c|}{ Sonstiges } \\
\hline Matrigel & $\begin{array}{c}\mathrm{BD} \\
\text { Bioscience }\end{array}$ & $\begin{array}{l}\text { Gelantineartiger } \\
\text { Proteinmix. } \\
\text { Fördert das Anhaften } \\
\text { der Zellen. } \\
\text { Bietet ähnliche natür- } \\
\text { liche Bedingungen, } \\
\text { wie im ursprüngli- } \\
\text { chen Gewebe. }\end{array}$ & $\begin{array}{l}\text { Klare Flüssigkeit; } \\
\text { Bei }-18^{\circ} \mathrm{C} \text { gelagert. }\end{array}$ & $\begin{array}{l}\text { Matrigel wird vor der Präpara- } \\
\text { tion auf die Deckgläser aufge- } \\
\text { tragen und fördert das Anhaf- } \\
\text { ten der Zellen. }\end{array}$ \\
\hline $\begin{array}{l}\text { Lipofectamin } \\
\text { (Lipofectamine } \\
\text { 2000 Reagent) }\end{array}$ & Invitrogen & $\begin{array}{l}\text { Kann durch Mizellen- } \\
\text { Bildung Substanzen } \\
\text { durch Zellmembran } \\
\text { befördern. }\end{array}$ & $\begin{array}{l}\text { Klare Flüssigkeit; } \\
\text { bei } 4{ }^{\circ} \mathrm{C} \text { gelagert. }\end{array}$ & $\begin{array}{l}\text { Ermöglicht die Transfektion } \\
\text { der Zellen mit der Redoxindi- } \\
\text { kator-kodierenden DNA. }\end{array}$ \\
\hline
\end{tabular}

\subsection{Lösungen}

\subsubsection{Artifizielle zerebrospinale Flüssigkeit (ACSF)}

Diese künstlich hergestellte liquorähnliche Salzlösung wird jeden Tag in einem Volumen von einem Liter frisch zubereitet und stellt die Grundlage meiner Versuche mit dem TPLSM dar.

Die Bestandteile der ACSF-Lösung sind wie folgt (in mM): $130 \mathrm{NaCl}, 24 \mathrm{NaHCO}_{3}, 10$ Dextrose, 3,5 KCl, 1,25 $\mathrm{NaH}_{2} \mathrm{PO}_{4}, 1,2 \mathrm{MgSO}_{4}$ und 1,2 $\mathrm{CaCl}_{2}$. 
Während der Mikroskopie und der Durchführung der gesamten Messungen befinden sich die Zellen in einer Submersions-Messkammer, vorsichtig umspült von der ca. $32{ }^{\circ} \mathrm{C}$ warmen, kontinuierlich zu- und abfließenden ACSF-Lösung. Die ACSF-Lösung befindet sich in einer Glasflasche in einem wärmenden Wasserbad mit einem gummierten Schlauch darin, der die Flüssigkeit ansaugt und zur Zellprobe bringt, sowie einem weiteren, der die „gebrauchte“ Flüssigkeit von der Messkammer abtransportiert und zurück in die Glasflasche befördert. Zusätzlich befindet sich neben den beiden Schläuchen ein weiterer mit einem perforierten Stein an seinem Ende, durch welchen er die Lösung kontinuierlich während der gesamten Messung mit Carbogen $\left(95 \% \mathrm{O}_{2}, 5 \% \mathrm{CO}_{2}\right)$ begast und damit einen konstanten pH-Wert von 7.4 gewährleistet. Unter diesen Umständen wird versucht, ähnliche Bedingungen, wie sie physiologisch im Gehirn vorliegen, für die zu untersuchenden Zellen zu schaffen.

\subsubsection{Zellkultur-Medien}

Während der Präparation und auch danach sind für die weitere Versorgung der Zellen zahlreiche Lösungen notwendig, welche beispielsweise ein optimales Anhaften an die Deckgläser oder ein schnelles und gesundes Wachstum der Zellen bedingen und fördern sollen.

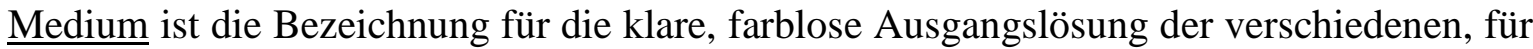
die Präparation notwendigen Substanzen. $110 \mathrm{ml}$ des Mediums bestehen aus $110 \mathrm{ml}$ MEM, 0,55 g Glucose, 0,022 $\mathrm{g} \mathrm{NaHCO}_{3}$ und 0,011 g Transferrin. Es wird regelmäßig, meist im Abstand von zwei Wochen steril neu zubereitet.

Plating-Medium wird ausschließlich während der Präparation gebraucht und beinhaltet wichtige Nährstoffe, welche die Zellen bedingungslos zum Überleben benötigen. Ca. $50 \mathrm{ml}$ der rötlich klaren Flüssigkeit beinhalten $45 \mathrm{ml}$ des zuvor hergestellten Mediums, $5 \mathrm{ml}$ FCS $10 \%$ (fötales Kälberserum), 0,5 ml L-Glutamin (0,2 M) und 0,1 ml Insulin. Es wird nach seiner Herstellung steril filtriert und bei $4{ }^{\circ} \mathrm{C}$ gelagert.

Growth-Medium fördert das Wachstum der präparierten Zellen auf den Deckgläsern und bietet ihnen die wichtigsten Nährstoffe, die sie für ein optimales Heranwachsen in der Zellkultur benötigen. $50 \mathrm{ml}$ des ebenfalls rötlich gefärbten, klaren Growth-Mediums sind zusammengesetzt aus 47,5 $\mathrm{ml}$ des zuvor zubereiteten Mediums, 2,5 $\mathrm{ml}$ FCS (5 \%), 0,125 ml L-Glutamine (0,2 M), $1 \mathrm{ml} \mathrm{B-27} \mathrm{Supplement,} 25 \mu 1$ Cytosin-Arabinosid (Ara-C) (4 $\mathrm{mM}$ ) und 0,5 $\mathrm{ml}$ des für das Growth-Medium charakteristischen Antibiotikums Penicil- 
lin/Streptomycin. Das Growth-Medium wird ebenfalls nach seiner Herstellung steril filtriert und bei $4{ }^{\circ} \mathrm{C}$ gelagert.

Hanks Balanced Salt Solution (HBSS) wird ausschließlich für die Präparation benötigt. Für die Herstellung wird eine 1 Liter Glasflasche mit $350 \mathrm{ml} \mathrm{NaHCO} 3$ (4 mM), 238 mg HEPES (4-(2-hydroxyethyl)-1-piperazineethanesulfonic acid) (1mM) und Hanks Pulver gefüllt. Diese Lösung wird mit destilliertem Wasser bis auf ein Volumen von einem Liter aufgefüllt, ist charakterisiert durch seine klare, rötliche Farbe und wird bei $4{ }^{\circ} \mathrm{C}$ aufbewahrt.

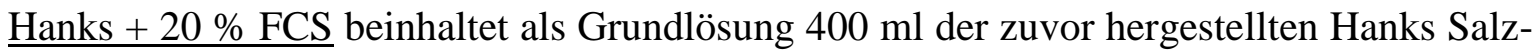
lösung. Hinzugefügt werden $100 \mathrm{ml}$ von 20-prozentigem FCS. Diese ebenfalls rötlich, klare Flüssigkeit wird nur für die Zellpräparation benötigt und bei $4{ }^{\circ} \mathrm{C}$ gelagert.

Die Dissoziationslösung besteht aus $100 \mathrm{ml}$ der bereits hergestellten Hanks Salzlösung und 0,166 g Magnesiumsulfat $\left(\mathrm{MgSO}_{4} ; 12 \mathrm{mM}\right)$ und ist entscheidend für die Herstellung einer Zellkultur, da sie die Zellen weitestgehend vereinzelt. Das Magnesiumsulfat schützt die Zellmembranen vor den schädigenden mechanischen und chemischen Einflüssen während der Präparation. Die klare, farblose Flüssigkeit wird bei $4{ }^{\circ} \mathrm{C}$ gelagert.

Die Digestionslösung ist ebenfalls unerlässlich für die Herstellung einer Zellkultur. Sie ist für das Anverdauen des Zellverbands notwendig und $100 \mathrm{ml}$ bestehen aus 0,8 g Kochsalz $(\mathrm{NaCl} ; 137 \mathrm{mM}), 0,037 \mathrm{~g}$ Kaliumchlorid $(\mathrm{KCl} ; 5 \mathrm{mM}), 0,009$ g Dinatriumhydrogenphosphat $\left(\mathrm{Na}_{2} \mathrm{HPO}_{4} ; 7 \mathrm{mM}\right)$ und 0,6 g HEPES $(25 \mathrm{mM})$. Die klare Flüssigkeit wird ebenfalls bei $4{ }^{\circ} \mathrm{C}$ aufbewahrt.

\subsection{Präparation}

\subsubsection{Mausmodell}

Für die Herstellung der Zellkulturen habe ich NMRI-Mäuse (Naval Medical Research Institute) verwendet. Diese Mäuse werden in Inzuchtstämme hineingeboren, welche besonders für verhaltensbiologische Tests eingesetzt werden. Sie sind frei von Krankheiten und genetischen Fehlern und werden unter nahezu sterilen Umständen gehalten. Während meiner Messreihen habe ich ausschließlich mit weiblichen oder männlichen Tieren im Alter vom zweiten bis zum fünften postnatalen Tag gearbeitet (P2 - P5). Sie befanden sich bis zu 
diesem Zeitpunkt zusammen mit dem Muttertier und gegebenenfalls Geschwistertieren in einem Käfig.

\subsubsection{Herstellung der hippokampalen Zellkulturen}

Um der Zellkultur einen passenden Untergrund zu bieten, werden vorbereitend mindestens eine Stunde vor Präparationsbeginn einzelne bereits autoklavierte und damit von jeglichen Bakterien und Viren befreite runde Deckgläser in vier Zellkulturplatten mit je vier Vertiefungen verteilt. $20 \mu \mathrm{l}$ Matrigel wird mit $980 \mu \mathrm{l}$ Plating-Medium gemischt und davon werden jeweils $50 \mu \mathrm{l}$ tropfenförmig jeweils in die Mitte eines jeden der 16 Deckgläser pipettiert. Diese Stelle lokalisiert die spätere Region, in der die Zellen anwachsen sollen, da das Matrigel trotz des späteren Absaugens einen dünnen Film auf den Deckgläsern hinterlässt. Die vier Platten werden nun für eine Stunde bei $37{ }^{\circ} \mathrm{C}$ im Wärmeschrank inkubiert. Währenddessen beginnt die eigentliche Präparation, welche stets unter Kühlung durch Eis stattfindet.

Nach der zügig durchgeführten Dekapitation der ein bis fünf Tage alten Maus (P2-P5), werden dem Tier sowohl die Kopfhaut als auch die Schädeldecke mit Skalpell, Schere und Pinzette entfernt, um das Gehirn freizulegen. Dieses wird schnellstmöglich isoliert, um einen Ischämiezustand durch eine Sauerstoffunterversorgung zu vermeiden. Es wird aus diesem Grund umgehend in die auf Eis gekühlte Hanks Salzlösung (HBBS) mit Zugabe von 20-prozentigem FCS befördert. Das Präparationsobjekt befindet sich auch während der Bearbeitung ständig in jener eisgekühlten Lösung. Der Hirnstamm wird mit Zuhilfenahme eines Lichtmikroskops entfernt, die beiden Hemisphären getrennt und jeweils der Hippocampus extrahiert. Die beiden sichelförmigen Hippocampi werden anschließend mithilfe eines Skalpells in kleinere Gewebsteile, möglichst acht pro Hippocampus, zerteilt. 

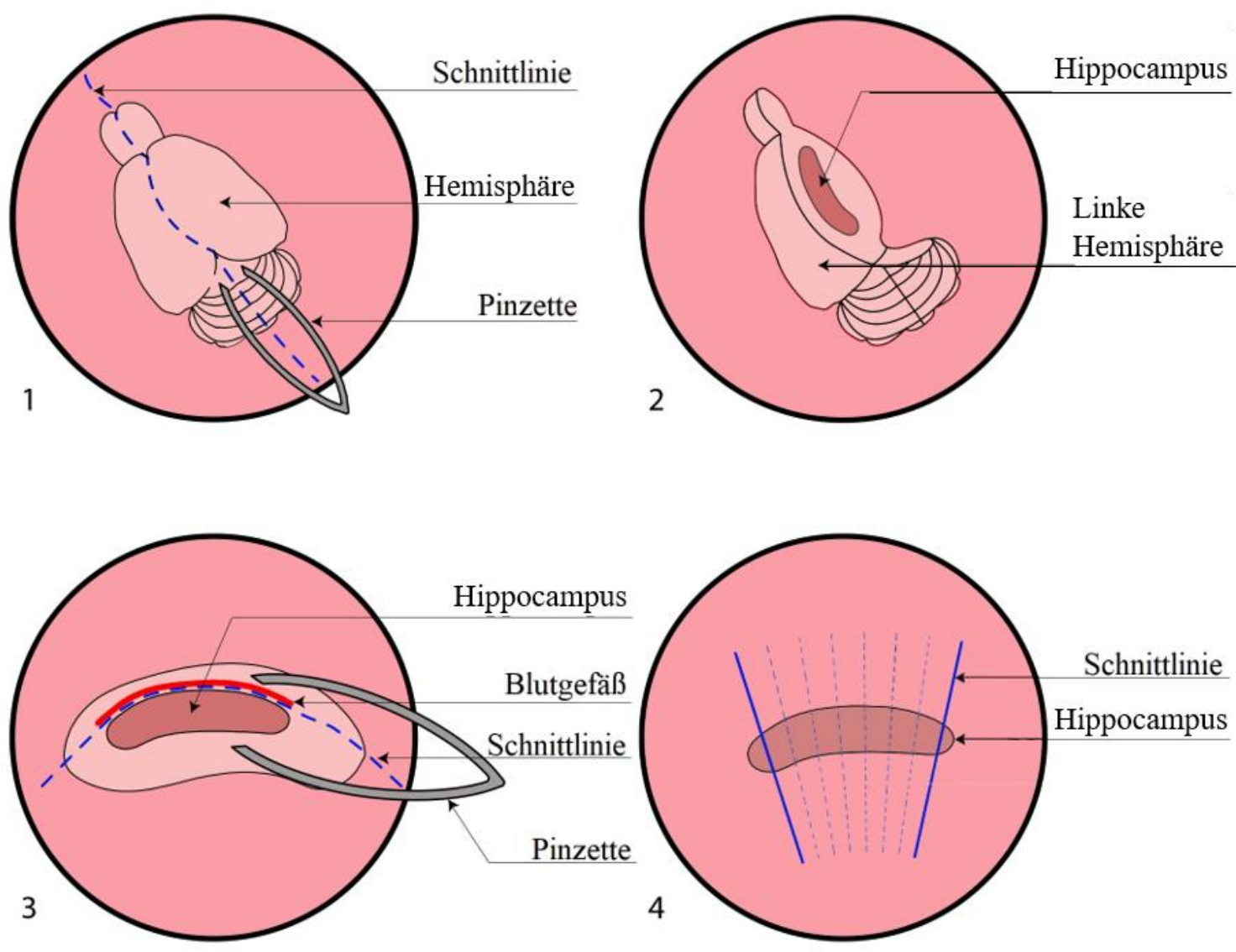

Abbildung 9: Schematische Darstellung der Hippocampus-Präparation. Das Gehirn befindet sich zu jeder Zeit in einer Petrischale mit Flüssigkeit (siehe 2.3.2 Herstellung der hippokampalen Zellkulturen). (1): Extrahiertes Mausgehirn mit imaginärer, hier blau eingezeichneter Schnittlinie. (2): Bereits durchgeführte Entfernung einer Hemisphäre. (3): Seitlicher Blick auf den Hippocampus mit imaginärer, hier eingezeichneter blauer Schnittlinie. (4): Teilung des extrahierten Hippocampus in ca. 8 Teile. Die Schnittführung ist hier in blau dargestellt.

Während des ersten Waschvorgangs werden die Gewebsteile mit der umgebenden Flüssigkeit mithilfe einer Pipette in ein Reaktionsgefäß überführt, welches sich in einem Becherglas gefüllt mit Eis befindet. Zuerst wird zweimal mit $10 \mathrm{ml}$ HBSS + 20 prozentigem FCS, danach dreimal mit $10 \mathrm{ml}$ reinem HBSS gewaschen. Die Definition des Wortes „Waschen“ wird hier als ein Prozess beschrieben, in dem die Zellen von möglichen Verunreinigungen durch Umspülen befreit werden. Die Hanks Salzlösung, beziehungsweise die Hanks Salzlösung plus FCS wird in das Reaktionsgefäß auf die Zellen pipettiert. Es wird kurz abgewartet, bis alle Gewebsteile zu Boden des Reaktionsgefäßes gesunken sind, bevor die Flüssigkeit, mit Aussparung der Gewebsteilchen, abgesaugt und erneut Flüssigkeit hinzu pipettiert wird. Nach diesem ersten Waschvorgang werden die Gewebsteile der Hippocampi anschließend mit einer Trypsinlösung (10 mg Trypsin, $2 \mathrm{ml}$ Digestionslösung, $40 \mu \mathrm{l}$ Desoxyribonuklease (DNase)) versetzt. Während einer darauffolgenden zehnminütigen Inku- 
bation bei $37^{\circ} \mathrm{C}$ in einer kleinen Petrischale wird die Gewebsoberfläche durch die Trypsinlösung angedaut und die spätere Zellvereinzelung somit vereinfacht.

Wie beim ersten Waschvorgang, werden auch beim zweiten die Gewebsteile, die sich in einem neuen Reaktionsgefäß auf Eis befinden, zuerst dreimal mit HBBS + 20-prozentigem FCS und schließlich wiederum dreimal mit reinem HBBS gewaschen, damit so das Trypsin wieder aus dem Gewebe entfernt wird.

Als letzter Schritt folgt das Dissoziieren, also das Vereinzeln und Herauslösen der Zellen aus seinem Gewebe, damit die Zellen sich am Deckglas anheften können und jeder einzelnen Zelle für den weiteren Wachstumsverlauf genügen Platz geboten werden kann.

Die Dissoziationslösung, welche zu den Zellen pipettiert wird, beinhaltet $\mathrm{MgSO}_{4}$. Dieses stabilisiert die Zellmembranen zusätzlich, da es durch das wiederholte Auf- und Abpipettieren zur gewünschten Zerkleinerung der Gewebsfragmente kommt, jedoch eine mechanische Beanspruchung oder sogar eine Schädigung der Zellen dabei nicht ausbleibt. Ebenfalls werden neben der Dissoziationslösung auch $40 \mu \mathrm{l}$ DNase zu den Zellen pipettiert. Diese zerstört freie DNA und verhindert ein gegenseitiges Anhaften der Neurone. Der Inhalt des Reaktionsgefäßes wird also auf- und abpipettiert, damit die immer kleiner werdenden Zellfragmente, DNase und Dissoziationslösung, gut durchmischt sind. Nachdem sich anschließend durch eine zehnminütige Zentrifugation alle größeren Gewebsbestandteile am Boden abgesetzt haben, wird die überstehende Flüssigkeit abgesaugt und mit $800 \mu$ l Plating-Medium ausreichend versetzt.

Nun werden die zu Beginn für mindestens eine Stunde inkubierten 4-Well Zellkulturplatten mit den mit Matrigel versehenen Deckgläsern herangezogen. Das Matrigel wird vorsichtig abgesaugt und durch einen $50 \mu 1$ Tropfen des Gemisches aus Plating-Medium und Zellen jeweils ersetzt. Damit die Zellen genügend Zeit haben auf dem Deckglas anzuwachsen, werden die Zellkulturplatten wiederum eine Stunde lang inkubiert, um danach die einzelnen 16 Vertiefungen der vier Zellkulturplatten, in denen sich die Deckgläser befinden, jeweils mit vorgewärmtem Plating-Medium (600 $\mu \mathrm{l})$ aufzufüllen. Nach diesem letzten Schritt werden die Zellkulturen bis zum nächsten Tag inkubiert.

Die Zellen befinden sich von nun an stets im Inkubator bei $37{ }^{\circ} \mathrm{C}$ in einer angefeuchteten Atmosphäre mit $5 \% \mathrm{CO}_{2}$, bis sie transfiziert, beziehungsweise für Messungen benötigt werden. Nach ca. 24 Stunden wird die gesamte Flüssigkeit aus jeder Vertiefung vorsichtig abgesaugt und durch vorgewärmtes Growth-Medium (800 $\mu 1)$, das zusätzlich Antibiotikum 
enthält, ersetzt. Danach wird in einem Rhythmus von 2 Tagen das Growth-Medium jeweils zur Hälfte abgesaugt und durch frisches $(400 \mu \mathrm{l})$ erneuert, damit den Zellen stets genügend Nährstoffe zum Wachstum zur Verfügung stehen. Bereits einen Tag nach der Präparation kann das Anhaften der Zellen und ihr beginnendes Wachstum mithilfe eines Lichtmikroskops überprüft werden. Sind hier bereits einige Pathologien der Zellen oder sogar ein allgemeines Zellsterben erkennbar, kann schnell gehandelt und bei Bedarf eine erneute Präparation durchgeführt werden.

\subsection{Transfektion}

Unter dem Begriff Transfektion wird das Einbringen einer Fremd-DNA oder -RNA in eine eukaryotische Zelle beschrieben. Sie führt in der Wirtszelle zur Stimulation der Proteinsynthese, wodurch das gewünschte Genprodukt der eingebrachten DNA gebildet wird. Während meiner Versuche stützte ich mich auf die Methode der Lipofektion mithilfe von Lipofectamin. Diese Substanz ist notwendig, damit die negativ geladene Redoxindikatorkodierende DNA, die ebenfalls negative und somit ohne Hilfsmittel nicht überwindbare lipophile Zellmembran durchdringen kann. Hierbei wird das in die Zelle einzuschleusende Genmaterial in lipophile Vesikel verpackt, wobei diese in der Lage sind, mit der Zellmembran zu fusionieren und somit seinen Inhalt in das Cytoplasma der Zelle abzugeben. Das Einbringen einer Fremd-DNA in eine Wirtszelle bringt einen sehr hohen mechanischen Stressfaktor für die betroffenen Zellen mit sich. Viele Zellen gehen bei diesem Vorgang zugrunde, einige verbleiben nicht transfiziert und wiederum andere sterben im weiteren Verlauf aufgrund einer Überproduktion des gewünschten Genprodukts innerhalb weniger Tage.

Die Transfektionseffizienz ist hierbei also besonders sensibel in Bezug auf die Menge des genetischen Materials, welches auf die Zellen einwirkt und auch bezüglich des Zeitraums, in dem den Zellen dieses genetische Material in deren Umgebung zur Verfügung steht. Ziel ist es also, dass so viele Zellen wie möglich transfiziert werden und gleichzeitig so viel DNA wie nötig aufgenommen wird, ohne Schäden zu verursachen.

Die zur Transfektion benötigten Materialien sind OPTI-MEM, Lipofectamin und die beiden DNAs in Form von Plasmidvektoren, die für die Proteine HyPer und roGFP1 kodieren. Die Plasmidvektoren, die die Expression von HyPer unter der Kontrolle des Promotors des Cytomegalievirus bedingen, wurden von der Firma Evrogen bezogen. Das Protein roGFP1 
wird durch den Plasmidvektor pEGFP-N1/roGFP1 exprimiert, den Prof. S.J. Remington, University of Oregon, freundlicherweise zur Verfügung stellte.

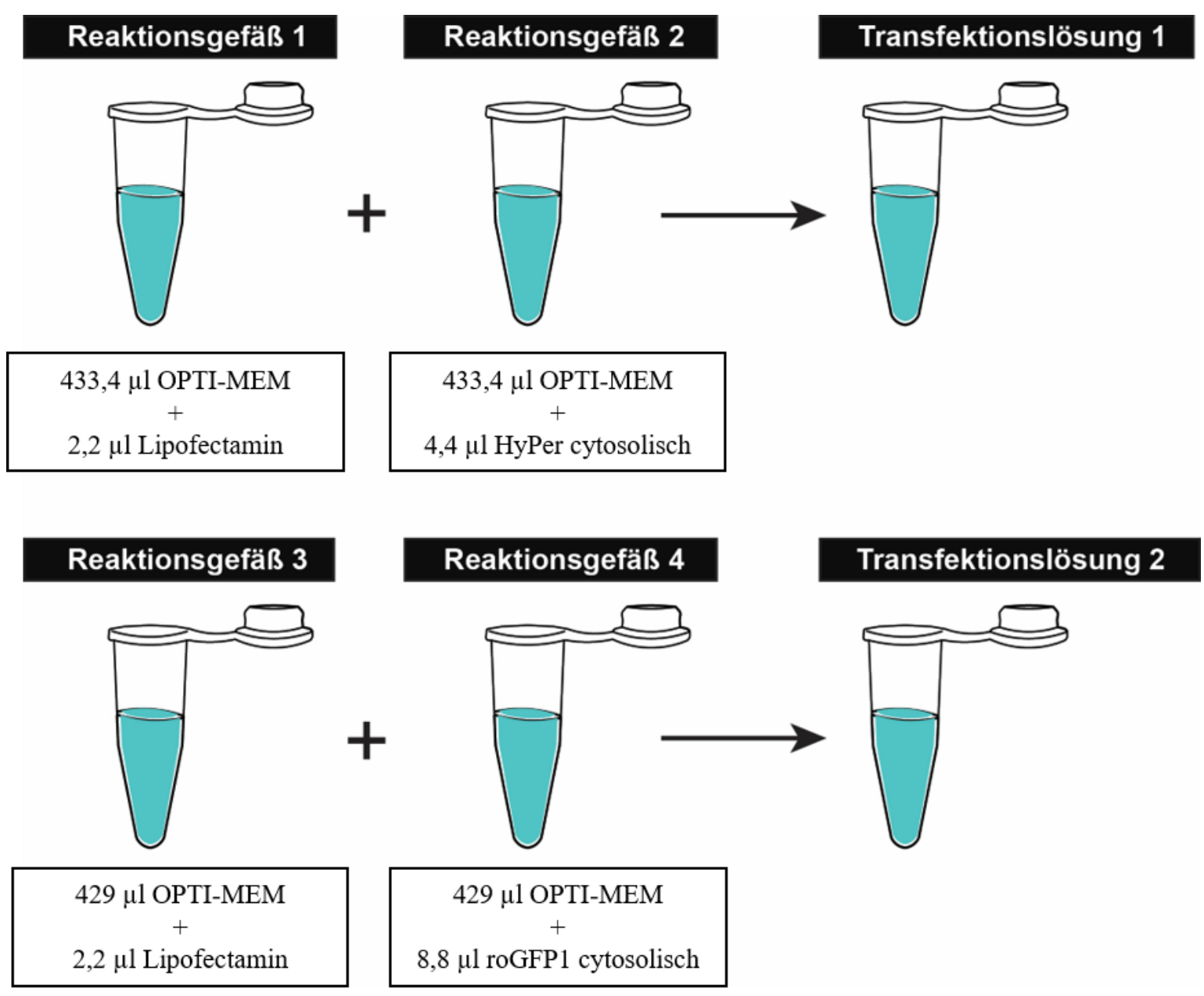

Abbildung 10: Herstellung der beiden Transfektionslösungen. Es werden insgesamt vier Reaktionsgefäße benötigt: Die Inhalte aus Reaktionsgefäß 1 und 2 werden zusammengeführt, es entsteht die Transfektionslösung 1. Gleichzeitig wird der Inhalt aus Reaktionsgefäß 3 in das Reaktionsgefäß 4 überführt. Es entsteht die Transfektionslösung 2.

Die Inhalte aller vier Reaktionsgefäße werden jeweils gut gemischt (Vortex-Mischer) und daraufhin zehn Minuten ruhen gelassen. Danach werden die Inhalte, wie in Abbildung 10 beschrieben, gemischt, danach 20 Minuten ruhen gelassen, um eine homogene Verteilung zu gewährleisten. Das Ergebnis sind zwei Transfektionslösungen, von denen beide sowohl OPTI-MEM als auch Lipofectamin enthalten, wobei eine Lösung zusätzlich HyPer, die andere roGFP1 beinhaltet.

Von den Zellkulturen der insgesamt vier Zellkulturplatten werden für meine Messungen wöchentlich zwei Zellkulturplatten mit jeweils vier Vertiefungen mit dem Redoxindikator HyPer und zwei mit roGFP1 transfiziert. Die Flüssigkeit wird aus den Vertiefungen, in 
denen sich die Deckgläser mit den dort angewachsenen Zellen befinden, komplett abgesaugt und $200 \mu \mathrm{l}$ einer der zuvor hergestellten Transfektionslösungen vorsichtig auf die Zellen pipettiert. Eine der vier Zellkulturplatten wird mit HyPer, die andere mit roGFP1 transfiziert. Da die Zellen nach der Transfektion mindestens 48 Stunden Zeit benötigen, um das gewünschte Genprodukt zu exprimieren, werden zuerst nur zwei der insgesamt vier Zellkulturplatten gleichzeitig transfiziert und nach drei Tagen die anderen beiden Platten, damit die ersten Zellen schon messbereit sind, während die anderen sich noch im Prozess der Transfektion befinden. So hatte ich für meine Messungen ausnahmslos Zellen zur Verfügung, die sich in einem Stadium nie älter als vier Tage nach der Transfektion befanden.

Nach einer bis eineinhalb Stunden Inkubation bei $37{ }^{\circ} \mathrm{C}$ wird die Transfektionslösung wieder abgesaugt und durch $800 \mu$ l vorgewärmtes Growth-Medium ersetzt, um keine Überproduktion des Genprodukts durch zu langes Einwirken der Transfektionslösung zu provozieren.

Wie nach der Präparation bereits durchgeführt, wird das die Zellen umgebende GrowthMedium jeweils nach zwei Tagen gewechselt, $400 \mu 1$ der bereits vorhandenen $800 \mu 1$ abgesaugt und mit neuem, frischem Growth-Medium (400 $\mu$ l) aufgefüllt, um eine optimale nährstoffreiche Versorgung der Zellen zu jedem Zeitpunkt zu gewährleisten.

\subsection{Allgemeiner Versuchsaufbau}

Um die Zellen während der Messung vital zu halten, befinden sich die Deckgläser, wie bereits beschrieben, mit der darauf anhaftenden Zellkultur stetig umspült von erwärmter, mit Carbogen $\left(95 \% \mathrm{O}_{2}, 5 \% \mathrm{CO}_{2}\right)$ begaster ACSF-Lösung in einer SubmersionsMesskammer unterhalb des Objektivs. Eine Pumpe, verbunden mit transparenten flexiblen Kunststoffschläuchen, treibt den Hin- und Rücktransport der ACSF-Lösung zur Messkammer mit einer Geschwindigkeit von ca. 1,6 m/min an. Unter Berücksichtigung dieser Tatsache benötigen Pharmaka oder andere Lösungen bis zum Erreichen der Messkammer eine bestimmte Zeit ( 1 min) und demnach liegt ein verzögerter Wirkungseintritt vor. Auf seinem Weg von dem $38{ }^{\circ} \mathrm{C}$ warmen Wasserbad über die Schläuche bis hin zur Messkammer, kühlt das ACSF auf eine Temperatur von $33{ }^{\circ} \mathrm{C}$ bis $34{ }^{\circ} \mathrm{C}$ herunter, welche jedoch adäquat für die Durchführung der Versuche ist.

Die optischen Messungen wurden mit einem Zwei-Photonen-Laser-Scanning-System (TPLSM) von LaVision BioTec durchgeführt. Dieses besteht aus einem aufrechten Mikro- 
skop (BX51 WI, Olympus), einem TriM Scope II Scankopf mit einer ImSpector Kontrollsoftware (LaVision BioTec) und einem einstellbaren Titan:Sapphir Laser (Mai Tai eHP DeepSee, Newport Spectra-Physics). Die Fluoreszenz-Emission wird detektiert von großflächigen, hochsensitiven Photomultiplier-Röhren (H7421/H7422 Serie, Hamamatsu). Um die Fluoreszenz-Zerfallsrate zu messen, wurde eine zeitkorrelierte Einzelphotonenzählung (TCSPC: time-correlated single photon counting) mithilfe des FLIM-Systems (fluorescence lifetime imaging microscopy) durchgeführt (FLIM X16; LaVisionBioTec). Als Objektiv kamen ein 63x, 1.0NA Objektiv (Zeiss Plan-Apochromat VIS-IR) sowie ein 40x, 0.8NA Objektiv (Zeiss IR Achroplan) zum Einsatz.

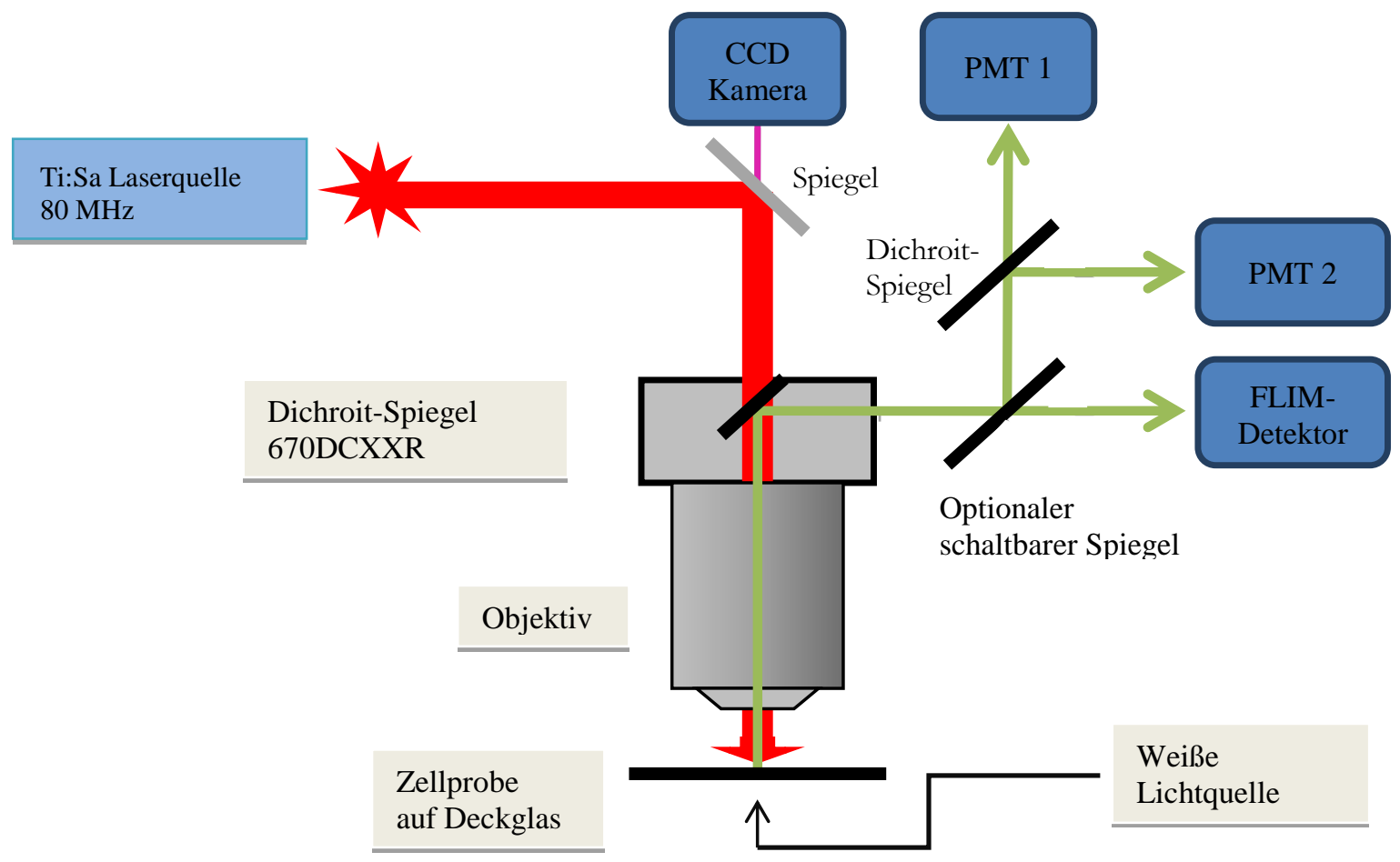

Abbildung 11: Das Zweiphotonen-Laser-Scanning-Mikroskop (TPLSM). Die Abbildung zeigt vereinfacht dargestellt den Aufbau des Mikroskops. Als Laserquelle dient der Ti:Sa Laser, über welchen die verschiedenen Wellenlängen eingestellt werden. Der NIR Laserstrahl gelangt durch das Objektiv auf die zu messende Probe. Die exprimierte Fluoreszenzemission wird von dem Dichroit-Spiegel 670DCXXR abgeleitet und durch einen optionalen Dichroit-Spiegel aufgeteilt. Das emittierte grüne Spektrum gelangt zu den Photomultipliern (PMT) 1 und 2. Alternativ wurde Licht zum FLIM-Detektor geleitet. Eine weiße Lichtquelle unter der Messkammer hilft bei der Lokalisierung der Zellen (modifiziert nach Müller et al. 2003 Abb. 3 und Keil et al. 2011, Abb. 2a+b, mit freundlicher Genehmigung von Springer und IOP Publishing).

Für eine einfache Aufnahme der Zellkulturen mit weißem Licht, befindet sich an dem Zweiphotonenmikroskop zusätzlich eine digitale CCD-Kamera (charge-coupled device) (Imago QE, PCO Imaging). Der Ti:Sa-Laser (Titan:Saphir) ermöglicht Impulse im Femto- 
sekunden-Bereich bei einer Frequenz von $80 \mathrm{MHz}$. Er weist eine große Bandbreite in Bezug auf die Wellenlängen im Bereich von ca. $670 \mathrm{~nm}$ bis $1070 \mathrm{~nm}$ auf (Moulton 1986). Der Photomultiplier (PMT) besteht aus einer Elektronenröhre, die zur Aufgabe hat, schwache Lichtsignale durch Erzeugung und Verstärkung eines elektrischen Signals zu detektieren (Hamamatsu Photonics 2006). Die in Abbildung 11 dargestellten dichroitischen Spiegel haben die Eigenschaft, Licht mit bestimmten Wellenlängen ungehindert durchzulassen und wiederum Licht mit anderen Wellenlängen zu spiegeln (Epstein 1981).

Um dreidimensionale Rekonstruktionen aus einem gemessenen Bildstapel zu erstellen, welche als Ansammlung von Schnitten waagerecht durch die Zelle definiert werden (zAchse), wurden Berechnungen mithilfe des Programms Metamorph Offline (Version 6.1/7.0; Molecular Devices) durchgeführt. Während des gesamten Messzeitraums war der Raum stets abgedunkelt, sodass so wenig Hintergrundlicht wie möglich von außen als Störquelle und somit als ergebnisverfälschende Komponente von den Detektoren registriert wird.

\subsection{Messtechniken}

\subsubsection{Kernfärbungen mit DAPI}

Die Nukleinsäurefarbstoff DAPI (4',6-Diamidin-2-phenylindol, dihydrochlorid; $14.3 \mathrm{mM}$ ) ist ein Fluoreszenzfarbstoff, der fast ausschließlich die DNA im Kern einer Zelle charakteristisch anfärbt (Kapuscinski 1995; Biancardi et al. 2013). Mit dieser blauen Fluoreszenz sticht DAPI gegenüber den grün/gelb fluoreszierenden Redox-Sensoren deutlich heraus. Bei einer DNA-Bindung liegt das Ein-Photonen-Exzitationsmaximum bei $358 \mathrm{~nm}$ und das Emissionsmaximum bei $461 \mathrm{~nm}$.

Auf die bereits transfizierten und messbereiten Zellen werden den $800 \mu 1$ Growth-Medium, das die Zellkultur umgibt, für ein Zeitintervall von 20 Minuten zusätzlich $0,5 \mu$ DAPI (14,3 mM) beigefügt. Danach befinden sich die Zellen in einem messbereiten Status. DAPI wurde internalisiert und es können Aufnahmen mit Kernfärbungen erstellt werden.

Mit dem Redoxindikator HyPer in Kombination mit DAPI wurden mehrere Bildstapel einer Zelle erstellt, welche anschließend zu einem dreidimensionalen Bild zusammengefügt werden konnten. Die Filterkombination aus dem Multiphoton-Emitter HC 680/SP, sowie dem DC 670 zeigte hierbei die besten Ergebnisse. Die erstellten Bildstapel beziehen sich 
auf die z-Achse eines Koordinatensystems: Der Laser scannt die Zelle in vordefinierten zAbständen und erstellt in axialer Richtung 2D-Abbildungen (Transversal/Horizontalschnitte). Diese können einzeln beurteilt oder zu einem 3D-Bild gestapelt werden.

\subsubsection{Zwei-Photonen-Anregungsspektrum der ROS-Indikatoren}

Ziel dieser Messreihe ist es, mit einer jeweiligen Durchschnittszellzahl von 18 bis 22 mit ACSF als neutral umgebende Flüssigkeit, ein Anregungsspektrum zu erstellen, aus dem Maxima und Minima entnommen und für weitere Messungen angewandt werden können.

Es werden zu Beginn im Wellenlängenbereich von 700 nm bis 1025 nm 14 Bilder erstellt. Die Zwischenschritte weisen als Abstand jeweils ein Inkrement von $25 \mathrm{~nm}$ auf. In den darauffolgenden Messungen wird der Abstand der Zwischenschritte auf $12 \mathrm{~nm}$ bzw. $13 \mathrm{~nm}$ verkleinert, um Änderungen präziser feststellen zu können. Da hierbei schließlich 27 Bilder entstehen und die Zellen durch die Messungen stärker beansprucht werden (Photobleaching), werden in weiteren Messreihen ausschließlich die neu hinzugekommenen intermittierenden Wellenlängen gemessen, sodass hier wieder nur noch 14 Bilder entstehen.

Diese Messreihen werden durchgeführt, um einen Überblick darüber zu gewinnen, wie die Intensität der Fluoreszenzen unter neutralen Bedingungen in Abhängigkeit von den Exzitationswellenlängen reagiert und sich verändert.

\subsubsection{Dynamische Messungen der Redoxbalance}

Bezüglich der weiteren Messungen wurden für roGFP1 die Wellenlängen $740 \mathrm{~nm}$ und 910 nm und für HyPer $760 \mathrm{~nm}$ und $920 \mathrm{~nm}$ festgelegt, da diese die ungefähren verdoppelten Wellenlängen der Ein-Photonen-Mikroskopie darstellen, welche bereits ausgiebig untersucht wurden und dort die Exzitationsmaxima, beziehungsweise -minima darstellen (Lukyanov und Belousov 2013; Weller et al. 2014). Zusätzlich wurde die Auswahl der Wellenlängen auch durch die gewonnenen Ergebnisse der Zwei-Photonen-Spektren aus den vorherigen Versuchen (siehe 3.2 Zwei-Photonen-Anregungsspektrum der ROSIndikatoren) beeinflusst.

Diese dynamischen Messungen ermöglichen ein automatisiertes Vorgehen beruhend auf einem immer gleichen Zeitintervall bei einer zuvor festgelegten Bildrate. Als Einheit wird der Zeitraum von 30 Sekunden gewählt, was bedeutet, dass jeweils nach 30 Sekunden automatisch computergesteuert eine Messung stattfindet. Einen Vorteil stellt demnach beson- 
ders dieser stetig exakt gleichbleibende, vordefinierte zeitliche Abstand zwischen den Messungen dar, was eine bessere Vergleichbarkeit schafft. Zudem soll dieses Vorgehen ein Bleichen des Fluorophors verhindern oder zumindest eingrenzen, da die Zellen dem Laserstrahl insgesamt für einen kürzeren Zeitraum ausgesetzt sind, im Vergleich zu den Messungen der Exzitationsspektren mit einer zeitlich längeren Laserexposition. Um einen stabilen Kontrollbereich als Basiswert festzulegen, befanden sich die Zellen während der ersten 15 Messungen, demnach in den ersten 7,5 Minuten, von ACSF als neutrales Medium umgeben. Vor Versuchsbeginn wurde bereits die zuvor festgelegte Anregungswellenlänge, jeweils für roGFP1 und HyPer, eingestellt. Nach diesen 15 anfänglichen Kontrollmessungen wird die DTT- bzw. $\mathrm{H}_{2} \mathrm{O}_{2}$-Lösung eingewaschen und nach weiteren 5 bis 6 Messungen (nach 2,5 bis 3 Minuten) zeigen sich erste Reaktionen der Zelle auf die eingewaschene Lösung. Die DTT- bzw. $\mathrm{H}_{2} \mathrm{O}_{2}$-Lösung benötigt, wie in den bisher durchgeführten Versuchen auch, eine Einwirkzeit von 5 Minuten (10 Messungen), bevor diese Testlösung wieder durch ACSF ersetzt wurden, damit die Zellen sich unter neutralen Bedingungen wieder vollständig erholen. Dies kann beinahe 10 bis 15 Minuten andauern, demnach finden in dieser Zeitspanne 20 bis 30 Messungen statt, währenddessen der Austausch von der DTT- bzw. $\mathrm{H}_{2} \mathrm{O}_{2}$-Lösung durch das neutrale ACSF stattfindet. Diese gesamte Messreihe wird nach 25 bis 30 Minuten beendet. Anschließend wird eine neue Messung mit derselben Zelle und der gleichen Vorgehensweise durchgeführt. Im Unterschied zur ersten Messereihe wird nun die jeweils andere Lösung (DTT oder $\mathrm{H}_{2} \mathrm{O}_{2}$ ) angewandt.

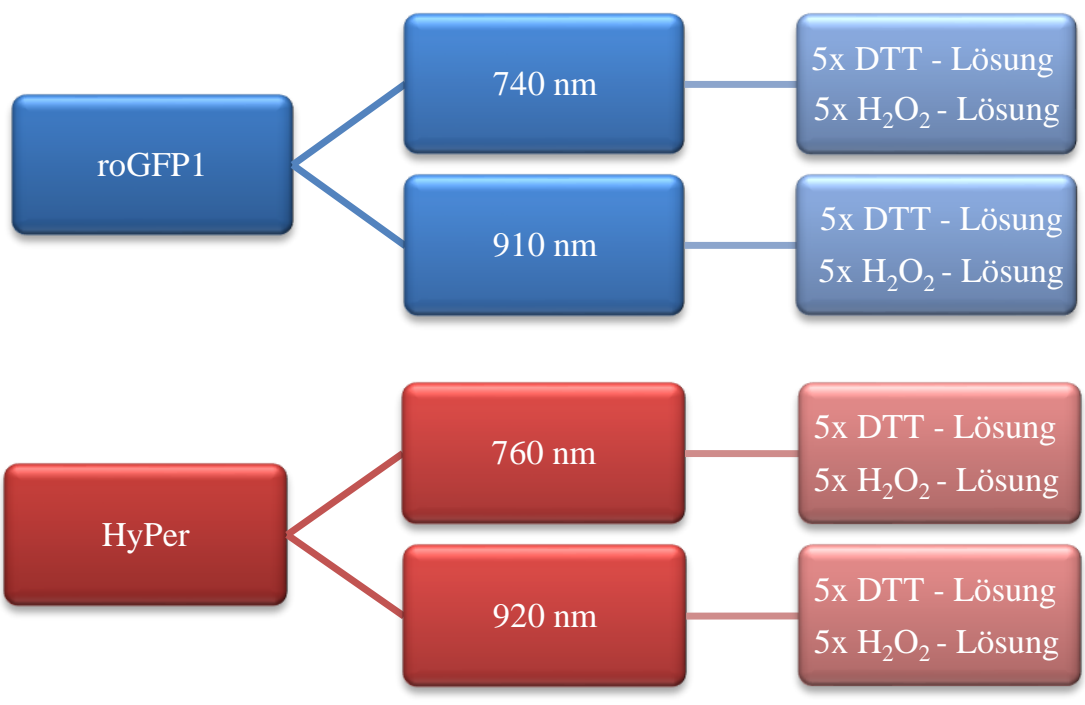

Abbildung 12: Einteilung der verschiedenen Messreihen auf einen Blick. Dieses Schema zeigt, dass mit jeweils zwei Wellenlängen, Proben mit roGFP1 und HyPer gemessen werden. Pro festgelegter Wellenlänge, finden insgesamt zehn Messungen statt: Fünf davon beeinflusst durch DTT, die anderen fünf durch $\mathrm{H}_{2} \mathrm{O}_{2}$. 
Während der Messung wird auf dem PC-Bildschirm ein Rechteck innerhalb des deutlich leuchtenden Zellkörpers, außerhalb des Nukleus, festgelegt (ROI: Region of interest). Daraus können Änderungen der Helligkeit unter Zugabe des Oxidations- beziehungsweise Reduktionsmittels festgehalten und errechnet werden. Um Bleichungseffekte beziehungsweise Laserreflexe während der Messung mit niedrigen Wellenlängen zu vermeiden, erwies sich die Filterkombination DT Green und Calflex X als sehr effektiv.

Ziel dieser Messreihe soll die Veranschaulichung der Reaktionen der Redoxindikatoren in Bezug auf die Zeit und die Emissionsintensität während Oxidation und Reduktion sein.

\subsubsection{Darstellung ratiometrischer Bildserien}

Das Erstellen ratiometrischer Bildserien hat das Ziel, Änderungen in Bezug auf die Intensität der Zellen unter Einfluss von $\mathrm{H}_{2} \mathrm{O}_{2}$ und DTT optisch darzustellen und quantitativ zu erfassen. Hierfür wurden pro Messreihe sechs Messungen mit der gleichen Zelle durchgeführt und demnach drei ratiometrische Bildpaare erstellt. Das erste Bildpaar entstand unter Kontrollbedingungen mit ACSF. Hierfür wurden wiederum jeweils die beiden zuvor festgelegten ratiometrischen Anregungswellenlängen eingestellt, für roGFP1 740 nm und 910 nm, für HyPer $760 \mathrm{~nm}$ und $920 \mathrm{~nm}$. Anschließend wurde die $\mathrm{H}_{2} \mathrm{O}_{2}$-Lösung eingewaschen und nach einer Einwirkzeit von 5 Minuten wurde ein Bildpaar unter Oxidation für die beiden Wellenlängen (Bild 3 und 4) erzeugt. Die $\mathrm{H}_{2} \mathrm{O}_{2}$-Lösung wurde daraufhin durch ACSF 10 Minuten lang ausgewaschen, um dann in die wiederhergestellte neutrale Umgebung die DTT-Lösung einzuwaschen. Nach 5 Minuten wurde ein Bildpaar unter Reduktion (Bild 5 und 6) aufgenommen. Bei dieser Versuchsreihe ist die Belastung durch den Laser und die Gefahr des Ausbleichens erheblich reduziert, da nur 6 Messungen pro Zelle durchgeführt werden. Als ein besonders wichtiger Punkt stellen sich hier die Warte- und Einwirkzeiten heraus, damit sich die hinzugeführten Lösungen nicht gegenseitig in ihrer Wirkung beeinflussen. Die nachfolgende Abbildung 13 zeigt einen Überblick über die Vorgehensweise dieser Versuchsreihe. 


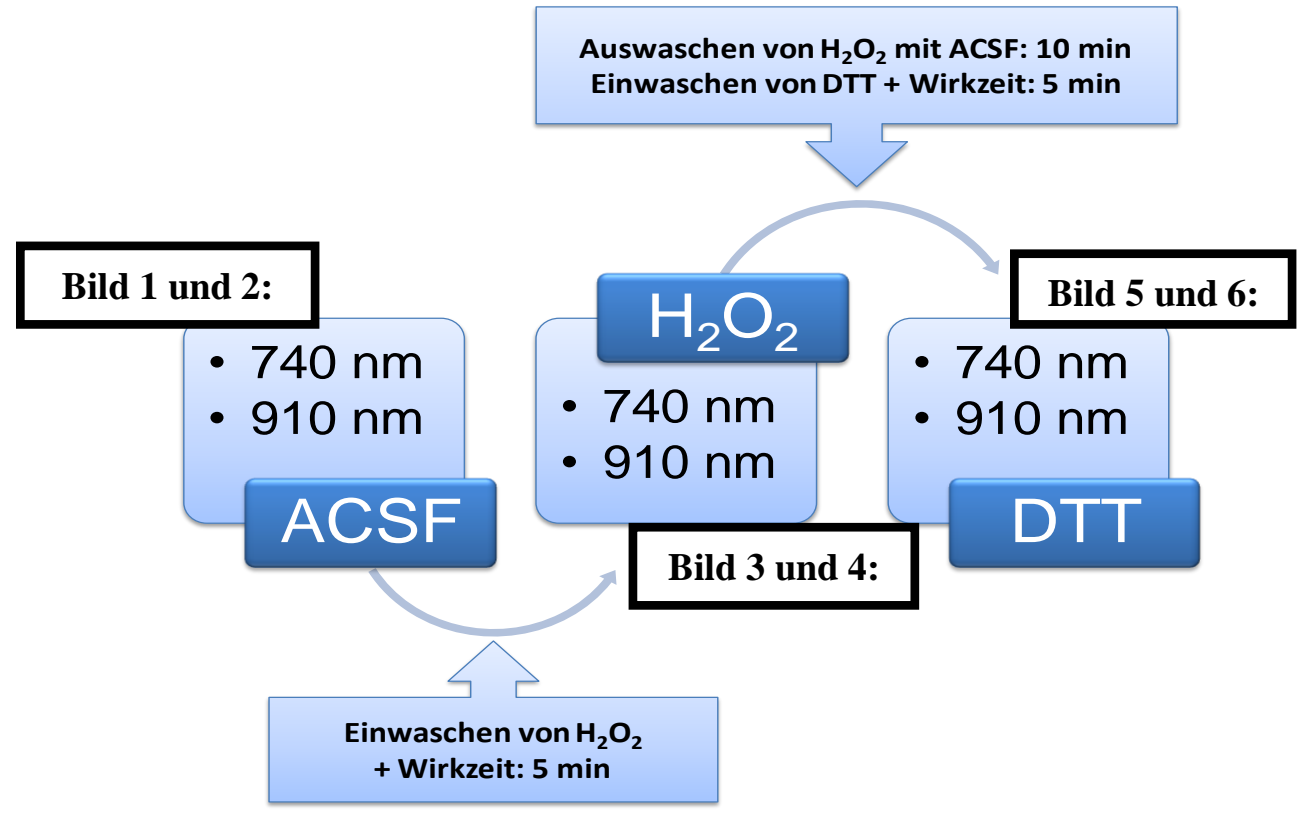

Abbildung 13: Aufzeichnung ratiometrischer Bildpaare. Diese Abbildung beinhaltet die festgelegten Wellenlängen bei der Messung mit roGFP1. Für den Redoxindikator HyPer werden die Wellenlängen 760 und $920 \mathrm{~nm}$ angewandt. Auch wurde in den Versuchen die Reihenfolge der hinzugegebenen $2 \mathrm{mM}$ DTT- und der $0.5 \mathrm{mM} \mathrm{H} \mathrm{O}_{2}$ - Lösung variiert, damit ausgeschlossen werden kann, dass die eine Lösung die andere trotz des zwischenzeitlichen Auswaschens mit ACSF beeinflusst.

Die Messungen wurden mit dem Objektiv von Zeiss IR 40x Achroplan durchgeführt. Es ermöglicht eine optimale und kontrastreiche Darstellung der Zielzellen. Die Filterkombination 475/35, DC 510, EmHG 510LP erleichtert das Auswählen einer transfizierten Zelle und kann unter Anregung von ultraviolettem Licht einen großen Kontrast zwischen den grün leuchtenden Zellen und dem dunklen Hintergrund erzielen. Gleichzeitig wurden weitere Filter angewandt: Bright Line HC 525/50 Emitter sowie ein Strahlenteiler T495 LP XR.

\subsubsection{Messungen der Fluoreszenzlebenszeit}

Das FLIM-System (fluorescence lifetime imaging microscopy) von LaVision BioTec (FLIM X16 - 76 MHz TCSPC Detektor) ist in der Lage, die durchschnittliche Lebenszeit einer Fluoreszenz zu bestimmen, also die Zeit, in der sich der Chromophor in einem angeregten Zustand befindet. Die ersten Forschungen bezüglich der Lebenszeit einer Fluoreszenz wurden 1992 von dem US-amerikanischen Biochemiker Joseph Lakowicz publiziert. Das Grundprinzip besteht in der Absorption eines (Licht-)Photons durch ein Atom, dadurch wird ein Elektron innerhalb dieses Atoms auf eine energiereichere Stufe angeho- 
ben, anschließend fällt es auf sein Ausgangsenergielevel zurück und emittiert dabei ein Photon, welches detektiert werden kann. Die Abkürzung TCSPC steht für „time correlated single photon counting“ und beschreibt das Messprinzip, jeweils nach einem einzelnen Laserpuls das zeitliche Abklingverhalten der Fluoreszenzemission zu bestimmen (Lakowicz et al. 1992; Lakowicz 2006; Becker 2012).

Als Fluoreszenzlebensdauer wird eine mittlere Zeit $\mathrm{G}$ beschrieben, in der sich ein Molekül in seinem angeregten Zustand befindet, bevor es ein Photon emittiert und in seinen Ausgangszustand zurückkehrt. Diese Zeit T lässt sich in den Nanosekundenbereich einordnen. Die Lebenszeit ist somit direkt abhängig von der Zeit, in der sich das Molekül im angeregten Zustand befindet. Sie ist spezifisch für jeden Fluorophor und charakterisiert diesen.

Die FLIM-Messungen haben den Vorteil, nicht von Schwankungen der Exzitationsintensität, sowie von der Konzentration der Probe oder der Länge des Lichtweges (light-path length) abhängig zu sein. Zudem ist eine potentiell inhomogene Verteilung des Fluorophors in der Probe für das Messergebnis nicht von Bedeutung. Als ein weiterer wichtiger Punkt ist festzuhalten, dass ein Photobleaching zwar gegebenenfalls in erheblichem Maße auftritt, dieses die Lebenszeit der Fluoreszenz jedoch nicht beeinflusst (Lakowicz et al. 1992; Lloyd et al. 2010). Die FLIM-gestützten Messungen sind besonders sensitiv für Erkenntnisse über Eigenschaften der räumlichen Umgebung des Fluorophors, zum Beispiel die Temperatur, den $\mathrm{pH}-$ Wert, die $\mathrm{O}_{2}$-Konzentration, Molekülbindungen, Lokalisationen von Molekülen innerhalb der Zelle, Ionenkonzentrationen und Funktionen biologischer Systeme. Das Fluoreszenz-Protein sollte aus diesem Grund stabil gegenüber diesen Komponenten, wie unter anderem dem $\mathrm{pH}-$ Wert, sein, um verfälschte Ergebnisse zu vermeiden (Resch-Genger et al. 2008). Mithilfe von FLIM ist es außerdem möglich, biochemische Reaktionen und Lokalisationen von Proteinen innerhalb der Zelle in verschiedenen Zellsubkompartimenten, die mithilfe des Mikroskops bildlich aufgelöst werden können, darzustellen. Idealerweise sollten diese Informationen mit möglichst nur einer minimalen Störung des physiologischen Status der lebenden Zelle erlangt werden (Lhoste 1991; Gerritsen et al. 1997; Bastiaens und Squire 1999; Tadrous 2000; Suhling et al. 2002; Efting 2002; Wallrabe und Periasamy 2005; Chen et al. 2013).

Das Prinzip des TCSPC beruht auf einer Zeitmessung, ähnlich dem Prinzip einer Stoppuhr (siehe Abbildung 14): Ein Zyklus der Messung beginnt mit der Anregung des Fluorophors durch den Laserimpuls, der sich in einem Bereich von Pikosekunden befindet, und endet mit der Emission eines Photons durch den Fluorophor. Während dieser Zeit befindet sich 
der Fluorophor in seinem angeregten Zustand (Becker et al. 2004; Chen et al. 2013). In einem jeweiligen Abstand von 12,5 ns erzeugt der Laser neue Pulse. In der Regel wird jeweils pro Fluorophor nur ein einzelnes Photon emittiert und detektiert. Um dies zu gewährleisten, trifft der Laserstrahl mit sehr geringer Intensität auf die Gewebsprobe. Eine zu hohe Energie würde die Chance erhöhen, dass mehrere Photonen gleichzeitig oder sehr kurz hintereinander emittiert werden, was das Ergebnis verfälschen könnte. Zudem erzeugt nicht jeder Laserpuls eine Antwort, die von den Detektoren aufgezeichnet wird (Chen et al. 2013). Die Detektoren benötigen zudem eine kurze Erholungszeit (dead-time), in der sie keine weiteren Photonen detektieren können (Wahl et al. 2007). Dieser Zustand tritt unmittelbar nach der Detektion eines Photons ein und liegt im $\mu$ s-Bereich. Aufgrund dessen ist es vorteilhaft, dass die emittierten Photonen aufgrund der reduzierten Laserkraft einen gewissen zeitlichen Abstand voneinander gewinnen. Die Emission beruht auf dem Zufallsprinzip: Mit der niedrigen Laserkraft kann jedoch die Chance auf ein einzelnes emittiertes Photon erhöht werden. Insgesamt verlängert sich die Gesamtmessdauer dadurch jedoch deutlich (Wahl 2014).

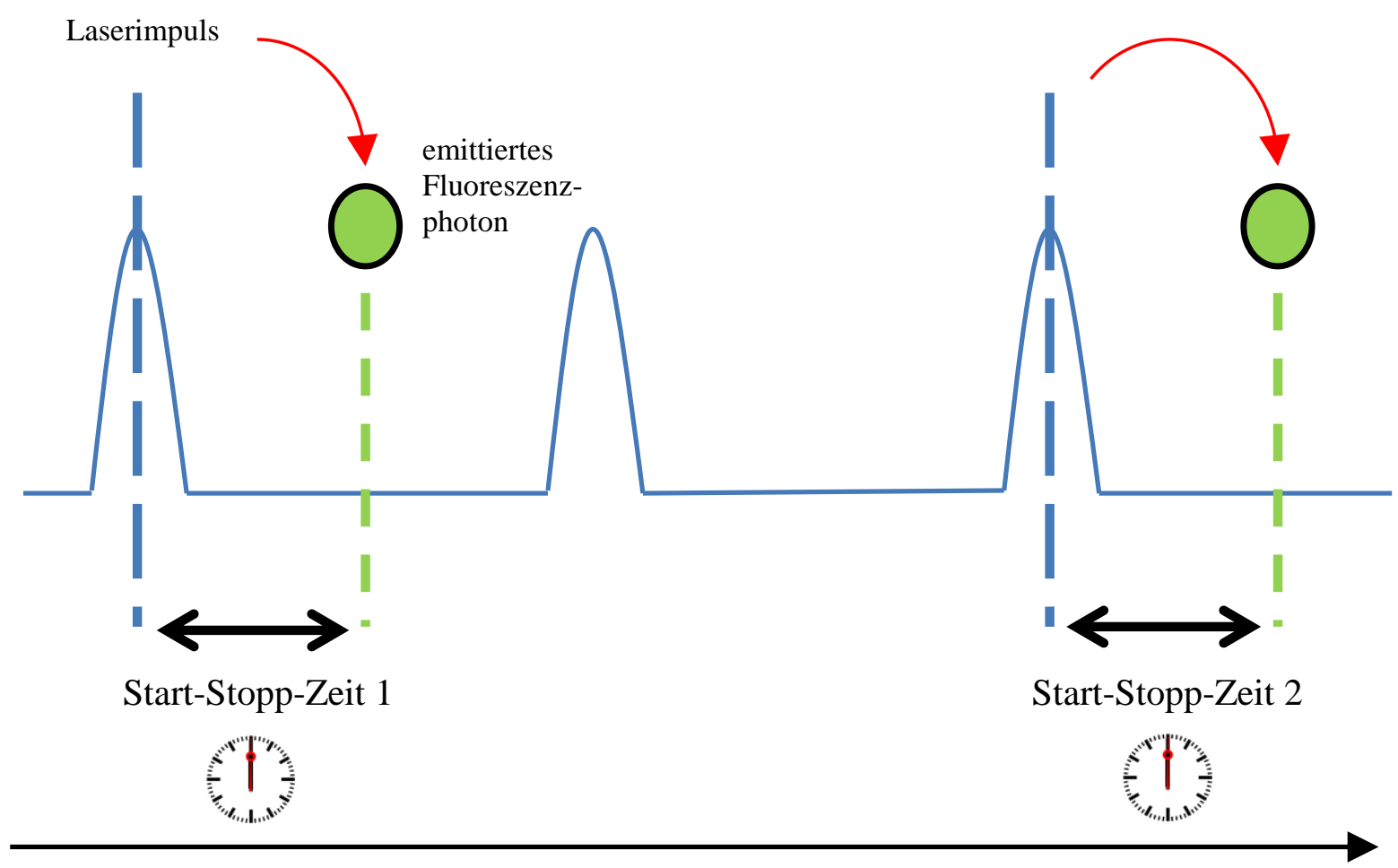

Zeitlicher Verlauf der Messung (t) Abbildung 14: Vereinfachte Darstellung des TCSPC-Prinzips. Die Zeitmessung beginnt nach
gesetztem Laserimpuls und endet mit der Emission eines Photons. Hier sind mehrere Zyklen darge-
stellt. Es besteht jedoch auch die Wahrscheinlichkeit (mittlerer Laserimpuls), dass kein Photon
nach einem Laserimpuls emittiert wird (angelehnt an Abbildung 1 aus Wahl 2014 mit freundlicher
Genehmigung von PicoQuant GmbH). 
Dieser Messablauf, veranschaulicht in Abbildung 14, wird mehrfach wiederholt. Das Zufallsprinzip spielt hier eine entscheidende Rolle, da nicht jeder Laserimpuls ein Photon zur Emission anregt. Anschließend werden die gesammelten Start-Stopp-Zeiten aufsummiert und in ein TCSPC-Histogramm übertragen, das einen exponentiellen Abfall der Lebenszeiten in Bezug auf die gemessene Zeit darstellt.

\section{Detektorsignale}

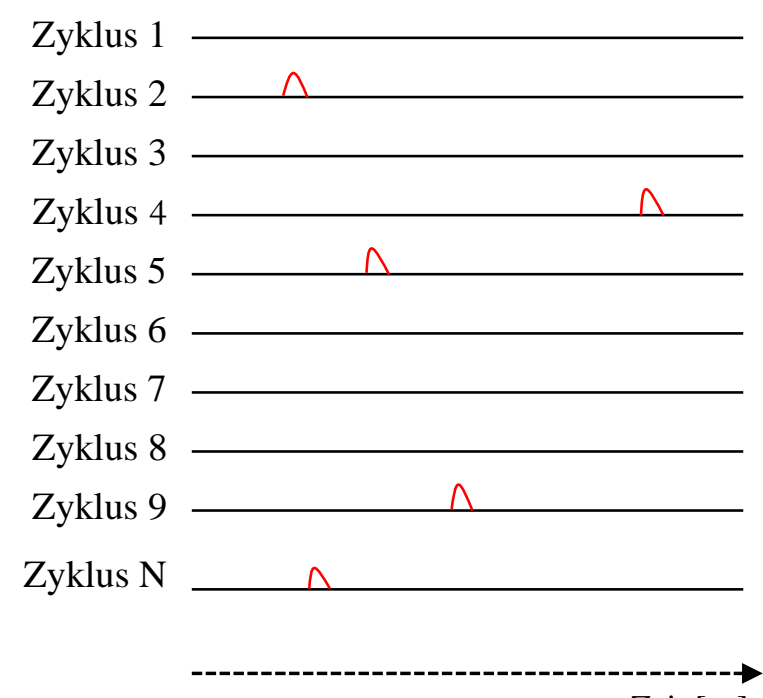

Zeit [ns]

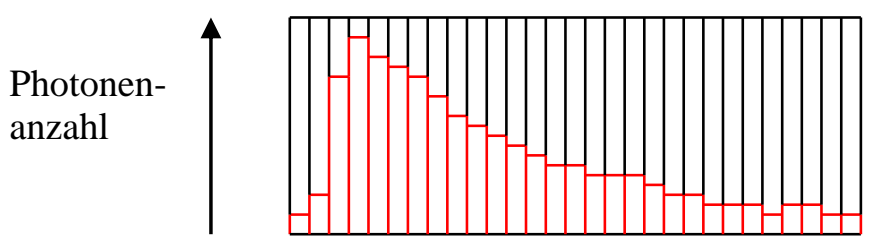

Ergebnis nach mehreren Zyklen

Abbildung 15: Prinzip des TCSPC. Es werden beispielhaft verschiedene Zyklen dargestellt, von denen einige eine Photonenemission zu einem bestimmten Zeitpunkt zeigen (z. B. Zyklus 2), andere wiederum nicht (z. B. Zyklus 3). Internetquelle, mit freundlicher Genehmigung:

https://www.tu-braunschweig.de/pci/research/gericke/forschung/multiphotonen/zweiphotonen (abgerufen am 02.10.17)

Als optimale Wellenlängen bezüglich der FLIM-Messungen stellten sich mithilfe der zuvor bestimmten Exzitationsspektren (siehe 3.2 Zwei-Photonen-Anregungsspektrum der ROSIndikatoren) für die Redoxindikatoren roGFP1 $890 \mathrm{~nm}$ und HyPer $840 \mathrm{~nm}$ heraus, da diese Wellenlängen in den jeweiligen Spektren eine intensive Emission zeigen. Zu Beginn der jeweiligen Messreihe wurden, wie bei den vorherigen Messreihen auch, Basismessungen mit neutralem ACSF durchgeführt. Um Kontrollbedingungen zu schaffen, wurde von der Zielzelle jeweils ein PMT-Bild und anschließend ein FLIM-Bild aufgenommen. 
Für die Erstellung des PMT-Bildes liegen folgende Systemeinstellungen vor:

\begin{tabular}{|c|c|c|}
\hline Größe: & $100 \times 100 \mu \mathrm{m}$ & Laserpower: $3 \%$ \\
\hline Pixel: & 476 x 476 Pixel & PMT Gain: \\
\hline Frequenz: & $800 \mathrm{~Hz}$ & \\
\hline
\end{tabular}

\section{Durchschnittlich gemittelte Linien: 5}

Für die Erstellung des FLIM-Bildes liegen folgende Systemeinstellungen vor:

$\begin{array}{llll}\text { Größe: } & 100 \times 100 \mu \mathrm{m} & \text { Laserpower: } & 3 \% \\ \text { Pixel: } & 256 \times 256 \text { Pixel } & \text { Time: } & 12 \mathrm{~ns}\end{array}$

Frequenz: $\quad 200 \mathrm{~Hz}$

\section{Durchschnittlich gemittelte Linien: $\quad$ 5-30}

Die Anzahl der durchschnittlich gemittelten Linien in den Einstellungsparametern des FLIM-Systems variiert erheblich und ist abhängig von der Helligkeit der Zelle. Befindet sich diese unter einem Schwellenwert von 600 Photonen/s, muss die Anzahl der durchschnittlich gemessenen Linien erhöht werden, bis ein Wert größer als 600 Photonen/s erreicht wird. Erst dann kann die Messung sinnvoll durchgeführt und auch zuverlässig ausgewertet werden.

Von einem Deckglas werden zuerst vier bis fünf Zellen, welche die Kontrollwerte bilden, jeweils mit PMT und FLIM bei umgebendem ACSF dargestellt. Danach wird eine weitere Zelle zuerst ebenfalls bei umgebendem ACSF mit PMT und FLIM gemessen und schließlich die $500 \mu$ molare $\mathrm{H}_{2} \mathrm{O}_{2}$-Lösung eingewaschen. Nach einer fünfminütigen Einwirkzeit der Substanz wird ein weiteres FLIM-Bild derselben Zelle mit denselben Einstellungen aufgezeichnet. Daraufhin wird die $2 \mathrm{mM}$ DTT-Lösung eingewaschen, wiederum eine fünfminütige Einwirkzeit abgewartet und ein FLIM-Bild aufgezeichnet. Nach der Messung wird das Deckglas mit der Zellkultur verworfen und ein neues für die nachfolgenden Messungen herangezogen. Um mögliche ergebnisverfälschende Störfaktoren zu beseitigen, werden weitere Messungen ausschließlich unter Hinzugabe von nur einer Lösung durchgeführt. Nach der Aufnahme des Kontrollbildes wird demnach entweder die $\mathrm{H}_{2} \mathrm{O}_{2}$-Lösung oder die DTT-Lösung eingewaschen und das Deckglas nach Abschluss der Messung verworfen.

Zusätzlich wird nach einigen Messungen sowohl die Konzentration der $\mathrm{H}_{2} \mathrm{O}_{2}$-Lösung von $500 \mu \mathrm{M}$ auf $2 \mathrm{mM}$ als auch die der DTT-Lösung von $2 \mathrm{mM}$ auf $10 \mathrm{mM}$ erhöht, um gege- 
benenfalls einen deutlicheren Unterschied $\mathrm{zu}$ erzielen und eine Dosis-WirkungAbhängigkeit zu untersuchen. 


\section{Ergebnisse}

\subsection{Kernfärbungen mit DAPI}

Die Darstellung der Syntheseorte für das Protein roGFP1 wird charakterisiert durch eine homogene Verteilung des Fluorophors, sowohl im Zytosol, in den Axonen und Dendriten, als auch im Nukleus (Abbildung 16 A). Hier lässt sich farblich kein Unterschied zwischen Zellkern und Zytosol erkennen, somit ist der Kern einer mit roGFP1 transfizierten Zelle kaum von seinem Zytosol abgrenzbar. Da HyPer (Abbildung 16 B) im Vergleich zu roGFP1 (Abbildung 16 A) ein verhältnismäßig großes Molekül ist, stellt die Kernmembran eine beinahe unüberwindbare Barriere für das Protein dar. Es kann sich also ohne eine speziell angeknüpfte Sequenz, die den Eintritt in den Zellkern ermöglichen würde, beinahe ausschließlich im Zytosol, in den Axonen und Dendriten verteilen, der Zellkern bleibt somit größtenteils ausgespart.

Die unter Anwendung von DAPI entstandenen Bilder in Abbildung $16 \mathrm{C}$ zeigten charakteristisch separat blau gefärbte Zellkerne, umgeben von dem grünleuchtenden Zytosol. In einer mit HyPer transfizierten Zelle befindet sich also an der Stelle, an dem der Zellkern lokalisiert ist, ohne DAPI ein nur leicht grünlich gefärbter, dunkler Bereich. Umso deutlicher erscheint hier das Ergebnis unter Gebrauch der Kernfärbung DAPI: Es wird bestätigt, dass unter Expression des Fluoreszenzproteins HyPer eine inhomogene Färbung der Zelle auftritt, bei der der Kern offenbar größtenteils ausgenommen bleibt. 

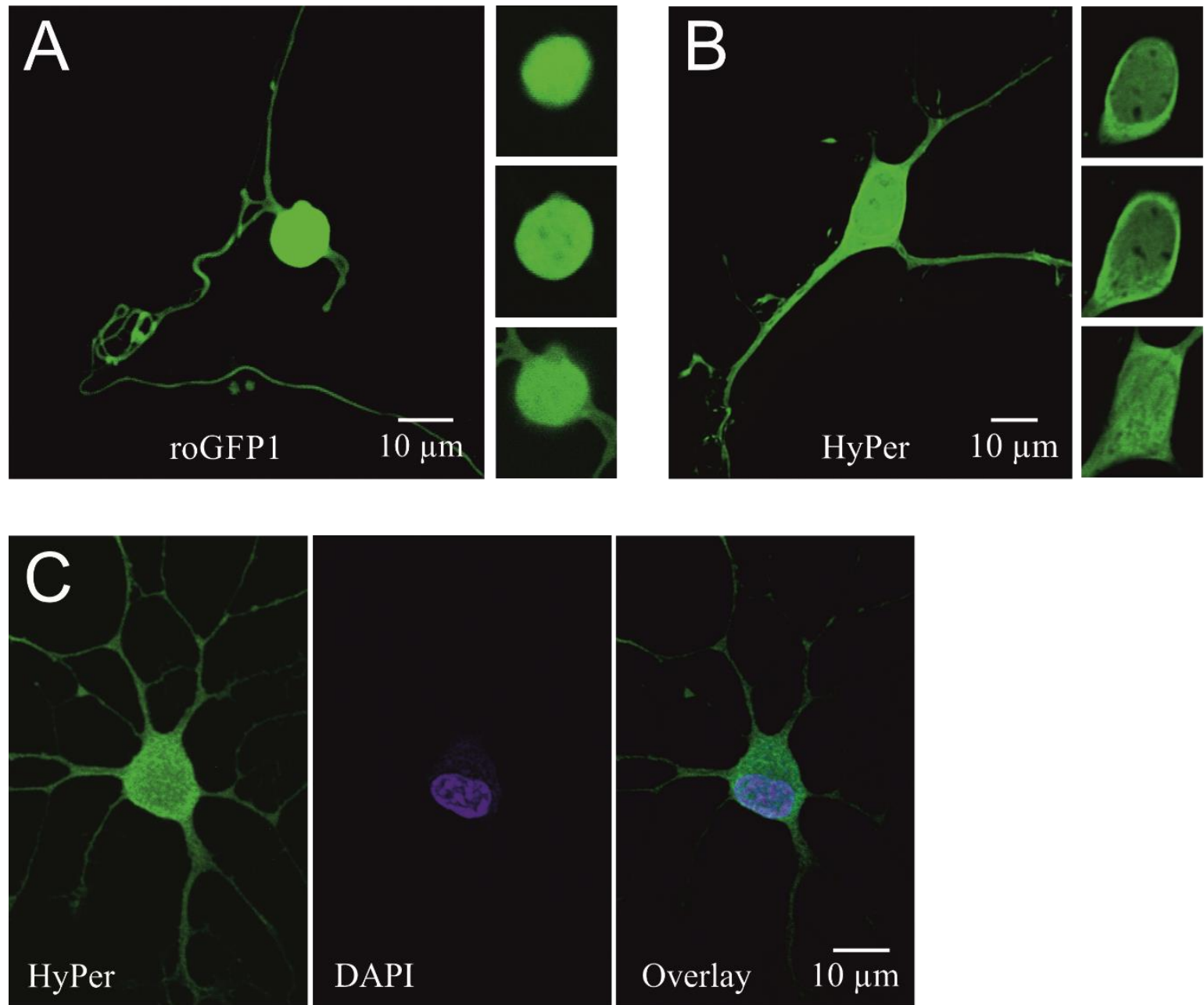

Abbildung 16: Darstellung einer Zelle mit roGFP1, HyPer und einer Kombination aus einer HyPer-Zelle mit DAPI. (A) Homogene Verteilung des fluoreszierenden Proteins im Zytosol, sowie im Kern in der mit roGFP1 transfizierten Zelle. Am Bildrand (A): Darstellung fokussiert auf den Kern in verschiedenen Schnittebenen. (B) Homogene zytosolische Verteilung von HyPer. Das größere Bild zeigt die Maximalprojektion der Intensität eines Bilderstapels (z-stack). In verschiedenen Schnittebenen wird der ausgesparte Zellkern dargestellt (B, rechter Bildrand). (C) Nach Anfärben des Nukleus mit DAPI wird offenbar die ausgeprägte zytosolische Expression von HyPer deutlich. Beide Aufnahmen, die Kernfärbung mit DAPI und die reguläre zytosolische Färbung durch HyPer, werden mit verschiedenen Emissionsfiltern und Detektionskanälen aufgenommen und schließlich als „Overlay“ übereinandergelegt (Weller et al. 2014, Abb. $1 \mathrm{C}+1 \mathrm{D}$, mit freundlicher Genehmigung von Elsevier).

\subsection{Zwei-Photonen-Anregungsspektrum der ROS-Indikatoren}

Wie bereits im Kapitel „Material und Methoden“ festgehalten, ist ein Schwerpunkt meiner Arbeit die Bestimmung von Zweiphotonenanregungsspektren für die beiden RedoxIndikatoren roGFP1 und HyPer. Ziel dieses Versuchsabschnitts ist es, eine oder mehrere Exzitationswellenlängen herauszufiltern, an denen die Emission am größten ist, um mit diesen die nächsten, darauf aufbauenden Versuchsschritte durchzuführen. Die dafür not- 
wendigen relativen Intensitäten werden errechnet, indem sie in Bezug auf den Hintergrund, die Laserpower und die maximale Intensität der jeweiligen Zelle normiert werden.

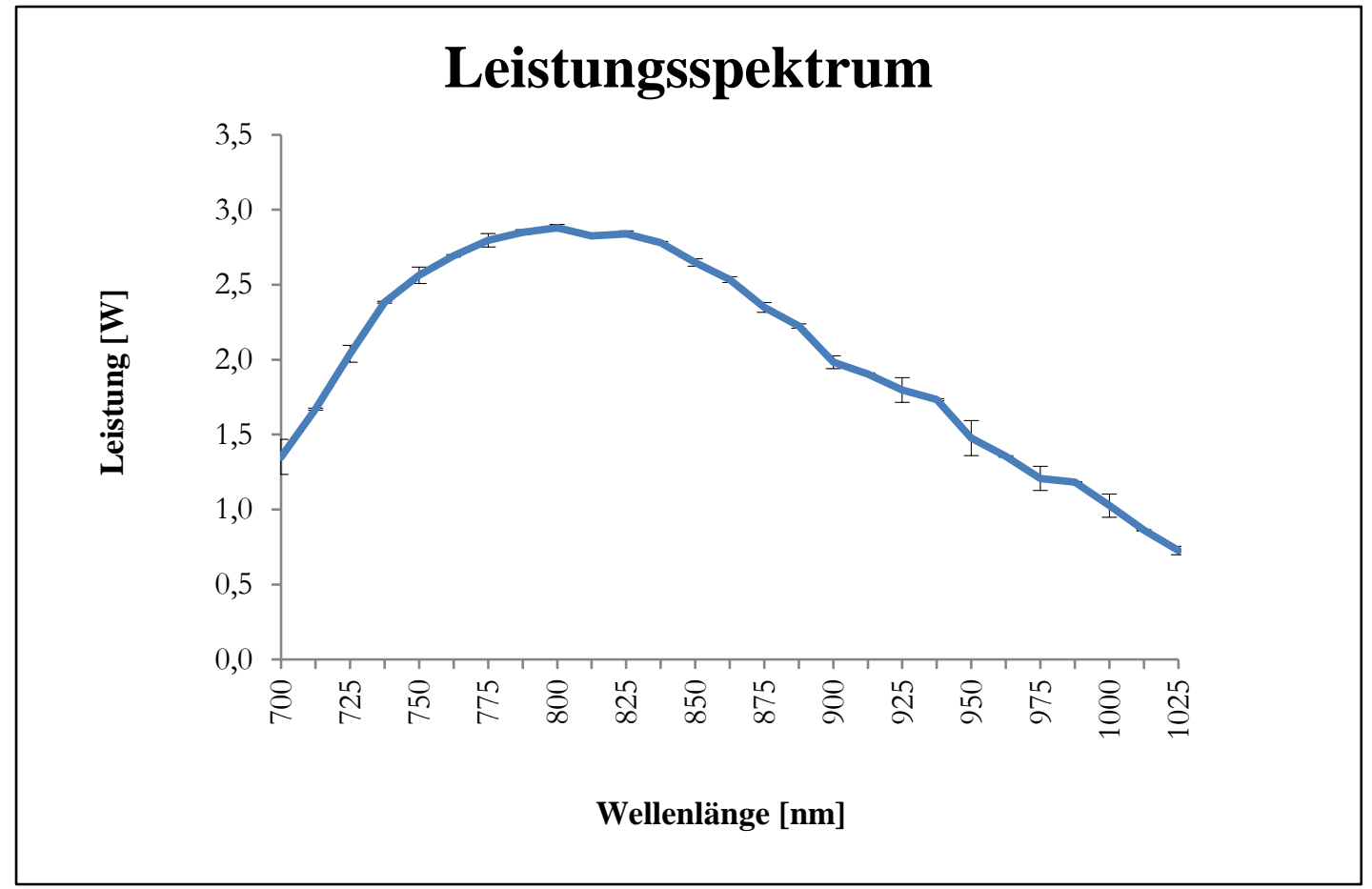

Abbildung 17: Ausgangsspektrum des Ti:Sa-Lasers. Darstellung in Abhängigkeit von den verschiedenen Wellenlängen.

Da die Laserleistung nicht für alle Wellenlängen gleich groß ist, muss diese mit den gemessenen Werten verrechnet werden, um ein aussagekräftiges und vergleichbares Ergebnis erzielen zu können. Die verschiedenen Werte für die Laserleistung werden in Abbildung 17 dargestellt: In Abhängigkeit von den Wellenlängen ist anfangs ein steiler Anstieg der Leistung zu verzeichnen, die etwa bei $800 \mathrm{~nm}$ ihr Maximum ( 3 W) erreicht. Anschließend folgt ein stetiger Abfall bis auf $\sim 1 \mathrm{~W}$.

Für die Durchführung der ersten Messreihe, also der Kontrollmessung unter neutralem ACSF, wurden 14 Bilder von immer derselben Zelle mit verschiedenen Wellenlängen in einem Bereich von $700 \mathrm{~nm}$ bis $1025 \mathrm{~nm}$, jeweils mit einem Inkrement von $25 \mathrm{~nm}$ bzw. 12 und $13 \mathrm{~nm}$ gemessen.

Die sich ergebenden Intensitätswerte in Abhängigkeit von den Exzitationswellenlängen sind in dem folgenden Diagramm dargestellt. 


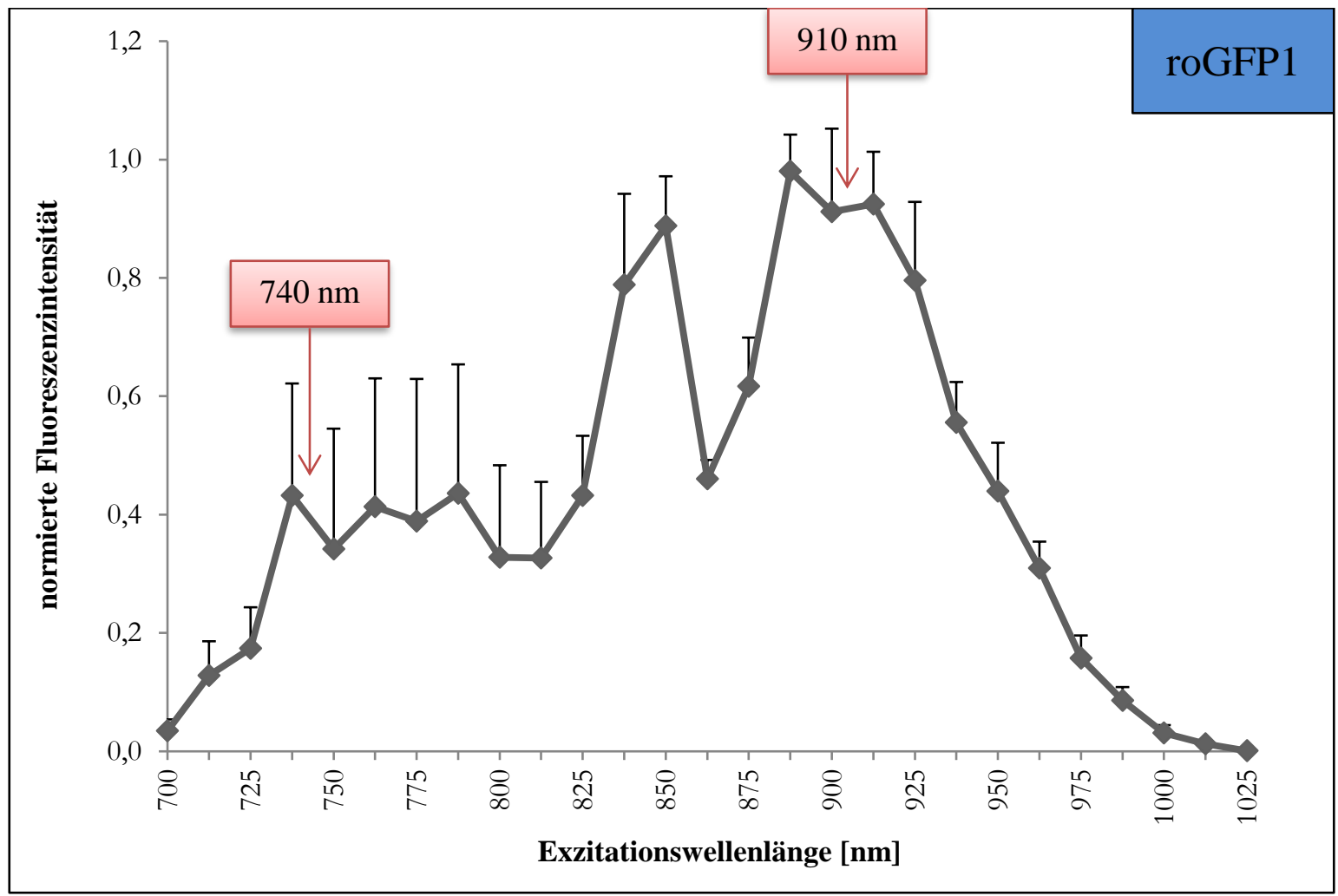

Abbildung 18: Zwei-Photonen-Spektrum von roGFP1 in ACSF. Die aufgetragenen Daten sind normiert in Bezug auf den Hintergrund, die Laserleistung und die maximale Intensität der jeweiligen Zelle. Hier sind jeweils die ausgewählten Wellenlängen gekennzeichnet (rot), die für die weiteren ratiometrischen Messungen eingesetzt wurden (740 nm und $910 \mathrm{~nm}$ ) (modifiziert nach Wagener et al. 2016, Abb. 10 A, mit freundlicher Genehmigung von Mary Ann Liebert.).

In diesem Diagramm (Abbildung 18) wird das auffällig breite Fluoreszenzspektrum von mit roGPF1 transfizierten hippokampalen Zellen sehr deutlich. Es liegen keine konkreten Maxima vor, jedoch zeigt sich eine durchschnittlich erhöhte Intensität im Bereich zwischen $825 \mathrm{~nm}$ und $938 \mathrm{~nm}$ mit einem tiefen Einschnitt bei $862 \mathrm{~nm}$. Betrachtet man ausschließlich die Grenzwerte im Bereich von $700 \mathrm{~nm}$ und $1025 \mathrm{~nm}$, ist dort eine deutlich geringere Emission erkennbar. Ab einer Wellenlänge von 925 nm und länger sinkt die Intensität kontinuierlich ab, bis im oberen Grenzbereich bei $1025 \mathrm{~nm}$ beinahe keine Emission mehr messbar ist. Hätten sich hier spezifische Maxima gezeigt, könnten diese als Richtwerte für meine weiteren Versuche genutzt werden.

Abbildung 18 zeigt zudem, dass es möglich ist, roGFP1 über einen breiten Wellenlängenbereich mithilfe des TPLSM anzuregen, jedoch können keine konkreten Punkte als Maxima bestimmt werden. Aus diesem Grund wurden die ungefähren verdoppelten Wellenlängen der Anregungsmaxima der bereits genau erforschten Ein-Photonen-Mikroskopie für die weiteren Messungen genutzt, welche in Abbildung 18 rot markiert sind (740 nm und $910 \mathrm{~nm})$. 
Wie im Spektrum von roGFP1 dargestellt, zeigen sich auch für HyPer (Abbildung 19) keine eindeutigen Anregungsmaxima, sondern vielmehr ein ähnlich breites Exzitationsspektrum.

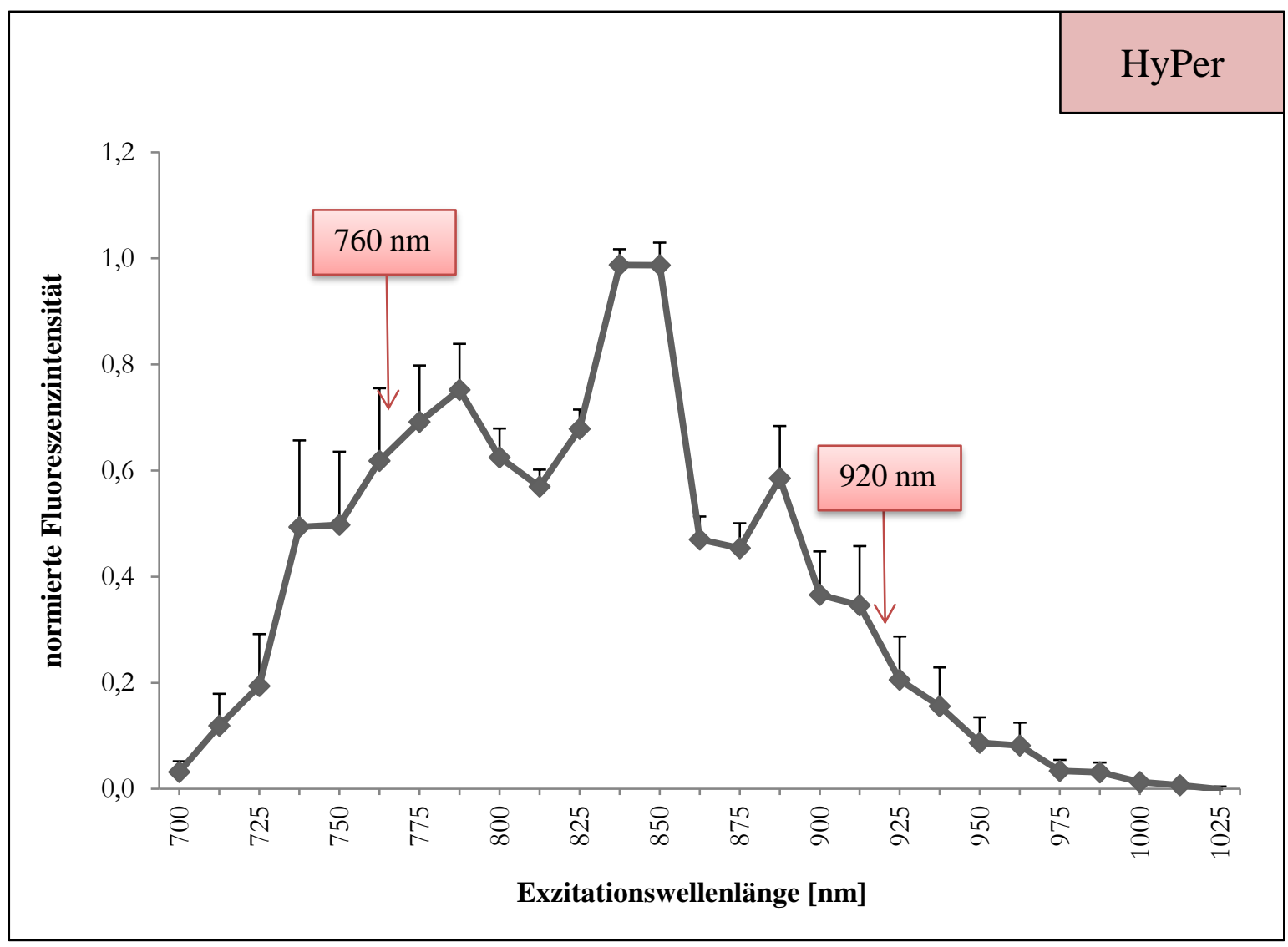

Abbildung 19: Zwei-Photonen-Spektrum von HyPer in ACSF. Normiert in Bezug auf den Hintergrund, die Laserpower und die maximale Intensität der jeweiligen Zelle (modifiziert nach Weller et al. 2014, Abb. 8 A, mit freundlicher Genehmigung von Elsevier).

Ebenso ist hier anhand Abbildung 19 festzuhalten, dass im Bereich der beiden Grenzwerte bei $700 \mathrm{~nm}$ und über $1000 \mathrm{~nm}$ beinahe keine resultierende Fluoreszenzemission erkennbar ist und ab ca. $900 \mathrm{~nm}$ die Emission in Richtung des oberen Grenzwertes (1025 nm) kontinuierlich abnimmt. Ein deutlicher Einbruch der Intensität ist auch hier bei Wellenlängen zwischen $850 \mathrm{~nm}$ und $875 \mathrm{~nm}$ zu verzeichnen. Zusätzlich sind in Abbildung 19 ebenfalls jeweils die ausgewählten Anregungswellenlängen gekennzeichnet (rot), die für die weiteren Messungen eingesetzt werden $(760 \mathrm{~nm}$ und $920 \mathrm{~nm})$. Zusammenfassend gesagt, werden für diese Versuchsreihe sowohl für roGFP1 als auch für HyPer jeweils zwei Anregungswellenlängen für weitere Versuchsreihen festgelegt. Diese beiden Wellenlängen sollten unter anderem einen ausreichenden Abstand zueinander aufweisen, demnach nicht zu dicht nebeneinanderliegen und zusätzlich auf die Ergebnisse der Ein-PhotonenMikroskopie zurückzuführen sein. 


\subsection{Dynamische Messungen der Redoxbalance}

Für die Messungen in diesem Kapitel wurden zuvor für die Redoxindikatoren HyPer und roGFP1 jeweils zwei spezifische Wellenlängen im NIR-Bereich für die Zwei-PhotonenMikroskopie bestimmt. Für roGFP1 liegen diese bei 740 nm und 910 nm, für HyPer bei $760 \mathrm{~nm}$ und $920 \mathrm{~nm}$, basierend auf den bisherigen Ergebnissen (Abbildung 18 und 19) und auf Forschungen bezüglich der Ein-Photonen-Mikroskopie (Lukyanov und Belousov 2013; Weller et al. 2014).

Ziel dieser Messreihe ist es, anhand einer kontinuierlichen, zeitlich fortschreitenden Messung während einer Dauer von 25 bis 30 Minuten, die maximalen Änderungsraten der Fluoreszenzen unter Einfluss des Oxidationsmittels $\mathrm{H}_{2} \mathrm{O}_{2}$ und des Reduktionsmittels DTT mit einer Einwirkzeit von jeweils fünf Minuten darzustellen. Es wird überprüft, ob in der Tat auch bei Anregung durch die TPE entgegengesetzte Fluoreszenzänderungen in Bezug auf die beiden Wellenlängen $\mathrm{zu}$ beobachten sind, wie es bereits für die Ein-PhotonenMikroskopie gezeigt wurde (Weller et al. 2014). Insgesamt wurden 50 bis 60 Bilder einer Zelle in einem Abstand von 30 Sekunden aufgezeichnet. Zu erwarten wäre bezüglich des Proteins roGFP1 für die kürzere Wellenlänge von 740 nm ein Anstieg der zu ermittelnden Kurve unter Einfluss von $\mathrm{H}_{2} \mathrm{O}_{2}(500 \mu \mathrm{M}, 5$ Minuten) und ein Absinken bedingt durch DTT (2 mM, 5 Minuten). Eine genau gegensätzliche Reaktion soll bei $910 \mathrm{~nm}$ ablaufen (Abbildung 20).

In Bezug auf das Protein HyPer sollte die Kurve jedoch theoretisch bei der zuvor festgelegten niedrigen Wellenlänge, $760 \mathrm{~nm}$, nach Behandlung mit $\mathrm{H}_{2} \mathrm{O}_{2}(500 \mu \mathrm{M}$, 5 Minuten $)$ absinken und nach Behandlung mit DTT ( $2 \mathrm{mM}, 5$ Minuten) ansteigen, sowie bei der längeren Wellenlänge von $920 \mathrm{~nm}$ gegensätzlich unter Anwesenheit von $\mathrm{H}_{2} \mathrm{O}_{2}$ ansteigen und unter Anwesenheit von DTT absinken (Abbildung 20). 

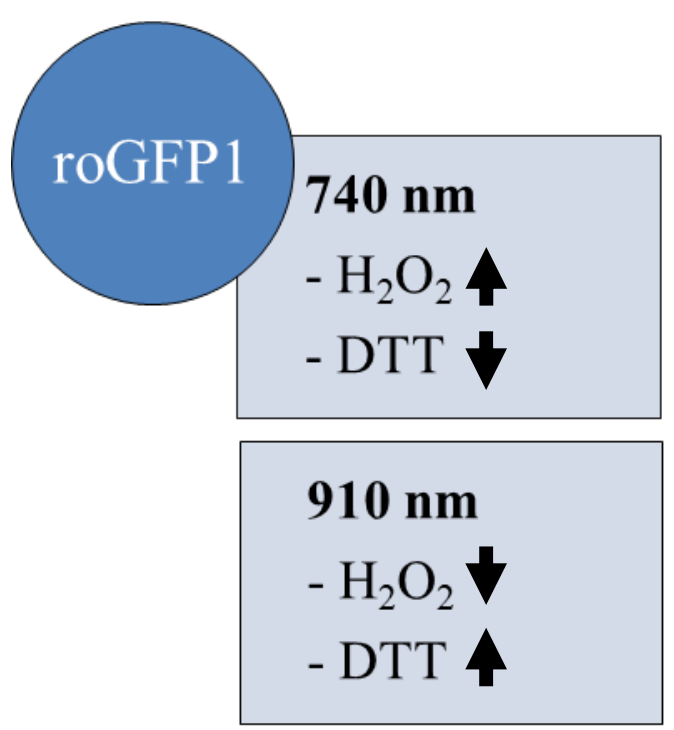

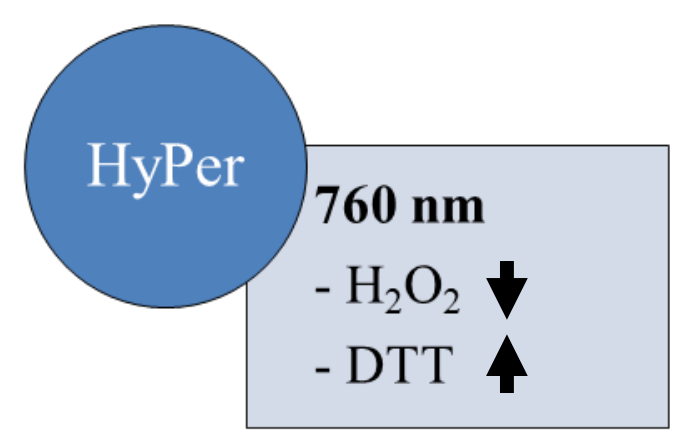

$920 \mathrm{~nm}$

$-\mathrm{H}_{2} \mathrm{O}_{2}$

- DTT

\section{Ratiometrische Bilder}
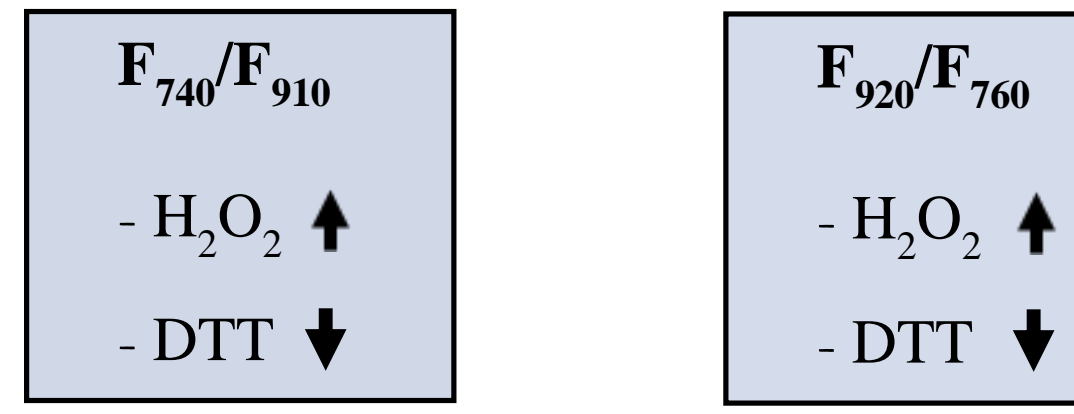

Abbildung 20: Zu erwartende Ergebnisse der Messreihe "Dynamische Messungen der Redoxbalance" im Überblick. Die schwarzen Pfeile geben jeweils in Bezug auf den Redoxindikator, die Wellenlänge und das Reduktionsmittel DTT sowie das Oxidationsmittel $\mathrm{H}_{2} \mathrm{O}_{2}$ die zu erwartenden Änderungen wieder. Ein nach unten gerichteter Pfeil bedeutet einen Abfall der Fluoreszenzintensität, wohingegen ein nach oben gerichteter Pfeil einen Anstieg der Fluoreszenzintensität anzeigt.

Die zu erwartenden Intensitätswerte (Abbildung 20) wurden für HyPer und roGFP1 allerdings nur teilweise bestätigt. Als Ergebnis wurden jeweils die ratiometrischen Werte dargestellt, um für einen Vergleich von roGFP1 und HyPer eine äquivalente Basis zu schaffen.

Für das Protein roGFP1 war anfangs eine stabile Basislinie unter ACSF bei Messungen mit einer Wellenlänge von $910 \mathrm{~nm}$ zu erkennen. Danach zeigten sich die Änderungen abhängig von der eingewaschenen Lösung. Das roGFP1 reagiert also deutlich und schnell mit einem Intensitätsanstieg bei DTT und einem Abfall der Fluoreszenzintensität unter Einfluss von 
$\mathrm{H}_{2} \mathrm{O}_{2}$. Im Kontrast dazu zeigten sich bei der Durchführung dieses Versuchs mit einer Wellenlänge von $740 \mathrm{~nm}$ nicht wie erwartet eine abfallende Kurve unter Einwirkung von DTT und ein Anstieg bei Umspülung mit der $\mathrm{H}_{2} \mathrm{O}_{2}$-Lösung. Es scheint, als wurde mit der Auswahl der Wellenlänge von $740 \mathrm{~nm}$ der isosbestische Punkt getroffen. Dieser wird definiert als die Wellenlänge, bei der sich die Lichtabsorption während einer chemischen Reaktion nicht ändert (McNaught und Wilkinson 1997). Vielmehr scheint es, als würde der Redoxindikator hier nicht auf Oxidation oder Reduktion reagieren. Hier wird auf den ersten Blick deutlich, dass nicht die theoretisch erwartete Reaktion stattfindet. Um den isosbestischen Punkt zu umgehen, müsste eine Wellenlänge gewählt werden, welche sich auf der Skala des Wellenlängenspektrums links von diesem Punkt befindet, also im Bereich der kürzeren Wellenlängen. Das Spektrum des Anregungslasers beginnt jedoch erst bei 700 nm. Hier wird beinahe keine Fluoreszenz mehr erzeugt (siehe Abbildung 7) und es tritt bei dieser kurzen Wellenlänge zusätzlich ein starkes Bleichen des roGFP-Sensors auf. Aus diesem Grund sind diese kürzeren Wellenlängen hier nicht praktikabel, jedoch sind auch bei einer Anregung am isosbestischen Punkt ratiometrische Messungen und deren Auswertungen möglich.

In Abbildung $21 \mathrm{~A}$ und $\mathrm{B}$ sind die Reaktionen für die mit HyPer transfizierten Zellen unter Einfluss von $\mathrm{H}_{2} \mathrm{O}_{2}$ (A) und DTT (B) in Abhängigkeit von der Zeit dargestellt. Jeweils im Abstand von $30 \mathrm{~s}$ wurden Messungen durchgeführt, um die Zelle nicht dauerhaft durch einen kontinuierlichen Laserstrahl zu belasten.

In Abbildung 21 A sind die Reaktionskurven für zwei verschiedene Wellenlängen (760 nm und $920 \mathrm{~nm}$ ) dargestellt. Unter Betrachtung des zeitlichen Verlaufs sind in beiden Graphen deutliche Stufen zu erkennen, die die Einwirkung von $\mathrm{H}_{2} \mathrm{O}_{2}$ auf die HyPer-Zelle zeigen. Es können durchaus wie erwartet zuverlässige Reaktionen für beide Wellenlängen (760 nm und $920 \mathrm{~nm})$ unter Einfluss von $\mathrm{H}_{2} \mathrm{O}_{2}(500 \mu \mathrm{M}, 5 \mathrm{~min})$ dokumentiert werden. Bei $760 \mathrm{~nm}$ nimmt die Intensität der Fluoreszenz im Mittel um 27,4 $\pm 20,8 \%(n=8)$ ab und steigt bei $920 \mathrm{~nm}$ um 76,8 $\pm 62,8 \%(\mathrm{n}=10)$ im Vergleich zur Kontrollmessung unter ACSF an.

Jedoch fallen die Ergebnisse in Bezug auf DTT ( $2 \mathrm{mM}, 5 \mathrm{~min}$ ) hier nicht wie erwartet aus (Abbildung $21 \mathrm{~B}$ ): Die Intensität der Fluoreszenz fällt bei $760 \mathrm{~nm}$ um 8,3 $\pm 5,9 \%$ (n=8) und steigt bei $920 \mathrm{~nm}$ um 92,3 \pm 74,8 \% (n=6) an. Die Graphik zeigt für die TPE eine nicht eindeutige Reaktion der HyPer-Zelle auf die DTT-Lösung. Es scheint eher die Reaktion, wie sie unter $\mathrm{H}_{2} \mathrm{O}_{2}$ auftritt, zu imitieren. Dieses Ergebnis konnte bereits für die EinPhotonen-Mikroskopie beobachtet werden (Weller et al. 2014). Aufgrund der Tatsache, 
dass jedoch definitiv eine Reaktion auf DTT stattfindet, kann HyPer nicht als spezifisch für Reaktionen auf $\mathrm{H}_{2} \mathrm{O}_{2}$ bezeichnet werden (Lukyanov und Belousov 2013). Zudem scheint HyPer unter Ruhebedingungen im Zytosol bereits weitestgehend reduziert zu sein, was einen weiteren Reduktionsprozess erschwert (Weller et al. 2014).

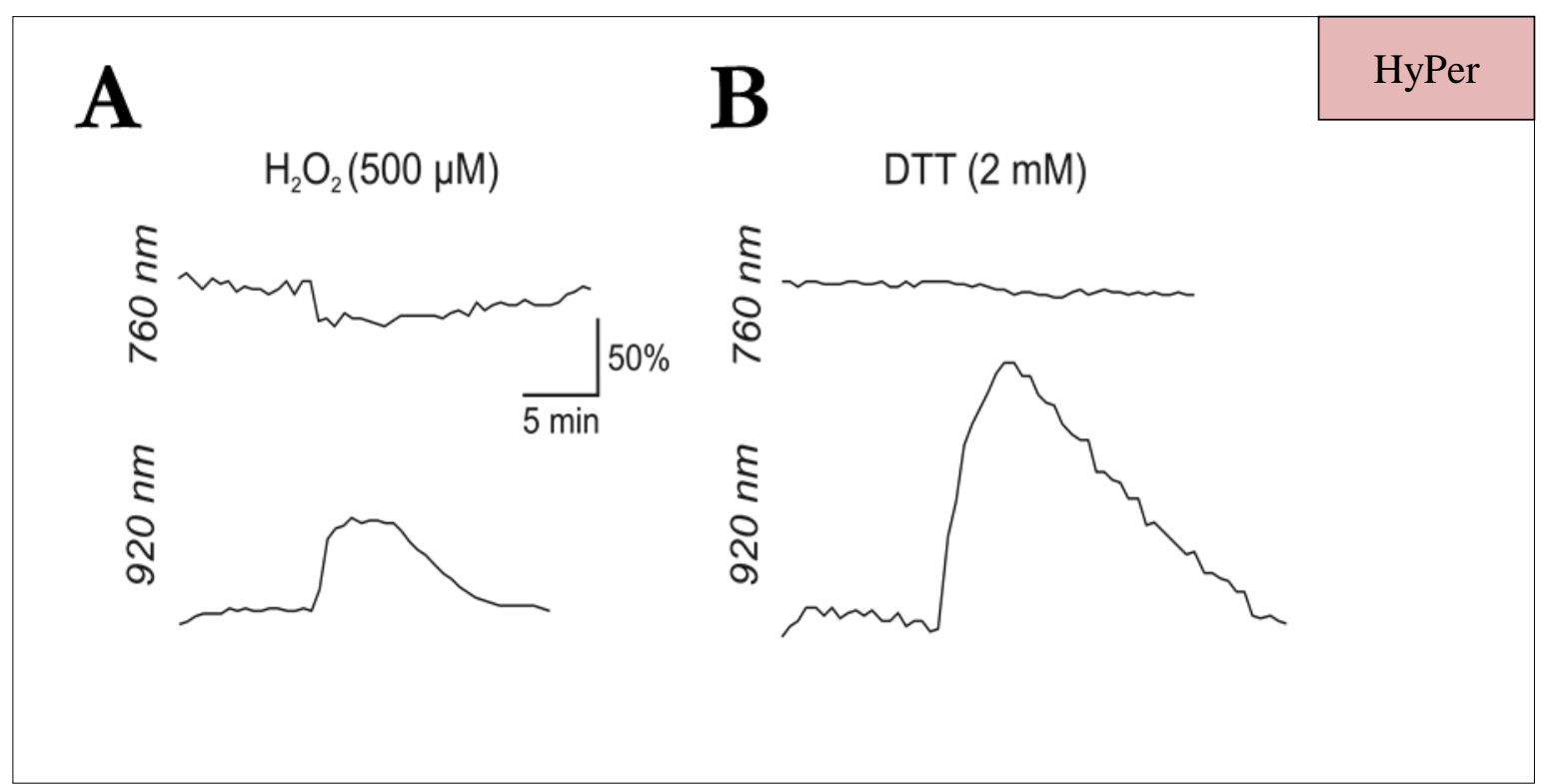

Abbildung 21: Dynamische Messungen der Redoxbalance von HyPer. Darstellung der Reaktion der Fluoreszenzintensität unter Einwirkung von $\mathrm{H}_{2} \mathrm{O}_{2}$ und DTT in Abhängigkeit von verschiedenen Wellenlängen und der Zeit (Weller et al. 2014, Abb. 8 C, mit freundlicher Genehmigung von Elsevier).

\subsection{Darstellung ratiometrischer Bildserien}

Dieser Versuchsabschnitt beinhaltet ein Konzept aus drei ratiometrischen Bildpaaren. Dies hat zum Vorteil, dass die Zielzelle nicht wie zuvor mit der Aufnahme von 50 bis 60 Bildern belastet wird, sondern lediglich mit einem Zehntel davon. Die zuvor festgelegten ratiometrischen Anregungswellenlängen werden hier beibehalten, somit sind für die mit HyPer transfizierten Zellen $760 \mathrm{~nm}$ und $920 \mathrm{~nm}$ und für die mit roGFP1 $740 \mathrm{~nm}$ und $910 \mathrm{~nm}$ festgelegt.

Vergleichend gegenübergestellt werden demnach 3 Bildpaare. Diese insgesamt 6 Bilder zeigen die Messergebnisse für die beiden ausgewählten Wellenlängen unter Kontrollbedingungen durch ACSF jeweils nach einer nacheinander folgenden fünfminütigen Einwirkzeit der beiden Substanzen DTT $(2 \mathrm{mM})$ sowie $\mathrm{H}_{2} \mathrm{O}_{2}(500 \mu \mathrm{M})$. Zusätzlich wird aus diesen Ergebnissen schließlich das ratiometrische Verhältnis der Fluoreszenzintensitäten gebildet, indem für HyPer die Aufnahmen der längeren Wellenlängen durch diejenigen der 
kürzeren $\left(\mathrm{F}_{920} / \mathrm{F}_{760}\right)$ und für roGFP1 die kürzeren durch die längeren Wellenlängen $\left(\mathrm{F}_{740} / \mathrm{F}_{910}\right)$ dividiert werden (Abbildung 20).

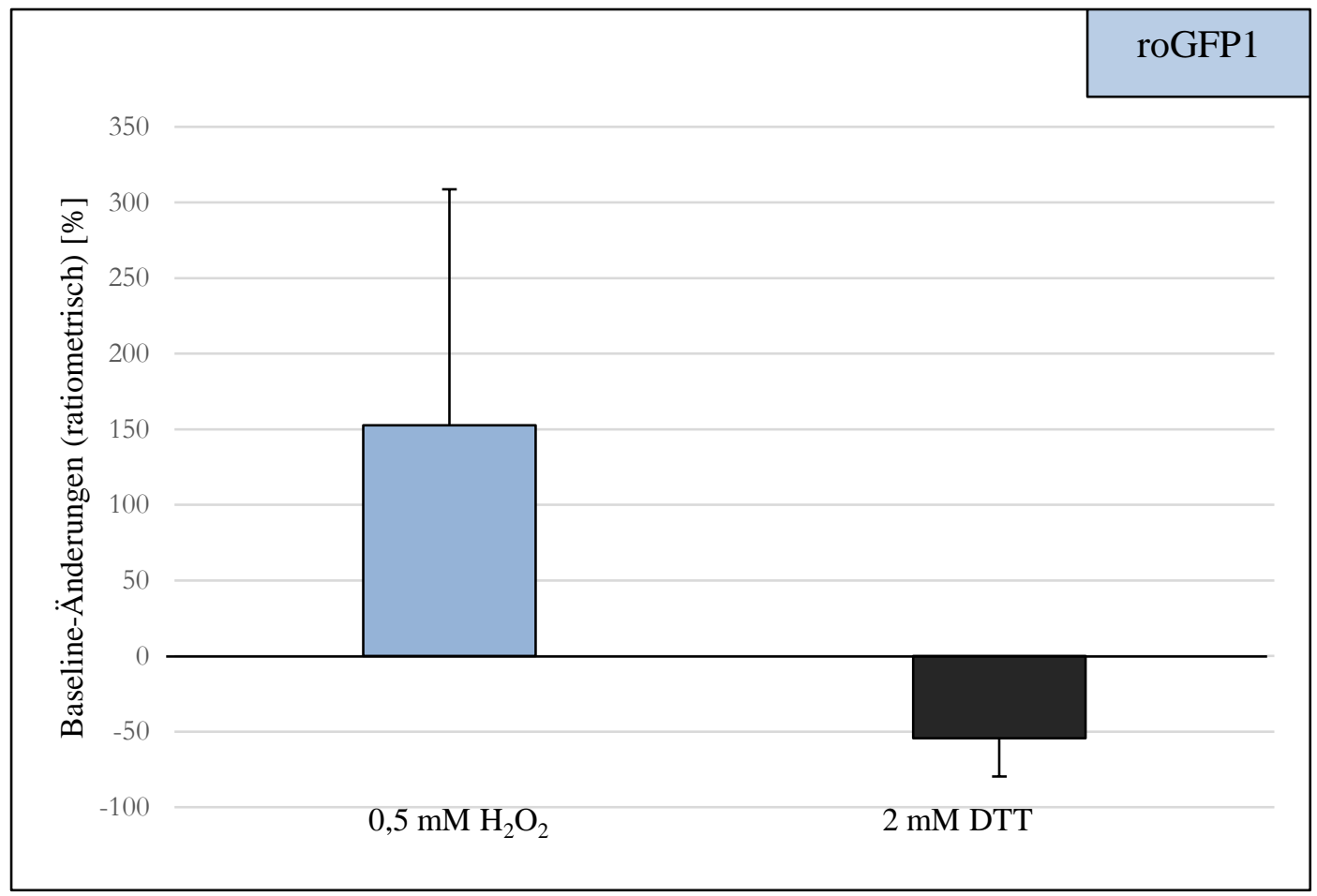

Abbildung 22: Ratiometrische Bildserie (F740/F910) mit roGFP1. Die Baseline bei $0 \%$ zeigt den Referenzwert bei der Messung mit neutralem ACSF (modifiziert nach Wagener et al. 2016, Abb. 10 C, mit freundlicher Genehmigung von Mary Ann Liebert).

In Abbildung 22 wird in Bezug auf den Redoxindikator roGFP1 deutlich, dass bei ratiometrischen Messungen die Intensität unter Einwirkung des Oxidationsmittels $\mathrm{H}_{2} \mathrm{O}_{2}$ $(500 \mu \mathrm{M}, 5 \mathrm{~min})$ um 152,6 $\pm 156,1 \%(\mathrm{n}=7)$ im Vergleich zu der Kontrollmessung mit ACSF ansteigt. Da nur die entsprechenden Fluoreszenzänderungen aufgetragen sind, wird hier das Kontrollniveau als Basislinie bei 0\% dargestellt. Im Gegensatz dazu zeigt sich die Intensität unter Einfluss des Reduktionsmittels DTT (2 mM, 5min) um 54,4 $\pm 25,3 \%$ $(n=13)$ als signifikant abgeschwächt. Die in der Theorie diskutierten Ergebnisse zeigen sich demnach hier als bestätigt (Abbildung 20). 

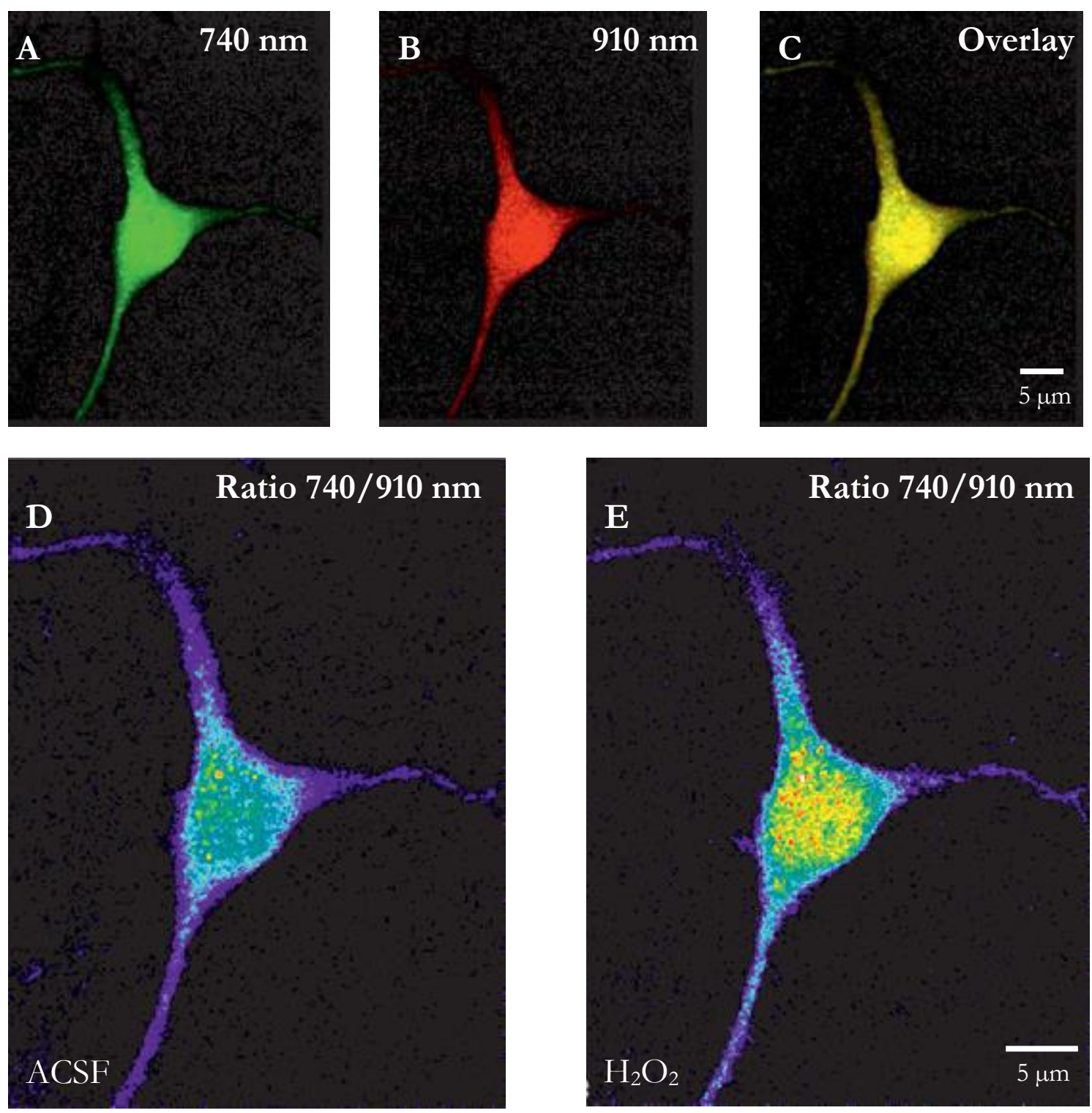

\section{reduziert}

\section{Oxidiert}

Abbildung 23: Ratiometrische Zwei-Photonen Messungen mit roGFP1. Verrechnung der Fluoreszenzänderungen von Bildpaaren mit verschiedenen Wellenlängen (740 nm und $910 \mathrm{~nm})$ unter Neutralbedingungen (ACSF) und nach Oxidation $\left(\mathrm{H}_{2} \mathrm{O}_{2}, 500 \mu \mathrm{M}\right.$ ), farblich veranschaulicht (Wagener et al. 2016, Abb. 10 B, mit freundlicher Genehmigung von Mary Ann Liebert).

In Abbildung 23 stellen die Bilder A, B und C eine mit dem Redoxindikator roGFP1 transfizierte Zelle dar, die mit einer Wellenlänge von $740 \mathrm{~nm}$, sowie $910 \mathrm{~nm}$ angeregt wurde. Zur besseren Unterscheidung ist die 740 nm Fluoreszenz grün und die 910 nm Fluoreszenz rot dargstellt. Bild $\mathrm{C}$ zeigt eine Überlagerung (Overlay) der beiden beschriebenen Abbildungen A und B (gelb). Diese beiden Abbildungen A und B wurden übereinandergelegt, um eine komplette Übereinstimmung der Zellposition zu veranschaulichen. Die zweite Bildreihe (Bild D und E) stellt dieselbe Zelle als aus den beiden Einzelbildern berechnete 
Verhältnisaufnahme dar (ratio 740/910 nm). Dabei zeigt Bild D zeigt die Zelle unter Einfluss von neutralem ACSF. Es imponieren hier hauptsächlich bläuliche Farbtöne: Die Zelle befindet sich demnach in einem relativ reduzierten Zustand. Die Verhältnisaufnahme E stellt die Zelle unter Einwirkung von $\mathrm{H}_{2} \mathrm{O}_{2}(500 \mu \mathrm{M}, 5 \mathrm{~min})$ dar. Es ist deutlich zu erkennen, dass der Zellkörper sich im gelb-orangenen Bereich befindet und somit ein deutlich oxidierterer Zustand vorliegt. Somit bestätigt sich, dass der Redoxindikator roGFP1 eine Oxidation durch $\mathrm{H}_{2} \mathrm{O}_{2}$ zuverlässig darstellt.

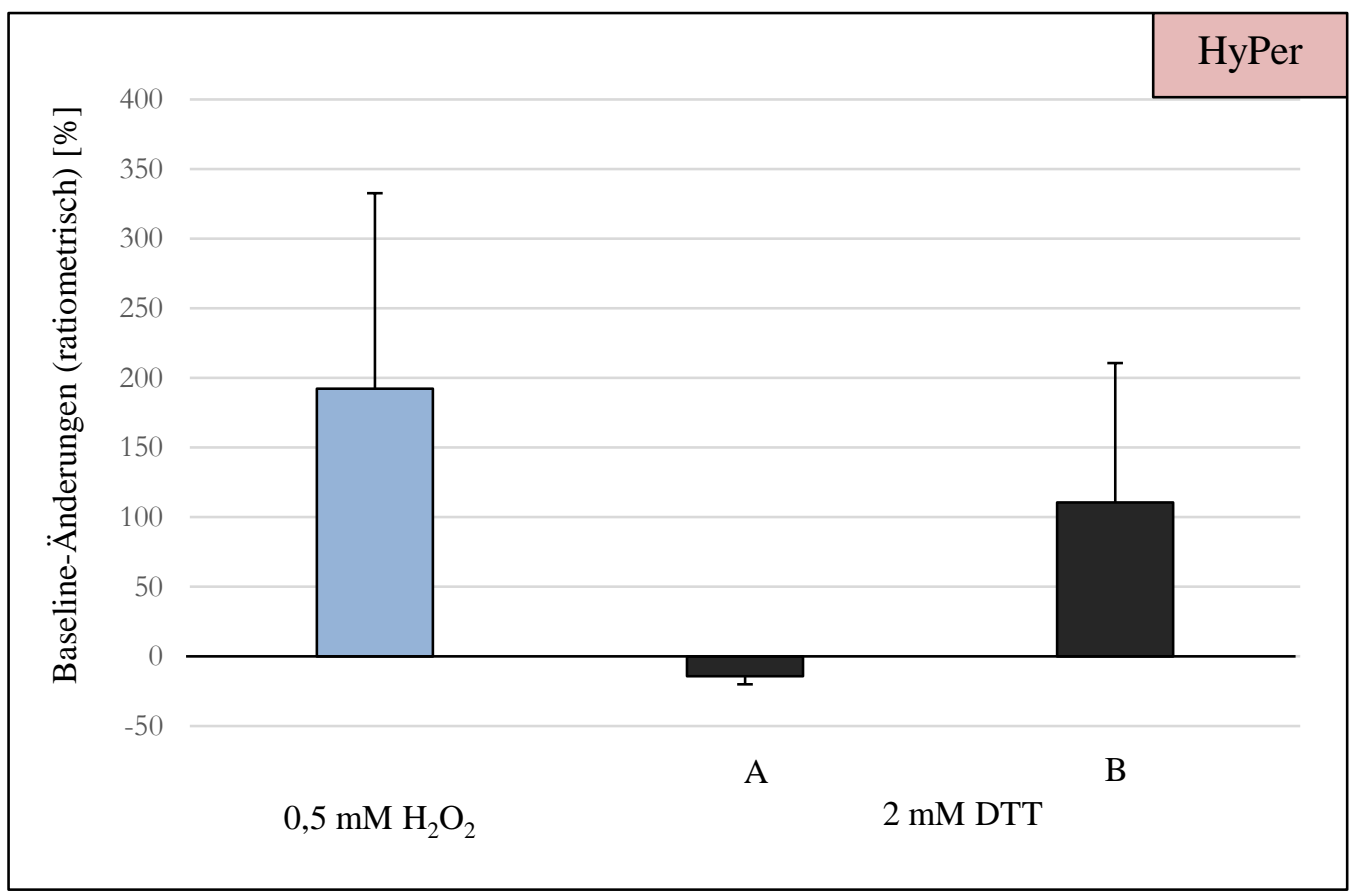

Abbildung 24: Ratiometrische Bildpaare (F920/F760) mit HyPer. Die Baseline bei $0 \%$ zeigt die Referenzwerte für Messungen mit ACSF (modifiziert nach Weller et al. 2014, Abb. 8 E, mit freundlicher Genehmigung von Elsevier).

In Abbildung 24 werden die ratiometrischen Verhältnisse $\left(\mathrm{F}_{920} / \mathrm{F}_{760}\right)$ des Indikators HyPer veranschaulicht. Die gemessene Intensität steigt unter $\mathrm{H}_{2} \mathrm{O}_{2}(500 \mu \mathrm{M}, 5 \mathrm{~min})$ signifikant um 192,3 \pm 140,4 \% ( $n=12)$ im Vergleich zu der Kontrollmessung mit ACSF an. Unter Einfluss des Reduktionsmittels DTT ( $2 \mathrm{mM}, 5 \mathrm{~min})$ zeigen sich ambivalente, divergierende Werte: Einige Zellen reagieren mit einem Abfall der Intensität (A) um 14,2 \pm 5,8 \% ( $n=3)$, andere (B) scheinen die Reaktion, wie sie unter $\mathrm{H}_{2} \mathrm{O}_{2}$ auftritt, zu imitieren und zeigen eine Steigerung der Intensität um 110,6 $\pm 100,1 \%(n=11)$. Dies stellt kein einheitlich zu deutendes Ergebnis für DTT dar und beweist, dass zuverlässige Messungen von mit HyPer transfizierten Zellen unter Einfluss von DTT nur bedingt praktikabel sind. 


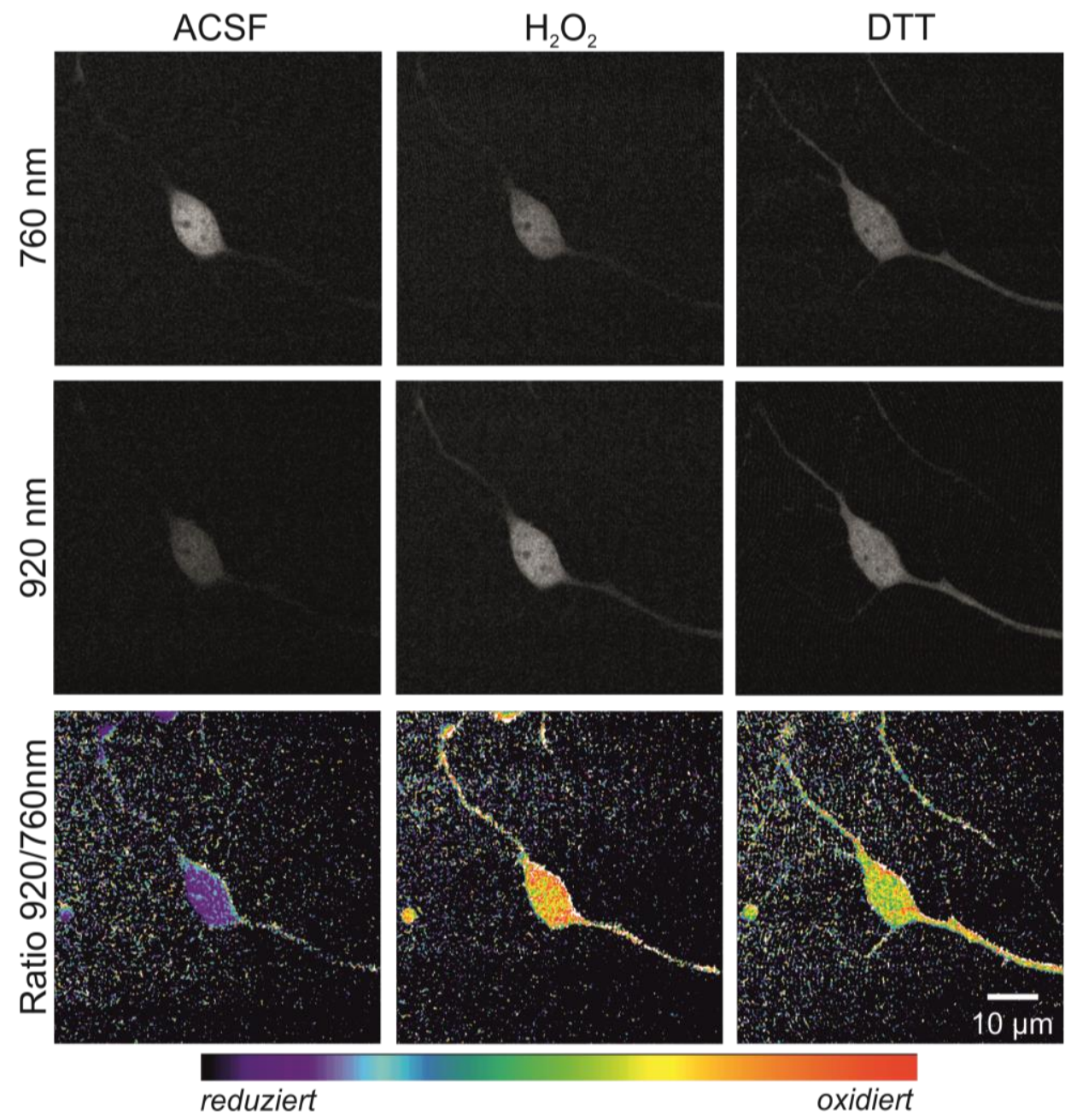

Abbildung 25: Ratiometrische Zwei-Photonen Messungen mit HyPer. Verrechnung der Fluoreszenzänderungen von Bildpaaren mit verschiedenen Wellenlängen $(760 \mathrm{~nm}$ und $920 \mathrm{~nm}$ ) nach Oxidation $\left(\mathrm{H}_{2} \mathrm{O}_{2}, 500 \mu \mathrm{M}\right)$ und Reduktion (DTT, $2 \mathrm{mM}$ ), farblich veranschaulicht (Weller et al. 2014, Abb. 8 D, mit freundlicher Genehmigung von Elsevier).

In Abbildung 25 ist farblich dargestellt, inwiefern sich die mit HyPer transfizierte Zelle hinsichtlich der Oxidation und Reduktion unter Einfluss von $\mathrm{H}_{2} \mathrm{O}_{2}$ sowie DTT verändert. Es zeigt sich unter neutralem ACSF bereits ein sehr reduzierter Zustand (violette Farbe). Das Verhältnis (Ratio) der beiden Wellenlängen unter Anwesenheit von $\mathrm{H}_{2} \mathrm{O}_{2}$ entspricht einem Zustand, der sich deutlich im oxidierten Bereich befindet (gelb/orangene Farbe). Auch unter Anwesenheit von DTT befindet sich die Zelle im oxidierten Bereich (grün/gelbe Farbe), jedoch ist sie hier weniger stark oxidiert, als unter $\mathrm{H}_{2} \mathrm{O}_{2}$. Insgesamt widerspricht dieses Ergebnis jedoch der Erwartung, dass DTT ausschließlich zu einer reduzierenden Antwort dieses Redoxindikators führt und zeigt zudem, dass HyPer auch auf andere Substanzen, außer $\mathrm{H}_{2} \mathrm{O}_{2}$, sensitiv reagiert (Abbildung 20). 


\subsection{Messungen der Fluoreszenzlebenszeit}

Prinzipiell existieren zwei Vorgehensweisen, mit denen eine Fluoreszenzlebenszeit ausgewertet werden kann: Dies ist zum einen die Frequenz-Domäne (frequency domain) und zum anderen die Zeit-Domäne (time domain). In meinen Auswertungen habe ich mich ausschließlich auf die Zeit-Domäne, die zeitkorrelierte Ein-Photonen-Zählung (TCSPC), beschränkt. Hierbei wird die Probe mit vielen kurzen Laserimpulsen angeregt. Gemessen wird schließlich die Zeit, beginnend mit dem Aussenden des Laserimpulses bis zur Emission und Detektion des ersten Photons (Chen et al. 2013).

Das Ziel dieser Versuchsreihe ist es, die Fluoreszenzlebenszeit $\mathrm{G}$ zu bestimmen (siehe „Material und Methoden“). Ratiometrische Analysen werden oft limitiert durch ein Bleichen (Bleaching) des Fluorophors. Mit dem Prinzip des TCSPC können quantitative Messungen durchgeführt werden, wobei zwar ebenfalls ein Photobleaching auftritt, dieses das Ergebnis jedoch nicht beeinflusst. Bei diesem Messverfahren wird nicht die Intensität, sondern das zeitliche Abklingen der roGFP1- und HyPer-Fluoreszenz analysiert und somit kann das Ergebnis durch Bleaching nicht verfälscht werden (Wilms et al. 2006). HyPer wurde in diesen Messreihen mit einer Wellenlänge von 840 nm angeregt, roGFP1 mit 890 nm. Diese ausgewählten Wellenlängen zeigten in den zuvor gemessenen Exzitationsspektren deutlich hohe Intensitäten. Gemittelt wurden 10 bis 20 Scans pro Linie, um eine ausreichende Anzahl von Photonen pro Pixel zu detektieren. Die instrument response function (IRF) wird aus dem Hintergrundsignal neben der abgebildeten Zelle herausgefiltert. Zusätzlich wird sie auch aus der Second Harmonic Generation (SHG) Emission von Harnstoff-Mikrokristallen bestimmt. 


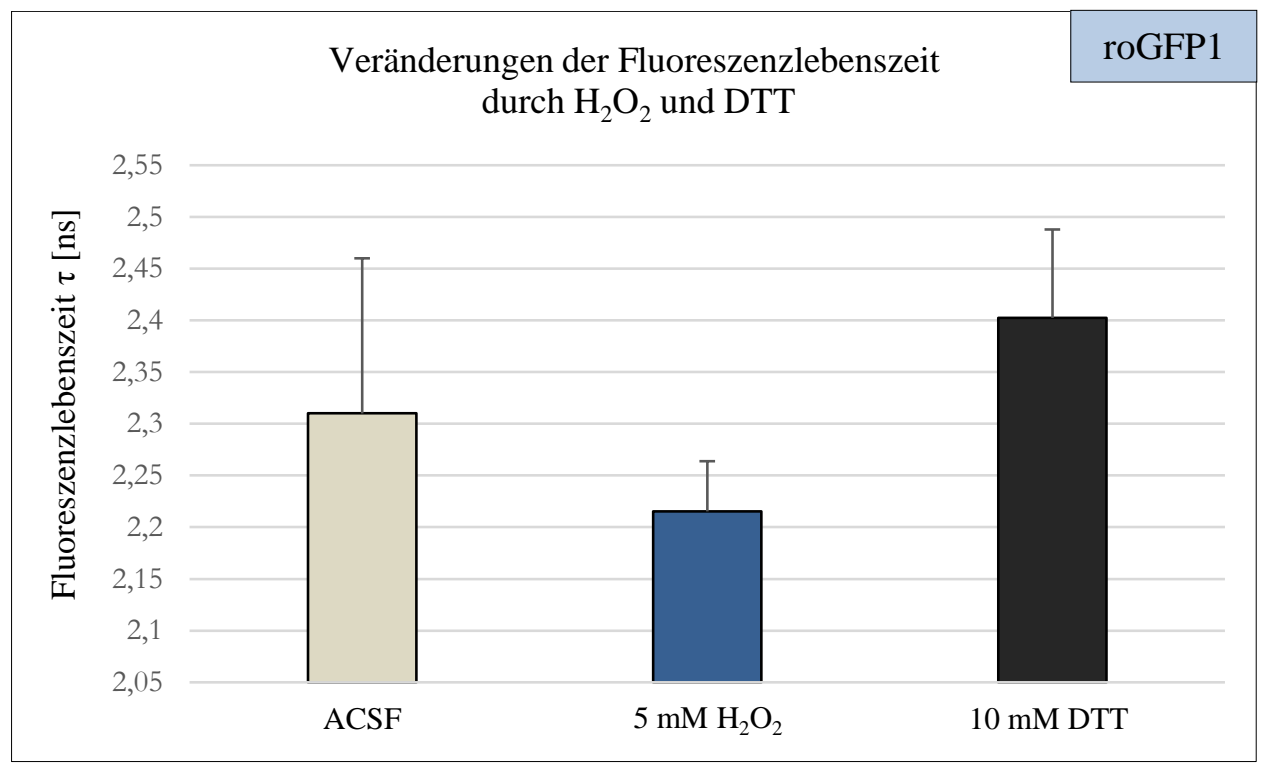

Abbildung 26: Redoxsensitivität der Fluoreszenzlebenszeit von roGFP1. Darstellung der Veränderungen durch $\mathrm{H}_{2} \mathrm{O}_{2}$ ( $5 \mathrm{mM}, 5$ Minuten), sowie durch DTT ( $2 \mathrm{mM}, 5$ Minuten) (modifiziert nach Wagener et al. 2016, Abb. 9B, mit freundlicher Genehmigung von Mary Ann Liebert).

Die durchschnittliche Fluoreszenzlebenszeit von roGFP1 wird mit einer Exzitationswellenlänge von $890 \mathrm{~nm}$ und einer Anzahl von 25 bis 30 Linien gemessen. Unter Kontrollbedingungen beträgt $\mathrm{G}=2,31 \pm 0,15 \mathrm{~ns}(\mathrm{n}=15)$ (Abbildung 26). Eine Oxidation durch $\mathrm{H}_{2} \mathrm{O}_{2}(5$ $\mathrm{mM}, 5 \mathrm{~min})$ verkürzt die Fluoreszenzlebenszeit nur geringfügig um 4,1 $\pm 2,1 \%(\mathrm{n}=8)$, eine Reduktion durch DTT (10 mM, 5min) verlängert die Lebenszeit um lediglich 4,0 \pm 3,7 \% $(n=6)$ in Bezug auf den Ausgangswert.

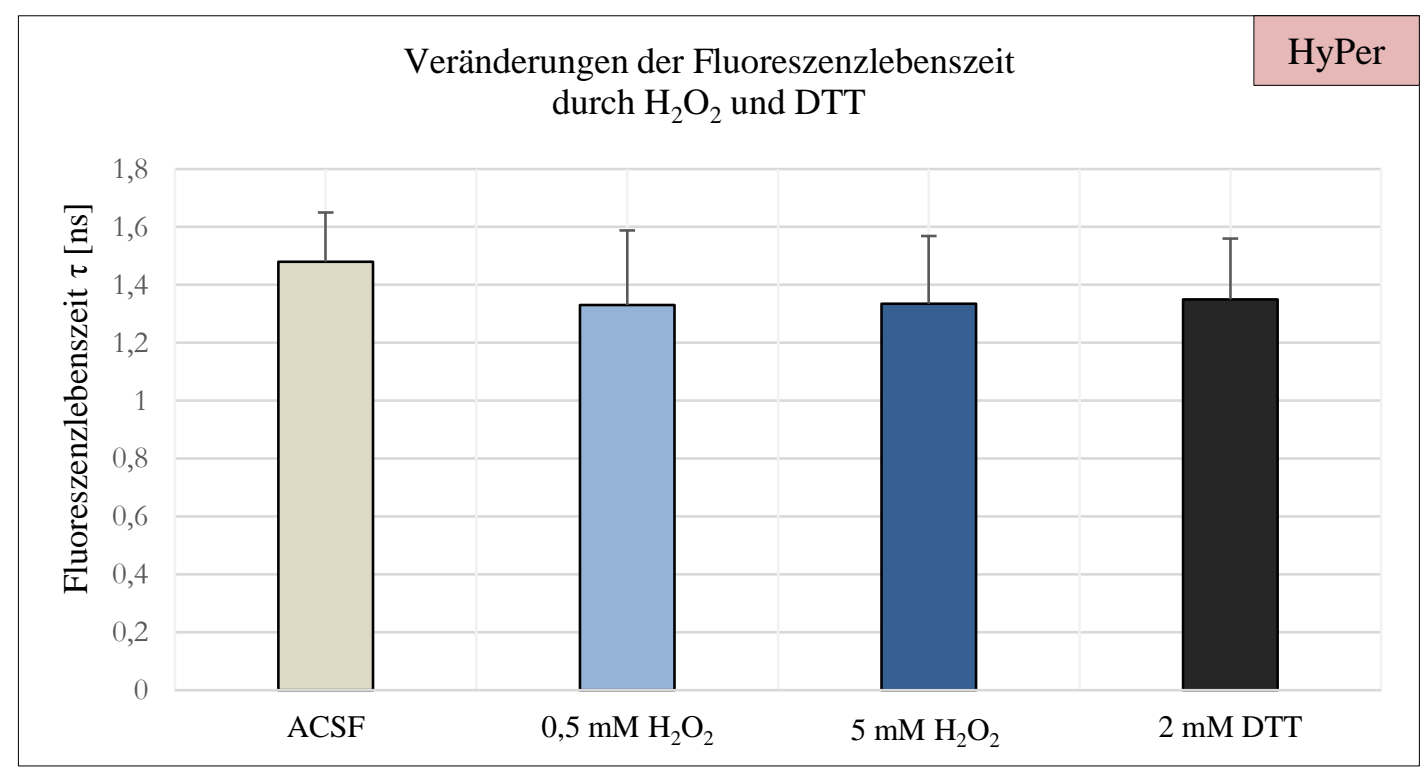

Abbildung 27: Redoxmodulation der Fluoreszenzlebenszeit von HyPer. Darstellung der Einwirkungen von $\mathrm{H}_{2} \mathrm{O}_{2}(0,5 \mathrm{mM}$ und $5 \mathrm{mM}$, 5 Minuten), sowie DTT ( $2 \mathrm{mM}, 5$ Minuten) auf die Zelle (modifiziert nach Weller et al. 2014, Abb. 9C, mit freundlicher Genehmigung von Elsevier). 
Ähnlich geringe Änderungen der Fluoreszenzlebenszeiten zeigten sich auch bei HyPer. Die einfach monoexponential gefittete Fluoreszenzlebenszeit von HyPer betrug $\mathrm{T}=1,48 \pm$ $0.17 \mathrm{~ns}(\mathrm{n}=28)$ für die Kontrollmessung unter ACSF (Abbildung 27). Unter Einfluss von $\mathrm{H}_{2} \mathrm{O}_{2}(500 \mu \mathrm{M}, 5$ min) wird diese Lebenszeit um 10,1 \pm 7,3 \% (n=7) deutlich verkürzt. Eine höhere Konzentration von $\mathrm{H}_{2} \mathrm{O}_{2}$ (5 mM, 5 Minuten) erzielt ähnliche, aber keine kontrastreicheren Ergebnisse: Eine Verkürzung der Lebenszeit um 9,8 \pm 6,0 \% $(n=7)$ ist das Resultat. Unter Anwendung des Reduktionsmittels DTT können keine aussagekräftigen Veränderungen der Fluoreszenzlebenszeiten bestimmt werden. Vielmehr wird die Reaktion, wie sie unter $\mathrm{H}_{2} \mathrm{O}_{2}$ auftritt, imitiert. Es zeigt sich hier ebenfalls eine verkürzte Fluoreszenzlebenszeit um $8,8 \pm 5,4 \%(n=8)$. Erwartet wurde hier aber eine verlängerte Lebenszeit, ähnlich, wie sie auch bei dem Protein roGFP1 auftritt. Diese Theorie wurde jedoch nicht bestätigt. 


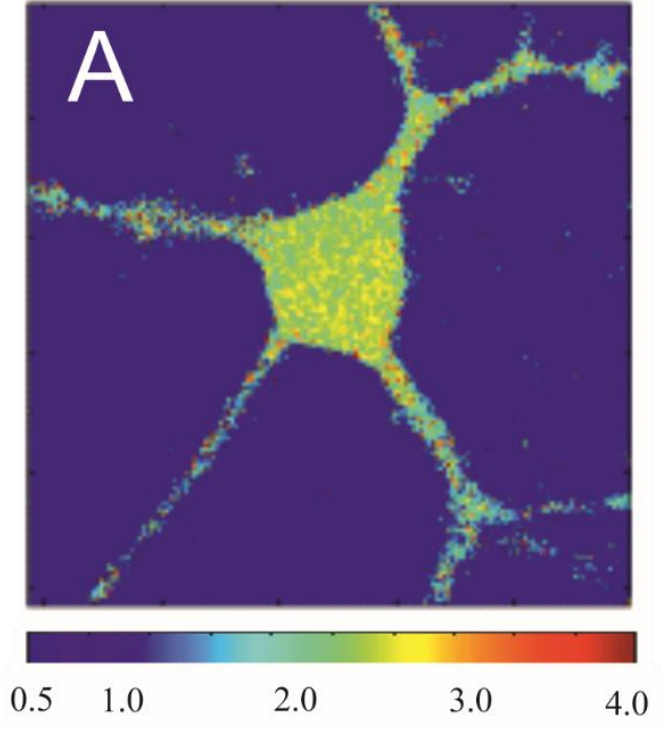

Fluoreszenzlebenszeit [ns]

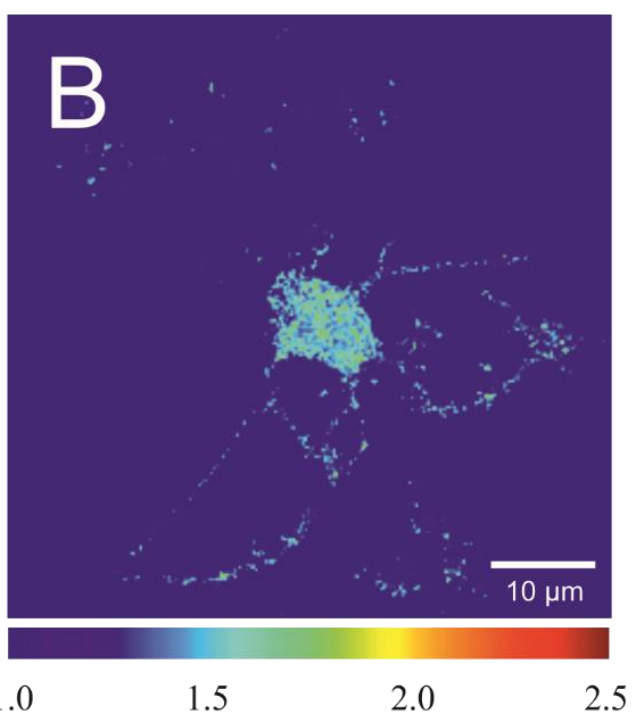

Fluoreszenzlebenszeit [ns]
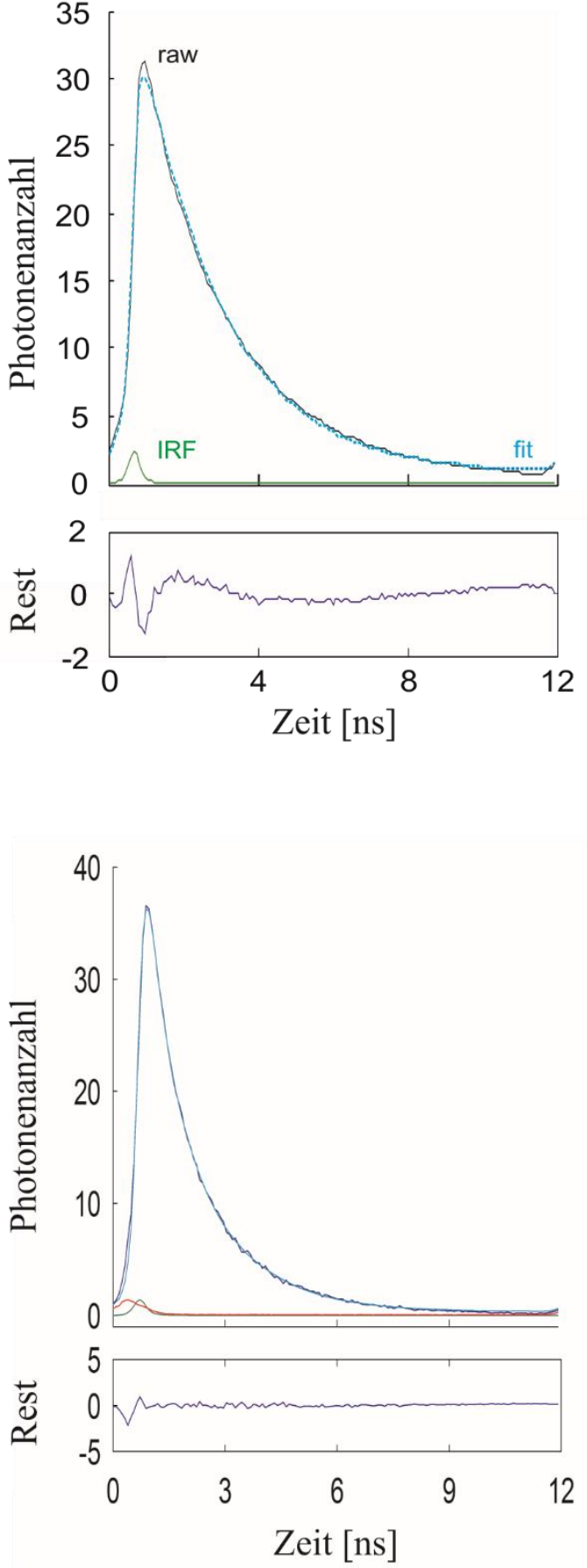

Abbildung 28: Messungen mit FLIM in der Zwei-Photonen-Mikroskopie. (A) Lebenszeit der Fluoreszenz einer roGFP1-exprimierenden Zelle. (B) Lebenszeit der Fluoreszenz einer HyPerexprimierenden Zelle. Die Graphen neben den beiden Abbildungen zeigen das Abklingen der Fluoreszenz in Abhängigkeit von der Zeit an. Der schmalere, untere Graph zeigt den Rest an, der beim bestmöglichen deutlicheren Fit nicht berücksichtigt wurde (je $<2$ Photonen) (modifiziert nach Wagener et al. 2016, Abb. 9 A, mit freundlicher Genehmigung von Mary Ann Liebert; Weller et al. 2014, Abb. 9 A, mit freundlicher Genehmigung von Elsevier).

In den Abbildungen 28 A und B wurde die Fluoreszenzlebenszeiten der beiden Redoxindikatoren HyPer und roGFP1 mithilfe des FLIM-Systems sowohl farblich als auch in Form eines dazugehörigen Graphen dargestellt. Der Graph neben den jeweiligen Abbildungen 
zeigt die Anzahl der Photonen in Bezug zu der Zeit an. Hier wurden 35 bis 40 Messungen von jeweils 12 ns durchgeführt. Auf der Y-Achse wird die Anzahl der detektierten Photonen aufgetragen. Das errechnete Tau T entspricht der Lebensdauer der jeweiligen Fluoreszenz in Nanosekunden. Die sich ergebende Abklingkurve wird durch einen typischen exponentiellen Abfall charakterisiert. Die farbigen Abbildungen verdeutlichen die etwas kürzere Fluoreszenzlebenszeit von HyPer im Vergleich zu der Lebenszeit einer roGFP1exprimierenden Zelle. Gemessen wurden die Lebenszeiten mithilfe einer region of interest (ROI), welche im Bereich des Zellsomas der jeweiligen Zelle lokalisiert wird.

Die Oxidation durch $\mathrm{H}_{2} \mathrm{O}_{2}(500 \mu \mathrm{M}, 5 \mathrm{mM}, 5$ Minuten) und die Reduktion durch DTT ( $2 \mathrm{mM}, 10 \mathrm{mM}, 5$ Minuten), beeinflussen unabhängig von der Konzentration des Fluorophors, der Intensität und einem Photobleaching die Lebenszeit der Fluoreszenz. 


\section{Diskussion}

Die Ursprünge der Erforschung fluoreszierender Proteine reichen nun schon über 50 Jahre zurück. Damals, 1962, entdeckten der Wissenschaftler Shimomura und seine Kollegen eher beiläufig das grün fluoreszierende Protein (GFP) bei Experimenten mit einer Qualle der Gattung Aquoria victoria (Shimomura et al. 1962). Anschließend gerieten die Forschungen in Bezug auf das GFP für beinahe 30 Jahre in den Hintergrund, bevor der Wissenschaftler Prasher im Jahre 1992 das Potential dieses Proteins entdeckte. Zu diesem Zeitpunkt war das GFP das einzig bekannte genetisch vollständig entschlüsselte fluoreszierende Protein (Prasher et al. 1992). In vielen bisherigen Publikationen wurden oft synthetisch hergestellte Färbstoffe angewandt.

Die Ergebnisse meiner Dissertation stellen Eigenschaften und Anwendungsmöglichkeiten der Redox-Indikatoren roGFP1 und HyPer dar, die nach einem langen Forschungszeitraum aus dem grün fluoreszierenden Protein entwickelt und modifiziert wurden (Hanson et al. 2004; Lukyanov und Belousov 2013). Die jeweilige Verteilung der beiden Proteine innerhalb einer Zelle stellte sich als sehr interessant heraus: Der Redoxindikator roGFP1 verteilte sich homogen sowohl im Zellsoma, den Axonen und Dendriten, als auch im Zellkern. HyPer hingegen ist ein großes Molekül (74 kDa) (Miyawaki et al. 1997) und verteilt sich überwiegend im Zellsoma, da es die den Nukleus umgebende Barriere kaum durchdringen kann (Abbildung 16B und C). Zur deutlicheren Darstellung des Zellkerns wurde die Nukleinsäurefärbung mit DAPI angewandt, die ausschließlich den Zellkern blau anfärbt (Abbildung 16C) (Kapuscinski 1995; Biancardi et al. 2013).

Die Darstellung der Exzitationsspektren der beiden Redoxsensoren HyPer und roGFP1 in der Zwei-Photonen-Mikroskopie erwies sich als eindrücklich: Die Fluoreszenzproteine schienen zwar in der konventionellen Ein-Photonen-Anregung klar definierte Absorptionsmaxima zu zeigen (Lukyanov und Belousov 2013; Weller et al. 2014), jedoch war dies bei der Zwei-Photonen-Anregung nicht der Fall (Abbildung 18 und 19). Die Anregungswellenlängen wurden im Bereich von $700 \mathrm{~nm}$ bis $1025 \mathrm{~nm}$ variiert und ergaben ein recht breites Anregungsspektrum. Das ursprüngliche Ziel dieser Versuchsreihe war es, für die Zwei-Photonen-Mikroskopie geeignete ratiometrische Exzitationswellenlängen herauszufiltern. Wären deutlich abgrenzbare Maxima aus der Versuchsreihe hervorgegangen, könnten nachfolgende Versuche mit gerade diesen Wellenlängen durchgeführt werden. Festzu- 
halten ist jedoch, dass sowohl für HyPer als auch für roGFP1 nur eine sehr geringe Emission für die Anregungswellenlängen erzielt werden konnten, die im oberen sowie im unteren Grenzbereich, also bei $700 \mathrm{~nm}$ und $1025 \mathrm{~nm}$, liegen. Dazwischen zeigte sich aber ein breites Exzitationsspektrum mit deutlicher Emission der Fluoreszenz in Bezug auf beinahe jede Wellenlänge. Vergleichbare systematische Studien in Bezug auf die Redoxindikatoren HyPer und roGFP1 wurden für die Zwei-Photonen-Mikroskopie bisher nicht durchgeführt.

Dynamische Messungen der Redoxbalance zeigten, mit welcher Geschwindigkeit und mit welcher Intensität die beiden Redoxindikatoren HyPer und roGFP1 sowohl auf Oxidation durch $\mathrm{H}_{2} \mathrm{O}_{2}$ als auch auf Reduktion durch DTT reagierten und in welchem Ausmaß diese Redox-Antworten reversibel waren. Zuvor wurden zwei ratiometrische Anregungswellenlängen festgelegt, die der ungefähren verdoppelten Wellenlängen der Exzitationsmaxima der Ein-Photonen-Anregung entsprechen (Lukyanov und Belousov 2013). Mit dem Protein HyPer ließen sich deutliche Ergebnisse bei Oxidation erzielen (Abbildung 21A): Die Kurve zeigte unter Einfluss von $\mathrm{H}_{2} \mathrm{O}_{2}$ bei $760 \mathrm{~nm}$ einen deutlichen Abfall und beim Auswaschen eine vollständige Reversibilität mit Erreichen des Ausgangsniveaus. Bei 920 nm war wie erwartet ein Anstieg der Fluoreszenzintensität zu verzeichnen. HyPer zeigte jedoch unter Einfluss von DTT bei einer Anregungswellenlänge von $760 \mathrm{~nm}$ keine Reaktion. Bei $920 \mathrm{~nm}$ stieg die Emission entgegen der theoretischen Erwartung ebenfalls an. DTT scheint hier also trotz seiner Wirkung als Reduktionsmittel nicht die entgegengesetzte Reaktion (Oxidation) zur erzielen. Bereits in der Ein-Photonen-Anregung zeigten sich ähnliche Ergebnisse in Bezug auf HyPer und DTT (Weller et al. 2014), sodass ein sinnvoller Einsatz des Proteins HyPer zur Erfassung reduzierender Änderungen fraglich erscheint. Im Gegensatz dazu schien der Redoxindikator roGFP1 zumindest bei einer Wellenlänge von $910 \mathrm{~nm}$, wie theoretisch erwartet, auf DTT zu reagieren: Die Fluoreszenzintensität stieg deutlich an. Bei gleicher Wellenlänge und unter Einfluss von $\mathrm{H}_{2} \mathrm{O}_{2}$ nahm die Intensität wie erwartet ab. Offenbar wurde mit der kürzer ausgewählten Wellenlänge von $740 \mathrm{~nm}$ jedoch der isosbestische Punkt getroffen, denn roGFP1 reagierte, angeregt durch diese Wellenlänge, weder auf $\mathrm{H}_{2} \mathrm{O}_{2}$ noch auf DTT. Es zeigten sich keine Veränderungen des Ausgangniveaus. Um diesen isosbestischen Punkt zu umgehen, müsste eine Wellenlänge gewählt werden, die sich unter $740 \mathrm{~nm}$ befindet. Da jedoch der Justierbereich des NiR Lasers erst bei $700 \mathrm{~nm}$ beginnt und in diesem Bereich beinahe keine nennenswerte Emission mehr entsteht, sind diese kürzeren Wellenlängen nicht praktikabel (siehe Abbildung 7). Zusätz- 
lich besteht für die kurzen Wellenlängen die Gefahr eines starken Bleichens der Fluoreszenz.

Da das Photobleaching während meiner Versuchsreihen generell ein erhebliches Problem darstellte, wurde versucht, mit gezielten ratiometrischen Bildpaaren die Belastung der Zellen durch den Laserstrahl zu verringern. Die Anzahl der Bilder konnte hier beinahe auf ein Zehntel reduziert werden. Die ratiometrischen Bilder für den Redoxindikator HyPer unter Einfluss des Oxidationsmittels $\mathrm{H}_{2} \mathrm{O}_{2}$ und des Reduktionsmittels DTT zeigten ähnliche Ergebnisse, wie sie schon in den vorherigen Versuchsreihen erhalten wurden: HyPer reagierte zuverlässig auf Oxidation mit einer gesteigerten Intensität des Ratios. Der Großteil der durch DTT beeinflussten Zellen hingegen zeigte jedoch ebenfalls, anders als theoretisch erwartet, eine Intensitätssteigerung (Abbildung 22 und 23). Nur drei von vierzehn Zellen wurden durch DTT in ihrer ratiometrischen Intensität herabgesetzt. Auch hier erzeugte die Kombination aus einer mit HyPer transfizierten Zelle, beeinflusst durch DTT keine zuverlässig auswertbaren Ergebnisse (Weller et al. 2014). Ratiometrische Messungen einer mit roGFP1 transfizierten Zelle zeigten wie erwartet, einen Intensitätsanstieg des Fluoreszenzverhältnisses bei Oxidation durch $\mathrm{H}_{2} \mathrm{O}_{2}$ und einen Intensitätsverlust bei Reduktion durch DTT (Abbildung 24 und 25).

Mithilfe des FLIM-Systems (fluorescence lifetime imaging microscopy) ist es möglich, die Fluoreszenzlebenszeit von mit HyPer und roGFP1 transfizierten Zellen zu bestimmen. In der durchgeführten Versuchsreihe zeigte sich für HyPer eine mittlere Lebenszeit der Fluoreszenz von $\mathrm{G}=1,48 \pm 0,17 \mathrm{~ns}(\mathrm{n}=28)$. Die Oxidation durch $\mathrm{H}_{2} \mathrm{O}_{2}(500 \mu \mathrm{M}, 5 \min )$ verkürzte die Lebenszeit der Fluoreszenz um 10,1 \pm 7,3 \% (n=7). Eine höhere Konzentration des Oxidationsmittels erzielte ähnliche Ergebnisse, verkürzte die Fluoreszenzlebenszeit jedoch nicht in größerem Maße (Abbildung 27). Unter reduzierenden Verhältnissen (DTTInkubation) sollte sich theoretisch die Lebenszeit der Fluoreszenz verlängern. Diesbezüglich zeigten Ergebnisse jedoch ebenfalls eine verkürzte Lebenszeit (Abbildung 27). In vorangegangenen Studien mit HeLa-Zellen, einer permanenten Zelllinie, wurde die Fluoreszenzlebenszeit für HyPer und seine Variante HyPer-3 bereits bestimmt. HyPer-3 ist eine Weiterentwicklung des Ausgangsproteins HyPer. Es wird charakterisiert durch eine größere dynamische Spannbreite und signifikant schnellere Reaktionen auf Reduktion und Oxidation (Bilan et al. 2013). Für HyPer ließ sich in dieser Studie eine Lebenszeit der Fluoreszenz von 1,73 $\pm 0,02 \mathrm{~ns}(\mathrm{n}=20)$ und für HyPer-3 eine ähnliche Zeit von 1,77 $\pm 0,05 \mathrm{~ns}$ $(\mathrm{n}=11)$ bestimmen. Diese Lebenszeiten sind also praktisch identisch mit den in meiner 
Versuchsreihe gemessenen Zeiten. Unter Einfluss von $\mathrm{H}_{2} \mathrm{O}_{2}(100 \mu \mathrm{M})$ zeigte sich dort jedoch ebenfalls eine Verkürzung der Lebenszeit des HyPer-3 Fluorophors $(1,44 \pm 0,13$ ns $(\mathrm{n}=20))$ um ca. $20 \%$. Festzuhalten ist hier also, dass für HyPer die Lebenszeit der Fluoreszenz unter Oxidation verkürzt wird, die Intensität jedoch beispielsweise bei ratiometrischen Messungen ansteigt. In Bezug auf HyPer-3 verkürzt sich die Lebenszeit unter Oxidation sogar um $25 \%$ bis $30 \%$ und zeigt damit noch deutlichere Ergebnisse, als HyPer (Bilan et al. 2013). Die Lebenszeit für das native eYFP (enhanced yellow fluorescent protein) ist deutlich länger und liegt bei 2.4 ns (Striker et al. 1999; Esposito et al. 2007). Referenzwerte für die Fluoreszenzlebenszeit von HyPer unter Einfluss von DTT sind bisher nicht publiziert.

Der Redoxindikator roGFP1 ist charakterisiert durch eine mittlere Fluoreszenzlebenszeit von $\mathrm{T}=2,31 \pm 0,15 \mathrm{~ns}(\mathrm{n}=15)$. Sie ist damit deutlich länger, als die von dem zuvor beschriebenen Protein HyPer. Die Fluoreszenzlebenszeit kann hier ebenfalls durch Oxidation mit $\mathrm{H}_{2} \mathrm{O}_{2}$ (5 mM, 5 min) um 4,1 $\pm 2,1 \%$ verkürzt werden, jedoch wird sie, im Gegensatz zu HyPer, durch Reduktion mit DTT (10 mM, $5 \mathrm{~min}$ ) um 4,0 \pm 3,7 \% verlängert. Damit antwortet roGFP1 zuverlässig auf Oxidation und Reduktion. Die resultierenden Änderungen der Lebenszeit sind jedoch sehr gering.

\subsection{Limitationen und methodische Einschränkungen}

Während der Durchführung meiner Versuchsreihen für diese Arbeit bin ich an verschiedenen Stellen an limitierende Punkte gestoßen, die in Bezug auf zukünftige Forschungsreihen verbessert oder umgangen werden können.

\subsubsection{Genetisch kodierte Fluoreszenzproteine und ROS}

Im Rahmen dieser Dissertation habe ich mich mit den beiden genetisch kodierten Fluoreszenzproteinen roGFP1 und HyPer beschäftigt. Sie haben die Eigenschaft, Veränderungen des Redox-Milieus verschiedener Zellsubkompartimente und ihrer Umgebung detektieren zu können (Miyawaki et al. 1997). Das Ziel der Anwendung von redox-sensitiven Fluoreszenzproteinen ist die hohe zeitliche und räumliche Auflösung von Veränderungen der ROS-Konzentration beziehungsweise der Redox-Bedingungen und deren Einfluss auf die Zellfunktion. Ein Großteil aller Proteine innerhalb einer Zelle scheint durch ein verändertes Redox-Milieu beeinflusst zu werden (Wagener et al. 2016; Weerapana et al. 2010). Die momentan zur Verfügung stehenden optischen Techniken, ROS und die dadurch bedingten 
Zellveränderungen zu detektieren, gehören zu dem Gebiet der invasiven Eingriffe, bei denen möglicherweise Ergebnisse verfälscht und Artefakte erzeugt werden können. Zukünftig soll es möglich werden, klar definierte Redox-Prozesse in einem natürlichen Kontext von lebenden Zellen, Geweben und Organismen zu beobachten, zu vergleichen und quantitativ zu messen. Die Fluoreszenzproben sollten die zellulären Eigenschaften während der Messungen möglichst nicht verändern und zudem für den Nutzer einfach in ihrer Anwendung und ihrem Gebrauch sein. Dieses Vorgehen ist heute noch in einigen Punkten limitiert, jedoch bieten die protein-basierten Redoxindikatoren bereits enorme Vorteile: Sie können gezielt in Subkompartimenten der Zelle exprimiert werden, gewährleisten Probenspezifität und einen hohen Grad an Sensitivität. Zudem sind sie unter physiologischen pHBedingungen stabil. Es besteht außerdem die Möglichkeit zur dynamischen in-vivoBildgebung von Redox-Prozessen (Meyer und Dick 2010). Konventionelle Färbungen, deren Anwendungen heute noch weit verbreitet sind, können die Zelle irreversibel schädigen und anhand von Artefakten die Ergebnisse verfälschen. Sie sind zudem kaum spezifisch einsetzbar und empfindlich für Autooxidation. Die protein-basierten RedoxIndikatoren, roGFP1 und HyPer, sind den konventionellen Farbstoffen in vielen Punkten deutlich überlegen, zumal sie sensibler und vor allem auch reversibel antworten (Østergaard et al. 2001; Østergaard et al. 2004; Dooley et al. 2004).

Das Fluoreszenzprotein roGFP1 zeigt während meiner Versuchsreihen zuverlässige Ergebnisse in Bezug auf oxidierende und reduzierende Verhältnisse und ist somit dem Protein HyPer klar überlegen. Das Fluoreszenzprotein HyPer wurde ursprünglich mit dem Ziel entwickelt, ein spezifisch sensitiver Marker für Änderungen der intrazellulären $\mathrm{H}_{2} \mathrm{O}_{2}$ Konzentration zu sein. Demzufolge sollte HyPer nicht durch andere reaktive Sauerstoffspezies oder durch eine Veränderung des pH-Wertes oder der Ionenkonzentration beeinflusst werden können (Belousov et al. 2006; Meyer und Dick 2010; Malinouski et al. 2011). Diese Theorie kann widerlegt werden, da HyPer auch bei Kontakt mit DTT Veränderungen zeigt. Zwar ist diese Reaktion nicht wie theoretisch erwartet, jedoch wurde die Intensität und auch die Lebenszeit der Fluoreszenz eindeutig von DTT beeinflusst. In bereits zuvor durchgeführten Versuchsreihen zeigte HyPer unter Einfluss von DTT eine Abnahme der Intensität (Malinouski et al. 2011). Verglichen mit meiner Versuchsreihe stellt dies eine gegensätzliche Reaktion dar. Eine mögliche Erklärung dafür wäre, dass HyPer in Zellkulturen des Hippocampus bereits vollständig reduziert vorliegt und somit durch DTT 
nicht mehr weiter reduziert werden kann. Auch die pH-Sensitivität limitiert den Nutzen von HyPer in verschiedenen Situationen (Schwarzländer et al. 2011).

Zukünftig besteht weiterhin das Ziel, genetisch kodierte Fluoreszenzproteine zu entwickeln, die spezifisch auf bestimmte Moleküle reagieren und durch andere Substanzen, die auf die Zelle einwirken, unbeeinflusst bleiben. So könnte der Redox-Status einer Zelle wesentlich detaillierter und im physiologischen Kontext dargestellt werden (Meyer und Dick 2010). Bisherige Versuchsreihen mit HyPer wurden vor allem in Zell-Linien, beispielsweise mit HeLa-Zellen, durchgeführt. Nur wenige Publikationen konzentrieren sich auf die Anwendung von HyPer auf primärkultivierte Zellen des zentralen Nervensystems, wobei hier vor allem der Hippocampus eine Sensitivität für oxidativen Stress zeigt (Belousov et al. 2006; Wagener et al. 2016). HyPer wird zudem als ein sehr sensitives Fluoreszenzmolekül beschrieben, das sogar geringe Konzentrationsänderungen des Oxidationsmittels $\mathrm{H}_{2} \mathrm{O}_{2}$ detektieren kann. Studien zeigen, dass bereits $5 \mu \mathrm{M} \mathrm{H}_{2} \mathrm{O}_{2}$ die entstehende Fluoreszenzintensität ansteigen lässt (Belousov et al. 2006). Dennoch ist die pH-Sensitivität aber problematisch und schränkt die Einsetzbarkeit dieses Redox-Sensors erheblich ein.

Hinsichtlich der subzellulären Expression erwies sich HyPer jedoch als recht zuverlässig. Eine meiner Versuchsreihen zeigt die Anwendung der Nukleinsäurefärbung DAPI in einer mit HyPer transfizierten Zelle. Ohne DAPI zeigt das Zellsoma eine homogene Verteilung des Redoxindikators. Der Zellkern erscheint dunkel, jedoch nicht vollkommen ausgenommen von HyPer. Das Protein ist mit 74 kDa verhältnismäßig groß und kann deshalb die den Zellkern umgebende Barriere kaum durchdringen (Weller et al. 2014).

\subsubsection{Zwei-Photonen-Anregungsspektrum}

Ziel der Versuchsreihe der Anregungsspektren in der Zwei-Photonen-Mikroskopie war es, eine oder mehrere deutlich abgrenzbare Exzitationsmaxima zu detektieren, mit deren Einsatz weitere Versuchsreihen hätten durchgeführt werden können. Das Exzitationsspektrum zeigte sich hier jedoch sowohl für HyPer als auch für roGFP1 zwischen der minimal einstellbaren Wellenlänge von $700 \mathrm{~nm}$ und der maximal einstellbaren Wellenlänge von 1025 $\mathrm{nm}$ als sehr breit. Positiv ist, dass zwischen diesen beiden Wellenlängen eine Spannweite von $325 \mathrm{~nm}$ liegt, von der jede beliebige Exzitationswellenlänge eingestellt werden kann. Diesbezüglich wird in meiner Versuchsreihe jedoch deutlich, dass in einem bestimmten Bereich um die beiden Grenzwerte (700 nm und $1025 \mathrm{~nm}$ ) beinahe keine Emission gemessen wurde (Abbildung 18 und 19). 
Aufgrund der hohen Anzahl der Messungen und der damit verbundenen großen Belastung der Zellen durch den Laser wurde die Anzahl von zwischenzeitlich 27 Aufnahmen, die zur Erfassung der Exzitationsspektren in einem Abstand von 12 bzw.13 nm aufgezeichnet wurden, im Verlauf wieder auf die anfängliche Anzahl von nur 14 Bildern und einem Wellenlängen-Inkrement von $25 \mathrm{~nm}$ reduziert. Neben dem Photobleaching, welches aufgrund dieser hohen Anzahl der Messungen verzeichnet werden konnte, kam es zudem zum Anschwellen sowie einer minimalen Bewegung der Zellen. Der Laserstrahl konnte demnach die Zelle in einem so großen Maße strapazieren, dass sie anschwoll und eine erneute manuelle Fokussierung notwendig war.

\subsubsection{Dynamische Messungen und ratiometrische Bildserien}

Während der Durchführung der dynamischen Messungen der Redoxbalance mit einer Bildrate von ca. 60 Bildern trat das Problem des Photobleachings ebenfalls auf. Auch hier ist die Zelle, wie auch bei den Messungen der Exzitationsspektren, einer hohen Anzahl an Aufnahmen und somit einer großen Belastung durch den Laser ausgesetzt. Besonders in Bezug auf das Fluoreszenzprotein HyPer lässt sich festhalten, dass Zwei-PhotonenExzitationen mit Wellenlängen, die kürzer als $760 \mathrm{~nm}$ waren, ein sehr starkes Photobleaching mit nicht auswertbaren Ergebnissen erzeugten (Weller et al. 2014). Mit der zuvor festgelegten Wellenlänge von $740 \mathrm{~nm}$ für die Messungen mit dem Fluoreszenzprotein roGFP1, wurde jedoch anscheinend der isosbestische Punkt getroffen: Die Zugabe von $\mathrm{H}_{2} \mathrm{O}_{2}$, sowie von DTT zeigte keine Veränderungen der Fluoreszenzintensitäten bei dieser Wellenlänge. Um diesen isosbestischen Punkt zu umgehen, müsste eine Wellenlänge gewählt werden, die sich in dem Exzitationsspektrum noch weiter links, demnach in einem Bereich kürzer als $740 \mathrm{~nm}$ befindet. Hier wird jedoch nur noch wenig Emission erzeugt und zudem tritt ein starkes Photobleaching auf. Aufgrund nachfolgender Messreihen, in denen mit roGFP1 transfizierte Zellen mit $\mathrm{H}_{2} \mathrm{O}_{2}$ und DTT behandelt wurden, wurde deutlich, dass der Redox-Sensor roGFP1, der durch andere Exzitationswellenlängen angeregt wurde, durchaus zuverlässige Antworten auf Oxidation und Reduktion zeigte.

Auch ratiometrische Messungen (F740/910) der mit roGFP1 transfizierten Zellen zeigten zuverlässige Ergebnisse (Abbildung 24). 


\subsubsection{Messungen der Fluoreszenzlebenszeit (FLIM)}

Die Bestimmung der Lebenszeit einer Fluoreszenz mithilfe des FLIM-Systems (fluorescence lifetime imaging microscopy) ist eine Methode, die bereits seit 25 Jahren besteht: Die ersten Ergebnisse zu diesen Versuchsreihen wurden 1992 von dem Biochemiker Joseph Lakowicz publiziert. Die Messungen der Fluoreszenzlebenszeit unterliegen einer großen Flexibilität bezüglich ihrer Anwendung: Neben dem individuellen Wechsel der Laserwellenlängen ist es möglich, auch ohne ratiometrische Anregung Aussagen über den Redox-Status aufgrund der Redox-Modulaton der mittleren Lebenszeiten zu treffen. Das Ziel des FLIM-Systems war ursprünglich, biochemische Reaktionen in lebenden Zellen zu messen, ohne die zelluläre Architektur zu verändern oder zu schädigen (Bastiaens und Squire 1999). Ein ideal zu untersuchender Fluorophor darf weder toxisch noch instabil in verschiedenen pH-Bereichen oder Ionenkonzentrationen sein (Resch-Genger et al. 2008). Das Prinzip des TCSPC „time correlated single photon counting“ wurde im Kapitel „Material und Methoden“ bereits erläutert. An dieser Stelle ist jedoch zusätzlich zu erwähnen, dass nicht jeder Laserpuls eine Antwort erzeugt, die der Detektor aufzeichnet, da dieser sich kurz nach der Detektion eines Photons in einer kurzen Erholungszeit (dead time) befindet (Wahl et al. 2007). Um bei einer einzigen Anregung durch den Laser direkt die dazugehörige Antwort detektieren zu können, wären sehr schnelle Detektoren notwendig, die heute jedoch noch nicht zur Verfügung stehen. Um dieses Problem zu umgehen, wurde bei TCSPC FLIM ein periodisch verlaufendes Exzitationsschema angewandt. Bei diesem wurden anhand eines festgelegten zeitlichen Abstands, Laserimpulse über einen längeren Zeitraum ausgesandt, um die Anzahl der emittierten Photonen zu erhöhen. Als Nachteil stellte sich hier heraus, dass eine längere Zeit zur Erfassung notwendig war, um genug Photonen zu sammeln, die im gefitteten Graphen dargestellt werden können (Wahl et al. 2007; Wahl 2014; Ebrecht et al. 2014). Das erforderliche Mehrfach-Scannen jeder Bildlinie erzeugt gegebenenfalls ein unumgängliches Photobleaching, welches das Ergebnis der FLIMMessung jedoch unbeeinflusst ließ. Ein weiterer wichtiger Punkt ist die Entstehung von Autofluoreszenzen besonders bei kurzen Wellenlängen, beispielsweise durch die Coenzyme FAD (Flavin-Adenin-Dinucleotid) oder NADH (Nikotinamidadenindinukleotid), die in der Zelle unter physiologischen Bedingungen für die Katalyse von Redoxreaktionen verantwortlich sind (Lakowicz 2006; Zhang et al. 2004). Je nach Lebenszeit der verwendeten Redox-Sensoren könnten diese zellendogenen Metabolite somit zu einer Interferenz führen. 
Zudem wird alles in allem nur eine durchschnittliche Lebenszeit der Fluoreszenz bestimmt. Das System ist nicht in der Lage, aus der Kurve, die als Ergebnis entsteht, einzelne Lebenszeiten der verschiedenen Fluorophore und der autofluoreszierenden Zellinhaltsstoffe heraus zu extrahieren (O’Connor und Philips 1984). Daher sollte die Intensität der verwendeten Fluorophore nicht nur deutlich größer als die Autofluoreszenz sein, sondern sich idealerweise auch deutlich in der mittleren Lebenszeit unterscheiden.

\subsection{Ausblick}

\subsubsection{Detektion von ROS}

Die klinische Therapie und das mechanistische Verständnis von Gewebsschäden, die durch ROS verursacht werden, hängt davon ab, inwieweit die Wissenschaft die Eigenschaften reaktiver Sauerstoffspezies zukünftig in ihren Details erforschen kann: Je besser die Eigenschaften und Auswirkungen von ROS auf die menschlichen Zellen dargestellt werden können, desto spezifischer können demnach Therapien angesetzt werden (Halliwell 1991). Um den zellulären ROS-Status noch detaillierter und in seinem physiologischen Kontext darstellen zu können, wurden in den letzten Jahren bereits verschiedene Studien publiziert. Die konkrete Beziehung von Oxidantien, den Redox-Gleichgewichten und den durch ROS entstandenen Erkrankungen ist jedoch bis heute noch nicht bis ins Detail verstanden. Als ein Ziel der Forschungsarbeit mit reaktiven Sauerstoffspezies kann also die Entwicklung hochpräziser Techniken formuliert werden, um ROS-Prozesse und Redox-Beziehungen in ihrem spezifischen zellulären Kontext mit hoher räumlicher und zeitlicher Auflösung in vivo darstellen und auch beeinflussen zu können (Meyer und Dick 2010).

\subsubsection{Genetisch kodierte Fluoreszenzproteine}

Um Redox-Veränderungen innerhalb von Zellen und Zellsubkompartimenten qualitativ und quantitativ darstellen zu können, sind Färbungen mit klar definierten Eigenschaften notwendig. Noch heute ist die Anwendung von synthetischen Farbstoffen weit verbreitet. Diese Substanzen, wie DCF oder Hydroethidium, lassen sich jedoch nicht spezifisch in Zellsubkompartimente einbauen. Sie reagieren zwar sensitiv auf Oxidation, aber nicht auf Reduktion und ihre Reaktionen sind nicht reversibel. Zudem können sie in ihrem oxidierten, fluoreszierenden Zustand ihre ursprüngliche Lokalisation verlassen, indem sie zum Beispiel sekundär in Mitochondrien oder im Zellkern akkumulieren und verfälschen somit 
das Ergebnis, da die entstandene Fluoreszenz nicht mehr dem eigentlichen Ort der Oxidation zugeordnet werden kann (Can et al. 2017).

Für zukünftige Forschungen eignen sich daher vor allem die genetisch kodierten Redoxindikatoren. Sie sind den synthetischen Färbungen in vielen Punkten deutlich überlegen. Sie können spezifisch in Zellsubkompartimente, wie Mitochondrien, das endoplasmatische Retikulum oder auch in den Nukleus eingebaut werden, reagieren sensitiv sowohl auf Oxidation als auch auf Reduktion und sind dabei reversibel, können also in ihren ursprünglichen Redox-Ausgangszustand zurückkehren. Mit der Entdeckung dieser Redoxindikatoren ist demnach auch zukünftig eine genaue Detektion von ROS und deren Eigenschaften möglich (Gerich et al. 2009; Malinouski et al. 2011; Markvicheva et al. 2011). Die Auswahl des geeigneten Redoxindikators ist abhängig von den Konditionen der geplanten Versuchsreihe sowie von der detaillierten Fragestellung (Hanson et al. 2004; Belousov et al. 2006; Dooley et al. 2004).

Das genetisch kodierte Fluoreszenzprotein roGFP1 wurde im zeitlichen Verlauf weiterentwickelt: Es zeigt Vorteile für Messungen in bereits reduzierten Zellkompartimenten, roGFP2 hingegen zeigt deutlichere Antworten auf Redox-Veränderung in einer weniger reduzierten Umgebung und hat einen größeren dynamischen Messbereich (Schwarzländer et al. 2008; Meyer et al. 2007). Es gibt noch weitere Varianten, die die Proteine roGFP1 bis roGFP6 einschließen und sich in ihren Eigenschaften und Reaktionsergebnissen unterscheiden (Hanson et al. 2004). Zudem wurden Studien publiziert, in denen roGFP mit der Peroxidase Orp1 konjungiert wurde, was das gesamte Konstrukt (roGFP-Orp1) noch spezifischer für das Oxidationsmittel $\mathrm{H}_{2} \mathrm{O}_{2}$ machen soll (Gutscher et al. 2009). Das Protein roGFP1 kann mit verschiedenen Zielsequenzen ausgestattet werden, die dem Redoxindikator die Eigenschaft verleihen, spezifisch in Subkompartimente einer Zelle eingebaut werden zu können. Für das Einbringen des Proteins in die Mitochondrien einer Zelle wurde roGFPm entwickelt. Das Mitochondrium ist der Hauptort für die Produktion reaktiver Sauerstoffspezies. Aus diesem Grund ist es ein großer Vorteil, ROS direkt in seinem Entstehungsort qualitativ und quantitativ detektieren zu können (Wagener et al. 2016).

Das genetisch kodierte Fluoreszenzprotein HyPer wurde in den letzten Jahren ebenfalls weiterentwickelt und besitzt beispielsweise als HyPer-2 und HyPer-3 neue Eigenschaften zur Darstellung von ROS: HyPer-2 zeigte in Bezug auf ratiometrische Messungen einen doppelt so großen, jedoch zeitlich langsameren Anstieg der Intensität, im Vergleich zu seinem Vorgängerprotein HyPer, von dem es sich allein durch eine Punktmutation unter- 
scheidet. Diese Mutation stabilisiert das Protein und ermöglicht größere Messbereiche, damit auch kleinste ROS-Veränderungen detektiert werden können. HyPer-3 besitzt im Vergleich zu HyPer einen größeren dynamischen Messbereich und zeigt intensivere, kontrastreichere ratiometrische Veränderungen auf Oxidation. Signifikant schnellere Änderungen bezüglich der Oxidation und der Reduktion sind zudem im Vergleich zu HyPer-2 möglich (Bilan et al. 2013; Markvicheva et al. 2011). Zudem existieren auch für das Protein HyPer Varianten, die einen gezielten, spezifischen Einbau in die Mitochondrien ermöglichen (Belousov et al. 2006; Weller et al. 2014).

Auch in Bezug auf die weiterführenden Darstellungsmöglichkeiten der mit HyPer transfizierten Zellen wurden bereits Studien veröffentlicht: Ziel einer dieser Versuchsreihen war es, in dem auszuwertenden Bild einen größeren farblichen Kontrast und somit eine detailliertere räumliche Trennung zwischen verschiedenen fluoreszierenden Proteinen zu schaffen, da die momentan verfügbaren Redox-Sensoren grünes Licht emittieren, das sich mit dem Emissionsspektrum anderer Proben überschneiden kann. Aus diesem Grund wurde HyPerRed aus einem cpYFP entwickelt, welches rotes Licht emittiert aber die gleiche Sensitivität besitzt, wie die grün fluoreszierende Version (Ermakova et al. 2014). Das übergeordnete Ziel bleibt jedoch, dass mithilfe von HyPer auf verschiedenen Wegen versucht wird, Signalwege innerhalb der Zellorganellen so detailliert wie möglich darzustellen.

Es stellt heute immer noch eine Herausforderung dar, die kodierende DNA von HyPer und roGFP1 in die Zielzelle zu bringen. Eine Transduktion ist notwendig, bei der mithilfe eines Virus die DNA, die für das Fluoreszenzprotein kodiert, in die Zelle eingebracht wird. Dieses Verfahren kann die Zelle potentiell schädigen oder zumindest ihre Eigenschaften verändern. Zudem ist ein Zeitraum von einigen Tagen ab dem Zeitpunkt der Transduktion notwendig, bis die Zellen einen messbereiten Status erreichen. Um dieses Problem zu umgehen, wurde eine Redox-Indikator Maus entwickelt, die es ermöglicht, die Redox-Balance im Zytosol, im Mitochondrium und in Neuronen verschiedener Hirnregionen sowohl neonataler als auch adulter Mäuse mithilfe des Redoxindikators roGFP1 zu messen (Wagener et al. 2016). Vergleichbare Mausmodelle unter Einsatz von roGFP2, verschiedenen Promotern in Verbindung mit roGFP1 oder Proteinen, die allein in Mitochondrien exprimiert werden können, wurden bereits publiziert (Breckwoldt et al. 2014). Die Redox-IndikatorMaus exprimiert roGFP1 unter der Kontrolle des Promotors Thy-1 (thymocyte differentiation antigen 1), ohne die Maus phänotypisch oder in ihrem Verhalten zu verändern. Zukünftig entsteht dadurch also der Vorteil, dass alle Methoden der Präparation angewandt 
werden können und sogar isolierte adulte Hirnschnitte genutzt werden können, ohne dass zuvor eine Transformation/Transduktion mit ihren potentiell zellschädigenden Wirkungen erforderlich wäre (Wagener et al. 2016).

Werden die beiden genetisch kodierten Fluoreszenzproteine roGFP1 und HyPer einem direkten Vergleich unterzogen, stellen sich einige wichtige Punkte heraus, die roGFP1 in Bezug auf seine Eigenschaften und Anwendungsbereiche deutlich vor HyPer stellen. Das Protein roGFP1 ist ein allgemeiner Redox-Sensor, der vor allem den zellulären ThiolRedoxstatus detektiert. HyPer hingegen wurde bisher als $\mathrm{H}_{2} \mathrm{O}_{2}$-spezifisch charakterisiert, was unter anderem meine Versuchsreihen jedoch teilweise widerlegen. Zuverlässige Antworten auf Reduktion konnten jedoch nicht erhalten werden. HyPer ist zudem ein Protein, welches stark auf Änderungen des pH-Wertes reagiert und Messergebnisse dadurch verfälscht werden können. Das Protein roGFP1 hingegen zeigt eine vernachlässigbare und somit nicht ergebnisverfälschende pH-Sensitivität (Funke et al. 2011; Weller et al. 2014; Wagener et al. 2016).

\subsubsection{Messungen der Fluoreszenzlebenszeit (FLIM)}

Es besteht der Ansatz, die Bestimmung der Fluoreszenzlebenszeiten (FLIM-System) zukünftig in die Rubrik der medizinischen Diagnostik zu integrieren: Ziel dabei ist, den Proteinstatus von pathologisch veränderten Geweben und die gleichzeitige Interaktion mehrerer Biomoleküle mithilfe der unterschiedlichen Fluoreszenzlebenszeiten darzustellen (Bastiaens und Squire 1999). Auch der Tumordiagnostik sollen FLIM-basierte Methoden zukünftig Vorteile verschaffen: FLIM-basierte Endoskope sollen Zellverbände des Verdauungstrakts darstellen und das spezifische Auffinden von malignen Zellen erleichtern (Elson et al. 2007; Fatakdawala et al. 2013). Ebenso soll anhand der Fluoreszenzlebenszeit malignes Brustgewebe bei Patientinnen mit Mamma-Karzinom deutlich von benignen Zellen abgegrenzt werden können (Das et al. 1997; Tadrous 2000). Es ist somit davon auszugehen, dass bei diesen neuartigen technologischen Bestrebungen sicherlich auch der Einsatz hochentwickelter Redox-Sensoren nicht mehr lange auf sich warten lassen wird. 


\section{$5 \quad$ Zusammenfassung}

Die genetisch kodierten Redox-Indikatoren HyPer und roGFP1 sind den konventionellen Farbstoffen in vielen Punkten überlegen, da sie im physiologischen $\mathrm{pH}-$ Bereich stabil sind, Redox-Veränderungen reversibel darstellen und gezielt in Subkompartimente einer Zelle eingebaut werden können.

Um die Wirkung der reaktiven Sauerstoffspezies auf die Redoxbalance der Zellen und deren Signalwege zukünftig mithilfe der Zwei-Photonen-Mikroskopie besser darstellen zu können, bewertet die erste Versuchsreihe dieser Arbeit zunächst die Verteilung der redoxsensitiven Proteine HyPer und roGFP1 in der Zelle. Der roGFP1-Sensor verteilt sich homogen im Soma und den Dendriten der Zelle und gelangt offenbar auch in den Nukleus. HyPer hingegen ist ein verhältnismäßig großes Molekül und durchdringt die Membran des Nukleus nur zu einem geringen Anteil. Die resultierenden Bilder zeigen eine Zelle, deren Soma homogen und intensiv gefärbt ist, ähnlich der mit roGFP1 transfizierten Zelle. Der Unterschied ist jedoch, dass der Zellkern der mit HyPer transfizierten Zelle auffällig dunkler erscheint. Anfärbung mit dem Nukleinsäurefarbstoff DAPI bestätigt im Bereich des Zellkerns eine blaue Färbung, die sich deutlich vom umgebenden emittierten grünen Licht des Fluoreszenzproteins HyPer im Bereich des Zytosols abgrenzt.

Die zweite Versuchsreihe erfasste das Exzitationsspektrum der beiden Fluoreszenzproteine HyPer und roGFP1 in der Zwei-Photonen-Mikroskopie. Das Ziel war, deutliche Exzitationsmaxima für nachfolgende exzitationsratiometrische Untersuchungen zu definieren, was aufgrund des breiten Exzitationsspektrums jedoch nur bedingt möglich war. Da aus dieser Versuchsreihe keine eindeutig diskreten Ausgangsmaxima hervorgingen, wurden stattdessen für die nachfolgenden ratiometrischen Versuche die ungefähren verdoppelten Anregungs-Wellenlängen der Ein-Photonen-Mikroskopie angewandt.

Anhand des dritten Kapitels, der dynamischen Messungen der Redox-Balance, wird verdeutlicht, mit welchem zeitlichen Abstand und mit welcher Intensität die Redoxindikatoren auf Oxidation und Reduktion reagieren. Sowohl HyPer als auch roGFP1 zeigten unter den jeweiligen ratiometrischen Anregungswellenlängen deutliche und schnelle Reaktionen auf das Oxidationsmittel $\mathrm{H}_{2} \mathrm{O}_{2}$. Als ein wichtiger Punkt ist festzuhalten, dass diese Intensitätsänderungen vollständig reversibel sind. Einige Probleme zeigten sich für HyPer in Bezug auf das Reduktionsmittel DTT: Theoretisch sollte die Intensität bei Reduktion abnehmen 
und somit ein gegensätzliches Verhalten im Vergleich zu der Oxidation zeigen. DTT scheint jedoch eher die Reaktion, wie sie schon unter Oxidation auftritt, zu imitieren. Ursache dafür ist offenbar, dass HyPer sich im Zytosol bereits nahezu vollständig im reduzierten Zustand befindet. Eine weitere Reduktion durch DTT war somit nicht mehr möglich. Für diese Messreihe wurden für beide Fluoreszenzproteine, HyPer und roGFP1, zuvor jeweils eine ratiometrische Anregungswellenlänge im kurzwelligen sowie eine im langwelligen Bereich festgelegt: Diese entsprechen in etwa den verdoppelten Wellenlängen der Exzitationsmaxima in der Ein-Photonen-Anregung. Das Fluoreszenzprotein roGFP1 zeigt in den durchgeführten Versuchsreihen keine Änderungen bei der festgelegten kürzeren Wellenlänge von $740 \mathrm{~nm}$, weder für $\mathrm{H}_{2} \mathrm{O}_{2}$ noch für DTT. Es scheint, als sei hier der isosbestische Punkt getroffen, also die Wellenlänge, bei der die Ausgangsintensität unter Einwirkung verschiedener reaktiver Substanzen unverändert bleibt. Dennoch sind auch bei der Nutzung des isosbestischen Punktes ratiometrische Messungen möglich.

Die Darstellung ratiometrischer Bildpaare (Kapitel 3.4) zeigte ein zuverlässiges Ergebnis für das Fluoreszenzprotein roGFP1 unter Einfluss von $\mathrm{H}_{2} \mathrm{O}_{2}$ und DTT. Eine Oxidation durch $\mathrm{H}_{2} \mathrm{O}_{2}$ führte zu einer Intensitätssteigerung, wohingegen eine Reduktion durch DTT eine deutliche Intensitätsminderung des Fluoreszenzverhältnisses bewirkte. Auch das Protein HyPer zeigte mit einer Intensitätssteigerung im Vergleich zu den Ausgangswerten zuverlässige Ergebnisse unter oxidierenden Verhältnissen durch $\mathrm{H}_{2} \mathrm{O}_{2}$. Die Reduktion durch DTT bewirkte jedoch auch hier ambivalente Ergebnisse: Bei einigen Zellen wurde eine Steigerung, bei anderen eine Minderung der Fluoreszenz-Intensität hervorrufen.

Im fünften und letzten Kapitel wurden Messungen und Ergebnisse der Fluoreszenzlebenszeit mithilfe des FLIM-Systems dargestellt. Jede Fluoreszenz hat unter verschiedenen beeinflussenden Bedingungen ihrer jeweiligen Umgebung eine individuelle Lebenszeit, welche sowohl durch Oxidation als auch durch Reduktion verändert und beeinflusst werden kann. Die Lebenszeit einer Fluoreszenz liegt typischerweise im Nanosekundenbereich. Die mit roGFP1 transfizierten Zellen zeichnen sich unter Kontrollbedingungen durch eine längere Fluoreszenzlebenszeit aus im Vergleich zu den Zellen, die mit dem Protein HyPer transfiziert wurden. Unter Einfluss von $\mathrm{H}_{2} \mathrm{O}_{2}$-Lösungen in verschiedenen Konzentrationen verkürzte sich die HyPer-Fluoreszenzlebenszeit um bis zu $10 \%$. Das Reduktionsmittel DTT versagte auch hier und verlängerte die Fluoreszenzlebenszeit nicht. Die Fluoreszenzlebenszeit einer mit dem Protein roGFP1 transfizierten Zelle wird durch oxidierende Ver- 
hältnisse unter $\mathrm{H}_{2} \mathrm{O}_{2}$ um bis zu $4 \%$ verkürzt, wohingegen eine Reduktion durch DTT eine Verlängerung der Lebenszeit von etwa $4 \%$ hervorruft.

In Zusammenschau der Ergebnisse wird deutlich, dass der Redox-Sensor roGFP1 dem HyPer-Konstrukt in vielen Bereichen deutlich überlegen ist. Für roGFP1 zeigten sich klare ratiometrische Antworten bei Anregung durch die Zwei-Photonen-Mikroskopie. Es können zudem zuverlässige Veränderungen der zytosolischen Redox-Balance durch Oxidation $\left(\mathrm{H}_{2} \mathrm{O}_{2}\right)$ sowie Reduktion (DTT) detektiert werden. Für den Redoxsensor roGFP1 ließen sich darüber hinaus stabile FLIM-Antworten unter verschiedenen Redox-Bedingungen darstellen. Diese Änderungen der Fluoreszenzlebenszeit stellten sich jedoch nur als gering heraus, wodurch aber gesunde Zellen von deutlich Redox-entgleisten Zellen unterschieden werden können. Moderate Änderungen der zellulären Redox-Balance sind demnach jedoch nur limitiert mit FLIM darstellbar.

Die Methode der Wahl zur Detektion zuverlässiger zellulärer Redox-Antworten mithilfe des roGFP1-Sensors ist demnach die Messung ratiometrischer Bildpaare mithilfe der ZweiPhotonen-Anregung. Im Rahmen dieser Messreihe ist zudem eine ausreichend hohe Dynamik des Antwortbereichs ersichtlich, um auch physiologische Unterschiede der RedoxBalance zuverlässig erfassen zu können. 


\section{Literaturverzeichnis}

Agar J, Durham H (2003): Relevance of oxidative injury in the pathogenesis of motor neuron diseases. Amyotroph Lateral Scler Other Motor Neuron Disord 4 (4), 232-242

Aslund F, Zheng M, Beckwith J, Storz G (1999): Regulation of the OxyR transcription factor by hydrogen peroxide and the cellular thiol-disulfide status. Proc Natl Acad Sci U S A $\underline{96}(11), 6161-6165$

Austin CD, Wen X, Gazzard L, Nelson C, Scheller RH, Scales SJ (2005): Oxidizing potential of endosomes and lysosomes limits intracellular cleavage of disulfide-based antibody-drug conjugates. Proc Natl Acad Sci U S A 102 (50), 17987-17992

Balaban RS, Nemoto S, Finkel T (2005): Mitochondria Oxidants and Aging. Cell Signal $\underline{120}, 483-495$

Baldwin SR, Simon RH, Grum CM, Ketai LH, Boxer LA, Devall LJ (1986): Oxidant activity in expired breath of patients with adult respiratory distress syndrome. Lancet 1 (8471), 11-14

Banach-Latapy A, He T, Dardalhon M, Vernis L, Chanet R, Huang M (2013): Redoxsensitive YFP sensors for monitoring dynamic compartment-specific glutathione redox state. Free Radic Biol Med $\underline{65}$, 436-445

Bastiaens PI, Squire A (1999): Fluorescence lifetime imaging microscopy: spatial resolution of biochemical processes in the cell. Trends Cell Biol $\underline{9}$ (2), 48-52

Beal M (1998): Mitochondrial dysfunction in neurodegenerative diseases. BBABioenergetics 1366, 211-223

Becker LB (2004): New concepts in reactive oxygen species and cardiovascular reperfusion physiology. Cardiovasc Res $\underline{61}$ (3), 461-470

Becker W (2012): Fluorescence lifetime imaging--techniques and applications. J Microsc $\underline{247}$ (2), 119-136

Becker W, Bergmann A, Hink MA, König K, Benndorf K, Biskup C (2004): Fluorescence lifetime imaging by time-correlated single-photon counting. Microsc Res Tech $\underline{63}$ (1), $58-66$

Belousov VV, Fradkov AF, Lukyanov KA, Staroverov DB, Shakhbazov KS, Terskikh AV, Lukyanov S (2006): Genetically encoded fluorescent indicator for intracellular hydrogen peroxide. Nat Methods $\underline{3}$ (4), 281-286

Benninger RK, Piston DW (2013): Two-photon excitation microscopy for the study of living cells and tissues. Curr Protoc Cell Biol Chapter 4, Unit 4.11.1-24

Biancardi A, Biver T, Secco F, Mennucci B (2013): An investigation of the photophysical properties of minor groove bound and intercalated DAPI through quantum-mechanical and spectroscopic tools. Phys Chem Chem Phys $\underline{15}$ (13), 4596-4603

Bilan DS, Pase L, Joosen L, Gorokhovatsky AY, Ermakova YG, Gadella, Theodorus W J, Grabher C, Schultz C, Lukyanov S, Belousov VV (2013): HyPer-3: a genetically encoded $\mathrm{H}_{2} \mathrm{O}_{2}$ probe with improved performance for ratiometric and fluorescence lifetime imaging. ACS Chem Biol $\underline{8}$ (3), 535-542 
Boveris A, Chance B (1973): The mitochondrial generation of hydrogen peroxide. General properties and effect of hyperbaric oxygen. Biochem J 134 (3), 707-716

Breckwoldt MO, Pfister FMJ, Bradley PM, Marinković P, Williams PR, Brill MS, Plomer B, Schmalz A, St Clair DK, Naumann R (2014): Multiparametric optical analysis of mitochondrial redox signals during neuronal physiology and pathology in vivo. Nat Med $\underline{20}$ (5), 555-560

Brennan M, Hazen SL (2003): Amino acid and protein oxidation in cardiovascular disease. Amino Acids 25 (3-4), 365-374

Bush PG, Wokosin DL, Hall AC (2007): Two-versus one photon excitation laser scanning microscopy: critical importance of excitation wavelength. Front Biosci (Landmark Ed) $\underline{12}, 2646-2657$

Cadenas E, Davies KJ (2000): Mitochondrial free radical generation, oxidative stress, and aging. Free Radic Biol Med 29 (3-4), 222-230

Can K, Kügler S, Müller M: Live Imaging of Mitochondrial ROS Production and Dynamic Redox Balance in Neurons. In: Strack S, Usachev YM (Hrsg.): Techniques to Investigate Mitochondrial Function in Neurons. (Neuromethods 123); Springer Protocols, Humana Press, New York 2017, 179-197

Cannon MB, Remington SJ (2006): Re-engineering redox-sensitive green fluorescent protein for improved response rate. Protein Sci 15 (1), 45-57

Centonze VE, White JG (1998): Multiphoton excitation provides optical sections from deeper within scattering specimens than confocal imaging. Biophys J $\underline{75}$ (4), 2015-2024

Chalfie M, Tu Y, Euskirchen G, Ward WW, Prasher DC (1994): Green fluorescent protein as a marker for gene expression. Science 263 (5148), 802-805

Chan PH (2001): Reactive oxygen radicals in signaling and damage in the ischemic brain. J Cereb Blood Flow Metab 21 (1), 2-14

Chen LC, Lloyd III W, Chang CW, Sud D, Mycek MA (2013): Fluorescence lifetime imaging microscopy for quantitative biological imaging. Methods Cell Biol 114, 457-488

Choi H, Kim S, Mukhopadhyay P, Cho S, Woo J, Storz G, Ryu SE (2001): Structural basis of the redox switch in the OxyR transcription factor. Cell $\underline{105}$ (1), 103-113

Circu ML, Aw TY (2010): Reactive oxygen species, cellular redox systems, and apoptosis. Free Radic Biol Med $\underline{48}$ (6), 749-762

Cody CW, Prasher DC, Westler WM, Prendergast FG, Ward WW (1993): Chemical structure of the hexapeptide chromophore of the Aequorea green-fluorescent protein. Biochemistry $\underline{32}$ (5), 1212-1218

Cooper JM, Schapira AH (1997): Mitochondrial dysfunction in neurodegeneration. J Bioenerg Biomembr $\underline{29}$ (2), 175-183

Coyle JT, Puttfarcken P (1993): Oxidative stress, glutamate, and neurodegenerative disorders. Science 262 (5134), 689-695

Dardalhon M, Kumar C, Iraqui I, Vernis L, Kienda G, Banach-Latapy A, He T, Chanet R, Faye G, Outten CE (2012): Redox-sensitive YFP sensors monitor dynamic nuclear and cytosolic glutathione redox changes. Free Radic Biol Med 52 (11-12), 2254-2265

Das BB, Liu F, Alfono R (1997): Time-resolved fluorescence and photon migration studies in biomedical and model random media. Rep Prog Phys 60, 227-292 
Denk W, Strickler JH, Webb WW (1990): Two-photon laser scanning fluorescence microscopy. Science 248 (4951), 73-76

Denk W, Delaney K, Gelperin A, Kleinfeld D, Strowbridge B, Tank DW, Yuste R (1994): Anatomical and functional imaging of neurons using 2-photon laser scanning microscopy. J Neurosci Methods $\underline{54}$ (2), 151-162

Dhalla AK, Hill MF, Singal PK (1996): Role of oxidative stress in transition of hypertrophy to heart failure. J Am Coll Cardiol $\underline{28}$ (2), 506-514

Diaspro A, Bianchini P, Vicidomini G, Faretta M, Ramoino P, Usai C (2006): Multiphoton excitation microscopy. Biomed Eng Online $\underline{5}$ (36)

Dooley CT, Dore TM, Hanson GT, Jackson WC, Remington SJ, Tsien RY (2004): Imaging dynamic redox changes in mammalian cells with green fluorescent protein indicators. J Biol Chem $\underline{279}$ (21), 22284-22293

Dringen R (2000): Metabolism and functions of glutathione in brain. Prog Neurobiol $\underline{62}$ (6), 649-671

Dröge W (2002): Free radicals in the physiological control of cell function. Physiol Rev $\underline{82}$ (1), 47-95

Ebrecht R, Don Paul C, Wouters FS (2014): Fluorescence lifetime imaging microscopy in the medical sciences. Protoplasma 251 (2), 293-305

Efting MR: Fluorescence Quenching: Theory and Applications. In: Lakowicz JR (Hrsg.): Topics in Fluorescent Spectroscopy. Band 2; Springer, New York 2002, 53-126

Elsliger MA, Wachter RM, Hanson GT, Kallio K, Remington SJ (1999): Structural and spectral response of green fluorescent protein variants to changes in $\mathrm{pH}$. Biochemistry $\underline{38}(17), 5296-5301$

Elson DS, Jo JA, Marcu L (2007): Miniaturized side-viewing imaging probe for fluorescence lifetime imaging (FLIM): validation with fluorescence dyes, tissue structural proteins and tissue specimens. New J Phys $\underline{9}, 127$

Enyedi B, Vàrnai P, Geiszt M (2010): Redox State of the Endoplasmatic Reticulum is controlled by Ero1L-alpha and Intraluminal Calcium. Antioxid Redox Signal 13 (6), 721729

Epstein LI (1981): Dichroic filters: a simple design. Appl Opt 20 (4), 527-528

Ermakova YG, Bilan DS, Matlashov ME, Mishina NM, Markvicheva KN, Subach OM, Subach FV, Bogeski I, Hoth M, Enikolopov G (2014): Red fluorescent genetically encoded indicator for intracellular hydrogen peroxide. Nat Commun $\underline{5}$ (5222)

Esposito A, Dohm CP, Bähr M, Wouters FS (2007): Unsupervised fluorescence lifetime imaging microscopy for high content and high throughput screening. Mol Cell Proteomics $\underline{6}(8), 1446-1454$

Fatakdawala H, Poti S, Zhou F, Sun Y, Bec J, Liu J, Yankelevich DR, Tinling SP, Gandour-Edwards RF, Farwell DG (2013): Multimodal in vivo imaging of oral cancer using fluorescence lifetime, photoacoustic and ultrasound techniques. Biomed Opt Express $\underline{4}(9), 1724-1741$

Finkel T (2003): Oxidant signals and oxidative stress. Curr Opin Cell Biol 15 (2), 247-254

Finkel T (2011): Signal transduction by reactive oxygen species. J Cell Biol 194 (1), 7-15 
Finkel T, Holbrook NJ (2000): Oxidants, oxidative stress and the biology of ageing. Nature 408 (6809), 239-247

Foster KA, Galeffi F, Gerich FJ, Turner DA, Müller M (2006): Optical and pharmacological tools to investigate the role of mitochondria during oxidative stress and neurodegeneration. Prog Neurobiol 79 (3), 136-171

Fridovich I (1974): Superoxide dismutases. Adv Enzymol Relat Areas Mol Biol 41 (0), 35-97

Funke F, Gerich FJ, Muller M (2011): Dynamic, semi-quantitative imaging of intracellular ROS levels and redox status in rat hippocampal neurons. Neuroimage $\underline{54}$ (4), 2590 2602

Gerich FJ, Funke F, Hildebrandt B, Fasshauer M, Müller M (2009): $\mathrm{H}_{2} \mathrm{O}_{2}$-mediated modulation of cytosolic signaling and organelle function in rat hippocampus. Pflugers Arch $\underline{458}(5), 937-952$

Gerritsen HC, Sanders R, Draaijer A, Ince C, Levine YK (1997): Fluorescence lifetime imaging of oxygen in living cells. J Flouresc $\underline{7}$ (1), 11-15

Giacco F, Brownlee M (2010): Oxidative stress and diabetic complications. Circ Res 107 (9), 1058-1070

Göppert-Mayer M (1931): Über Elementarakte mit zwei Quantensprüngen. In: Ann Phys $\underline{401}, 273-294$

Grosser E, Hirt U, Janc OA, Menzfeld C, Fischer M, Kempkes B, Vogelgesang S, Manzke TU, Opitz L, Salinas-Riester G (2012): Oxidative burden and mitochondrial dysfunction in a mouse model of Rett syndrome. Neurobiol Dis $\underline{48}$ (1), 102-114

Gutscher M, Pauleau A, Marty L, Brach T, Wabnitz GH, Samstag Y, Meyer AJ, Dick TP (2008): Real-time imaging of the intracellular glutathione redox potential. Nat Methods $\underline{5}(6), 553-559$

Gutscher M, Sobotta MC, Wabnitz GH, Ballikaya S, Meyer AJ, Samstag Y, Dick TP (2009): Proximity-based protein thiol oxidation by $\mathrm{H} 2 \mathrm{O} 2$-scavenging peroxidases. J Biol Chem 284 (46), 31532-31540

Guzy RD, Hoyos B, Robin E, Chen H, Liu L, Mansfield KD, Simon MC, Hammerling U, Schumacker PT (2005): Mitochondrial complex III is required for hypoxia-induced ROS production and cellular oxygen sensing. Cell Metab 1 (6), 401-408

Halliwell B (1991): Reactive oxygen species in living systems: source, biochemistry, and role in human disease. Am J Med 19 (3C), 14S-22S

Halliwell B (1992): Reactive oxygen species and the central nervous system. J Neurochem $\underline{59}(5), 1609-1623$

Halliwell B, Cross CE (1994): Oxygen-derived species: their relation to human disease and environmental stress. Environ Health Perspect $\underline{102}$ (10), 5-12

Hamamatsu Photonics: Photomultiplier Tubes. Basics and Applications. 3. Auflage: Hamamatsu 2007

Hanson DA, Ziegler SF (2004): Fusion of green fluorescent protein to the C-terminus of granulysin alters its intracellular localization in comparison to the native molecule. $\mathrm{J}$ Negat Results Biomed $\underline{3}$ (2) 
Hanson GT, Aggeler R, Oglesbee D, Cannon MB, Capaldi RA, Tsien RY, Remington SJ (2004): Investigating mitochondrial redox potential with redox-sensitive green fluorescent protein indicators. J Biol Chem 279 (13), 13044-13053

Harman D (1956): Aging: a theory based on free radical and radiation chemistry. J Gerontol $\underline{11}$ (3), 298-300

Harman D (1992): Free radical theory of aging. Mutat Res $\underline{275}$ (3-6), 257-266

Heim R, Prasher DC, Tsien RY (1994): Wavelength mutations and posttranslational autoxidation of green fluorescent protein. Proc Natl Acad Sci U S A 91 (26), 12501-12504

Helmchen F, Denk W (2002): New developments in multiphoton microscopy. Curr Opin Neurobiol $\underline{12}$ (5), 593-601

Hugon J, Hugon F, Esclaire F, Lesort M, Diop AG (1996): The presence of calbindin in rat cortical neurons protects in vitro from oxydative stress. Brain Res $\underline{707}$ (2), 288-292

Hwang C, Sinskey AJ, Lodish HF (1992): Oxidized redox state of glutathione in the endoplasmic reticulum. Science 257 (5076), 1496-1502

Kapuscinski J (1995): DAPI: a DNA-specific fluorescent probe. Biotech Histochem $\underline{70}$ (5), 220-233

Karlsson M, Kurz T, Brunk UT, Nilsson SE, Frennesson CI (2010): What does the commonly used DCF test for oxidative stress really show? Biochem J $\underline{428}$ (2), 183-190

Keil VC, Funke F, Zeug A, Schild D, Müller M (2011): Ratiometric high-resolution imaging of JC-1 fluorescence reveals the subcellular heterogeneity of astrocytic mitochondria. Pflugers Arch $\underline{462}$ (5), 693-708

Kishida KT, Klann E (2007): Sources and targets of reactive oxygen species in synaptic plasticity and memory. Antioxid Redox Signal $\underline{9}$ (2), 233-244

Kondo S, Okabe S (2013): In vivo two-photon microscopy of microglia. Methods Mol Biol 1041, 319-335

Lakowicz, JR: Principles of fluorescence spectroscopy. 3. Auflage; Springer, New York 2006

Lakowicz JR, Szmacinski H, Nowaczyk K, Johnson ML (1992): Fluorescence lifetime imaging of free and protein-bound NADH. Proc Natl Acad Sci U S A $\underline{89}$ (4), 12711275

Lhoste JM: Luminescence techniques in chemical and biochemical analysis Practical spectroscopy series, volume 12, edited by WRG Baeyens, D De Keukeleire, K Korkidis, Marcel Dekker, New York, 1991, p 654. Biochimie 74 (6), 591-592

Lim WK (2010): From Jellyfish to the Nobel Prize: The Discovery and Uses of Green Fluorescent Protein. Malays J Biochem Mol Biol 18, 1-6

Liu Y, Fiskum G, Schubert D (2002): Generation of reactive oxygen species by the mitochondrial electron transport chain. J Neurochem $\underline{80}$ (5), 780-787

Lloyd WR, Wilson RH, Chang CW, Gillispie GD, Mycek M (2010): Instrumentation to rapidly acquire fluorescence wavelength-time matrices of biological tissues. Biomed Opt Express 1 (2), 574-586 
Lohman JR, Remington SJ (2008): Development of a family of redox-sensitive green fluorescent protein indicators for use in relatively oxidizing subcellular environments. Biochemistry $\underline{47}$ (33), 8678-8688

Love NR, Chen Y, Ishibashi S, Kritsiligkou P, Lea R, Koh Y, Gallop JL, Dorey K, Amaya E (2013): Amputation-induced reactive oxygen species are required for successful Xenopus tadpole tail regeneration. Nat Cell Biol 15 (2), 222-228

Lukyanov KA, Belousov VV (2013): Genetically encoded fluorescent redox sensors. Biochim Biophys Acta $\underline{1840}$ (2), 745-756

Malinouski M, Zhou Y, Belousov VV, Hatfield DL, Gladyshev VN (2011): Hydrogen peroxide probes directed to different cellular compartments. PLoS One $\underline{6}$ (1), e14564

Markvicheva KN, Bilan DS, Mishina NM, Gorokhovatsky AY, Vinokurov LM, Lukyanov $\mathrm{S}$, Belousov VV (2011): A genetically encoded sensor for $\mathrm{H}_{2} \mathrm{O}_{2}$ with expanded dynamic range. Bioorg Med Chem 19 (3), 1079-1084

Masters BR, So PT (2004): Antecedents of two-photon excitation laser scanning microscopy. Microsc Res Tech $\underline{63}$ (1), 3-11

McNaught AD, Wilkinson A: IUPAC. Isosbestic point. Compendium of Chemical Terminology. The „Gold Book“. 2. Auflage; Blackwell Scientific Publications, Oxford 1997

Meyer AJ, Dick TP (2010): Fluorescent protein-based redox probes. Antioxid Redox Signal 13 (5), 621-650

Meyer AJ, Brach T, Marty L, Kreye S, Rouhier N, Jacquot J, Hell R (2007): Redoxsensitive GFP in Arabidopsis thaliana is a quantitative biosensor for the redox potential of the cellular glutathione redox buffer. Plant J $\underline{52}$ (5), 973-986

Miesenböck G, De Angelis, D A, Rothman JE (1998): Visualizing secretion and synaptic transmission with pH-sensitive green fluorescent proteins. Nature $\underline{394}$ (6689), 192-195

Miller EW, Tulyathan O, Isacoff EY, Chang CJ (2007): Molecular imaging of hydrogen peroxide produced for cell signaling. Nat Chem Biol $\underline{3}$ (5), 263-267

Miyawaki A, Llopis J, Heim R, McCaffery JM, Adams JA, Ikura M, Tsien RY (1997): Fluorescent indicators for $\mathrm{Ca} 2+$ based on green fluorescent proteins and calmodulin. Nature $\underline{388}$ (6645), 882-887

Moneron G, Hell SW (2009): Two-photon excitation STED microscopy. Opt Express 17 (17), 14567-14573

Morise H, Shimomura O, Johnson FH, Winant J (1974): Intermolecular energy transfer in the bioluminescent system of Aequorea. Biochemistry 13 (12), 2656-2662

Moulton PF (1986): Spectroscopic and laser characteristics of $\mathrm{Ti}_{\mathrm{i}} \mathrm{Al}_{2} \mathrm{O}_{3}$. J Opt Soc Am B $\underline{3}$ (1), 125-133

Muller FL, Liu Y, van Remmen H (2004): Complex III releases superoxide to both sides of the inner mitochondrial membrane. J Biol Chem $\underline{279}$ (47), 49064-49073

Müller M, Schmidt J, Mironov S, Richter D (2003): Construction and performance of a custom-built two-photon laser scanning system. J Phys D Appl Phys $\underline{36}, 1747-1757$

Nemoto S, Takeda K, Yu ZX, Ferrans VJ, Finkel T (2000): Role for mitochondrial oxidants as regulators of cellular metabolism. Mol Cell Biol 20 (19), 7311-7318 
Niethammer P, Grabher C, Look AT, Mitchison TJ (2009): A tissue-scale gradient of hydrogen peroxide mediates rapid wound detection in zebrafish. Nature $\underline{459}$ (7249), 996999

O’Connor DV, Philips D: Time-Correlated Single Photon Counting. Academic Press, London 1984

Ormö M, Cubitt AB, Kallio K, Gross LA, Tsien RY, Remington SJ (1996): Crystal structure of the Aequorea victoria green fluorescent protein. Science 273 (5280), 1392-1395

Østergaard H, Henriksen A, Hansen FG, Winther JR (2001): Shedding light on disulfide bond formation: engineering a redox switch in green fluorescent protein. EMBO J $\underline{20}$ (21), 5853-5862

Østergaard H, Tachibana C, Winther JR (2004): Monitoring disulfide bond formation in the eukaryotic cytosol. J Cell Biol 166 (3), 337-345

Patterson GH, Piston DW (2000): Photobleaching in two-photon excitation microscopy. Biophys J $\underline{78}$ (4), 2159-2162

Piston DW (1999): Imaging living cells and tissues by two-photon excitation microscopy. Trends Cell Biol $\underline{9}$ (2), 66-69

Prasher DC, Eckenrode VK, Ward WW, Prendergast FG, Cormier MJ (1992): Primary structure of the Aequorea victoria green-fluorescent protein. Gene 111 (2), 229-233

Ray PD, Huang B, Tsuji Y (2012): Reactive oxygen species (ROS) homeostasis and redox regulation in cellular signaling. Cell Signal $\underline{24}$ (5), 981-990

Resch-Genger U, Grabolle M, Cavaliere-Jaricot S, Nitschke R, Nann T (2008): Quantum dots versus organic dyes as fluorescent labels. Nat Methods $\underline{5}(9), 763-775$

Rodrigo R, Fernández-Gajardo R, Gutiérrez R, Matamala JM, Carrasco R, MirandaMerchak A, Feuerhake W (2013): Oxidative stress and pathophysiology of ischemic stroke: novel therapeutic opportunities. CNS Neurol Disord Drug Targets $\underline{12}$ (5), 698714

Rubart M (2004): Two-photon microscopy of cells and tissue. Circ Res $\underline{95}$ (12), 11541166

Schafer FQ, Buettner GR (2001): Redox environment of the cell as viewed through the redox state of the glutathione disulfide/glutathione couple. Free Radic Biol Med $\underline{30}$ (11), 1191-1212

Schwarzländer M, Fricker MD, Müller C, Marty L, Brach T, Novak J, Sweetlove LJ, Hell R, Meyer AJ (2008): Confocal imaging of glutathione redox potential in living plant cells. J Microsc 231 (2), 299-316

Schwarzländer M, Logan DC, Fricker MD, Sweetlove LJ (2011): The circularly permuted yellow fluorescent protein cpYFP that has been used as a superoxide probe is highly responsive to $\mathrm{pH}$ but not superoxide in mitochondria: implications for the existence of superoxide 'flashes'. Biochem J 437 (3), 381-387

Shigenaga MK, Hagen TM, Ames BN (1994): Oxidative damage and mitochondrial decay in aging. Proc Natl Acad Sci U S A 91 (23), 10771-10778

Shimomura O (1979): Structure of the chromophore of Aequorea green fluorescent protein. FEBS Lett 104 (3), 220-222 
Shimomura O (2008): Discovery of green fluorescent protein (GFP) (Nobel Lecture). Angew Chem Int Ed Engl $\underline{48}$ (31), 5590-5602

Shimomura O, Johnson FH, Saiga Y (1962): Extraction, purification and properties of aequorin, a bioluminescent protein from the luminous hydromedusan, Aequorea. J Cell Comp Physiol 59, 223-239

Stetter C, Hirschberg M, Nieswandt B, Ernestus R, Heckmann M, Sirén A (2013): An experimental protocol for in vivo imaging of neuronal structural plasticity with 2-photon microscopy in mice. Exp Transl Stroke Med $\underline{5}$ (1), 9

Striker G, Subramaniam V, Seidel CA, Volkmer A (1999): Photochromicity and Fluorescence Lifetimes of Green Fluorescent Protein. J Phys Chem B $\underline{103}$ (40), 8612-8617

Suhling K, Siegel J, Phillips D, French PM, Lévêque-Fort S, Webb SE, Davis DM (2002): Imaging the environment of green fluorescent protein. Biophys $\mathbf{J} \underline{83}$ (6), 3589-3595

Tadrous PJ (2000): Methods for imaging the structure and function of living tissues and cells: 2. Fluorescence lifetime imaging. J Pathol 191 (3), 229-234

Theer P, Hasan MT, Denk W (2003): Two-photon imaging to a depth of 1000 microm in living brains by use of a Ti: $\mathrm{Al}_{2} \mathrm{O}_{3}$ regenerative amplifier. Opt Lett 28 (12), 1022-1024

Tsien RY (1998): The green fluorescent protein. Annu Rev Biochem 67, 509-544

Turrens JF (2003): Mitochondrial formation of reactive oxygen species. J Physiol 552 (2), $335-344$

Valko M, Izakovic M, Mazur M, Rhodes CJ, Telser J (2004): Role of oxygen radicals in DNA damage and cancer incidence. Mol Cell Biochem 266 (1-2), 37-56

Valko M, Leibfritz D, Moncol J, Cronin, Mark T D, Mazur M, Telser J (2006a): Free radicals and antioxidants in normal physiological functions and human disease. Int J Biochem Cell Biol $\underline{39}$ (1), 44-84

Valko M, Rhodes CJ, Moncol J, Izakovic M, Mazur M (2006b): Free radicals, metals and antioxidants in oxidative stress-induced cancer. Chem Biol Interact $\underline{160}$ (1), 1-40

Veal EA, Day AM, Morgan BA (2007): Hydrogen peroxide sensing and signaling. Mol Cell $\underline{26}(1), 1-14$

Wachter RM, Yarbrough D, Kallio K, Remington SJ (2000): Crystallographic and energetic analysis of binding of selected anions to the yellow variants of green fluorescent protein. J Mol Biol $\underline{301}$ (1), 157-171

Wagener KC, Kolbrink B, Dietrich K, Kizina KM, Terwitte LS, Kempkes B, Bao G, Müller M (2016): Redox Indicator Mice Stably Expressing Genetically Encoded Neuronal roGFP: Versatile Tools to Decipher Subcellular Redox Dynamics in Neuropathophysiology. Antioxid Redox Signal 25 (1), 41-58

Wahl M: Time-correlated Single Photon Counting. PicoQuant GmbH, Berlin 2014

Wahl M, Rahn H, Gregor I, Erdmann R, Enderlein J (2007): Dead-time optimized timecorrelated photon countinginstrument with synchronized, independent timing channels. Rev Sci Instrum 78, 033106

Wallrabe H, Periasamy A (2005): Imaging protein molecules using FRET and FLIM microscopy. Curr Opin Biotechnol 16 (1), 19-27 
Weerapana E, Wang C, Simon GM, Richter F, Khare S, Dillon, Myles B D, Bachovchin DA, Mowen K, Baker D, Cravatt BF (2010): Quantitative reactivity profiling predicts functional cysteines in proteomes. Nature $\underline{468}$ (7325), 790-795

Weller J, Kizina KM, Can K, Bao G, Müller M (2014): Response properties of the genetically encoded optical H2O2 sensor HyPer. Free Radic Biol Med 76, 227-241

Wilms CD, Schmidt H, Eilers J (2006): Quantitative two-photon Ca2+ imaging via fluorescence lifetime analysis. Cell Calcium $\underline{40}$ (1), 73-79

Winterbourn CC (2008): Reconciling the chemistry and biology of reactive oxygen species. Nat Chem Biol 4 (5), 278-286

Yang F, Moss LG, Phillips GN (1996): The molecular structure of green fluorescent protein. Nat Biotechnol $\underline{14}$ (10), 1246-1251

Zhang J, Campbell RE, Ting AY, Tsien RY (2002): Creating new fluorescent probes for cell biology. Nat Rev Mol Cell Biol $\underline{3}$ (12), 906-918

Zhang W, Zhou Y, Becker DF (2004): Regulation of PutA-membrane associations by flavin adenine dinucleotide reduction. Biochemistry $\underline{43}$ (41), 13165-13174

Zimmer M (2009): GFP: from jellyfish to the Nobel prize and beyond. Chem Soc Rev $\underline{38}$ (10), 2823-2832 


\section{Danksagung}

Ein ganz besonderer Dank gilt meinem Doktrovater, Herrn Prof. Dr. Michael Müller für die freundliche Überlassung des hochinteressanten Themas, die sehr gute Betreuung jederzeit und die Möglichkeit, in seinem Labor Einblicke in das wissenschaftliche Denken und Arbeiten zu erhalten.

Ich möchte zudem Belinda Kempkes danken, die mich geduldig in die Labortechniken eingearbeitet hat und immer eine Ansprechpartnerin für aufkommende theoretische und praktische Probleme war.

Bedanken möchte ich mich auch bei den beiden damaligen Mitdoktoranden Dr. Oliwia Janc und Dr. Karolina Can für konstruktive Gespräche, eine gute Zusammenarbeit und jegliche Unterstützung während meiner ersten Schritte im Bereich der wissenschaftlichen Forschung. 